Fig. 17. Flächenschnitt durch einen Proglottidenrand mitden Geschlechtsöfinungen.

Fig. 18. Keimzelle oder Primordialei.

Fig. 19-27. Taenia serpentulus.

Fig. 19. Haken des Scolex.

Fig. 20. Querschnitt durch deu Halstheil.

Fig. 21. Flächenansicht des Proglottidenrandes.

Fig. 22. Querschnitt durch eine geschlechtsreife Proglottide.

Fig. 23. Dotterzellen.

Fig. 24. Keimzellen.

Fig. 25. Haken der Oncosphäre.

Fig. 26. Cysticercus der Tänie aus Geotrupes sylvaticus.

Fig. 27. Cyste desselben, stärker vergrössert.

\title{
Ueber den Bau des elektrischen Organes von Torpedo mit besonderer Berücksichtigung der Nervenendigungen in demselben.
}

\author{
Von
}

\author{
Dr. med. Cimil Ballowitz, \\ Privatdocent und Prosector in Greifswald.
}

Hierzu Tafel XXIX, XXX und XXXI.

Das hohe physiologische Interesse, welches die elektrischen Organe der Fische darbieten, ist die Veranlassung gewesen, dass der feinere Aufbau dieser Organe sehr oft, wenn auch mit verschiedenem Erfolge, zum Gegenstande eingehender Untersuchnngen gemacht wurde. Die Schwierigkeiten, welche die Weichheit und die überaus zarte Beschaffenheit des Gewebes der elektrischen Organe ihrer Erforschung entgegensetzen, tragen die Schuld, dass die namhaftesten Forscher, wie R. Wagner, Remak, von Kölliker, M. Schultze, Ranvier, W. Krause, Ciaccio, Fritsch u. a. zu sehr abweichenden Resultaten gekommen sind und zur Zeit noch ungelöste Widersprüche bestehen, welche ge- 
rade die wichtigsten, besonders für die Lehre von der peripheren Nervenendigung bedeutungsvollsten Fragen betreffen.

Schon im Frühling 1891, während eines Aufenthaltes an der zoologischen Station zu Neapel, unternahm ich es, das clcktrische Organ von Torpedo nach den neuen Methorlen, vor Allem nach der Golgi'schen Methode, welcher die Wissenschalt so grossartige Erfolge auf dem Gesammtgebiet der Nerwenlehre verdankt, zu untersuchen. Leider gestattete mir die Kürze der Zeit meines Aufenthaltes nicht, diesen Arbeiten die gewünschte Ausdehnung zu geben; immerhin erhielt ich schon damals wichtige Resultate, welche mich veranlassten, diese Untersuchungen vieder ant'zunehmen. Herr Dr. Hermes, Direktor des Berliner Iquariums, war auch dieses Ial so liebenswiirclig, mich, wie schon so oft fiir andere Zweeke, mit lebendem Materiale zn versorenen. Ich fülıle mich gedrungen, Herrn Dr. Hermes für sein stets bereitwilliges und liebenswïldiges Entgegenkommen, welches ich zur Unterstïtzung meiner wissenschaftlichen Arbeiten am Berliner Aquarium jederzeit gefunden habe, an dieser Stelle meinen her\%lichsten Dank auszasprechen. Auch Herrn Peters, Inspector am Berliner Aquarium, sage ich für die vielen Mühen, denen er sich meinetwegen unterzogen hat, meinen aufrichtigsten Dank.

Die erneuten Untersuchungen des elektrischen Organes haben mir nun ansserordentlich klare, positive Resultate ergeben, Resultate, welche nicht angerweifelt werden können und in Stande sind, die vielen Widersprïche zu erklären und zu beseitigen. Diese Resultate stützen sich nicht auf einige wenige Präparate, vielmehr habe ich in zahlreichen, prächtig gelungenen mikroskopischen Prïparaten stets genau dasselbe gleich scharf und deutlich ausgeprägt gefunden. Die bestimmten Färbungen traten so regelmässig auf und waren immer so scharf gezeichnet, dass nicht daran gezweifelt werden kann, dass sie präformirten Strukturen entsprechen.

Bei der Darstellung der Präparate verfuhr ich in folgender Weise. In dem elektrischen Organ des erwachsenen, lebenden ${ }^{1}$ ) Thieres (Torpedo Narce Risso, $\delta$ und $\&$ Exemplare von $30-35 \mathrm{~cm}$ Länge) wurde nach Entfernung der Haut jedesmal ein elektrisches Säulchen in dem Gewebe der benach-

1) Die Thiere wurden sofort nach beendigter Operation getödtet. 
Ueber den Bau des elektrischen Organes von Torpedo etc. 461

barten Säulchen umschnitten und in der Höhe von $1 / 2-1 \mathrm{~cm}$ mit einem scharfen Rasirmesser abgetragen, so dass kleine Stickchen des elektrischen Gewebes erhalten wurden, in deren Mitte sich ein intakter Abschnitt eines einzelnen Süulchens befand. Hierdurch wurde eine Quetschung und Verletzung des herausgeschnittenen Säulenstückchens möglichst vermieden. Die Stücke wurden sofort in das Gemiseh von Kali bichromicum und Osmiumsäure bekannter Concentration $(4: 1)$ gelegt. Für einen Theil der Stücke nahm ich einen um das Doppelte grösseren Zusatz der $1 \%$ igen Osmiumsäure. Nach einem 3-4tägigen Aufentlalte in dem Gemisch wurden die Stïcke schnell in verdünnter Lösung von Argentum nitricum abgewaschen und solam auf $1-3$ Tage in $3 / 4 \%$ ige Lösung von Argentum nitricum gebracht. Geschnitten wurde freihändig olne weitere Behandlung, die Schnitte kamen in Xylol-Balsam. Naturgemäss kommen hier hauptsächlich Querschnitte durch die elektrischen Säulchen in Betracht.

In dieser Weise behandelte ich eine grosse Anzalıl von Stuickchen und fertigte ich viele Hunderte von mikroskopischen Präparaten an. Ich hatte dies nicht zu bercuen. Denn in viclen Stücken war keine oder nur eine geringe Färbung eingetreten. Manche Stücke zeigten diese Färbung, andere wiederum jene vorherrschend, bisweilen ausschliesslich, sodass ich nur der Behandlung vieler Stücke die Vollständigkeit der Resultate verdanke.

Eine gute Färbung trat nur in dem umschnittenen, central gelegenen Süulchen auf, während das verletzte clektrische Gewebe der Umgebung unregelmässige, meist krystallinische Niederschläge zeigte. Die guten Stellen verriethen sich schon durch eine braunrothe bis dunkelbraune Färbung. Eigenthümlich ist das fleckenweise Auftreten der Färbungen, welche sich auf die übereinander gelagerten elektrischen Platten unregelmässig vertheilten.

Ich will mit der Schilderung der Ergebnisse meiner eigenen Untersuchungen beginnen und zuerst die Nervenendigungen, sodann die Strukturen des übrigen Gewebes der elektrischen Platten berïcksichtigen, soweit dieselben durch die Golgi'sche Methode aufgedeckt werden. Manche bisher unbekannte und nicht genügend gekannte Bauverhältnisse treten bei Anwendung dieser Methode in überraschender Klarheit hervor.

Zur Controle der nach diesem Verfahren erbaltenen Resul- 
tate wurden auch andere Methoden, besonders die Behandlung der Gewebe mit Osmiumsiiure, in Anwendung gezogen.

Ferner soll untersucht werden, welchen Theilen des Querschnittbildes der elektrischen Platte, welches nach gewöhnlicher Fixirung und Paraffineinbettung erhalten wird, die nach der Golgi'schen Methode sichtbar genachten Strukturen entsprechen.

Als Anhang füge ich eine Literaturibersicht bei; in derselben werde ich bei den eimzelnen Arbeiten die von den fritheren Autoren erbaltenen Resultate kritisch besprechen. Ich will dieselben nicht schon im Text beruicksichtigen; bei dem Umfange der Literatur über das elektrische Organ wïrde die Uebersichtlichkeit der Darstellnng dadurch zu sehr geschädigt werden.

Bei der Schilderung der feineren Struktur des elektrischen Organes setze ich die Kenntniss seines gröberen Baues voraus. Es sei nur daran erinnert, dass jedes elektrische Organ von Torpedo aus sehr zahlreichen, mit ihrer Längsaxe dorso-ventral gestellten Prismen besteht, welche sich aus einer grossen Zahl quer gestellter, dorsalwärts leicht vorgewölbter Blättchen, den clektrischen Lamellen oder elektrischer Platten, zusammensetzt. Zwischen den Lamellen befindet sich in regelmässiger Wechselfolge eine Schicht von Gallertgewebe. Während die obere Seite der Lamelle glatt ist und von einem dünnen Häutchen, der Dorsalmembran, überzogen wird, treten an die ventrale Seite derselben die zahlreichen Nerven heran, deren gröbere Ramifikationen, ebenso wie die Gefässverästelungen, in dem interlamellären Gallertgewebe verlaufen. An jeder Lamelle wird eine dorsale und eine ventrale Schicht unterschieden; die letztere wird hauptsächlich von den Nervenendigungen gebildet.

Behandelt man in der angegebenen Weise die Stïcke des elektrischen Gewebes und fertigt Querschnitte durch die elektrischen Säulchen an (senkrecht zu der dorso-ventralen Längsaxe der Säulen), so trifft man in den Präparaten bei Untersuchung mit schwacher Vergrösserung als häufigen Befund gleichmässig bräunlich gefärbte, wie mit zahlreichen dunklen Pünktchen bestrente Stellen an. Gestalt und Grösse dieser braunen Stellen ist sehr verschieden. Meist besitzen sie das Aussehen kreisrunder oder ovaler Flecken von unregelmässig ansgezackter Begrenzung; oft dehnen sie sich aber auch auf grosse Flächen aus, sodass ein beträchtlicher Abschuitt der elektrischen Platte gefärbt erscheint. 
Ueber den Bau des elektrischen Organes von Torpedo etc. 463

Bei Untersuchung mit starken Systemen (homogene Immersion) lösen sich diese braunen Stellen nun in zierliche Netze von regelmässiger Anordnung auf, die mit eigenthümlichen stäbchenartigen Gebilden dicht besetzt sind. In den Figuren $1-3$ der Tafel XXIX sind diese elektrischen Stäbchennetze, wie ich sie nennen will, möglichst getreu nach Winkel's homogener Immersion 1/24 unter Anwendung des A bbe'schen Beleuchtungsapparates abgebildet. Fig. 1 zeigt ein reines Stäbchennetz, während in den Figuren 2 und 3 an dem Stäbchennetz schon weitere, sogleich zu besprechende Veränderungen eingetreten sind. Wie die Abbildungen am besten erkennen lassen, werden die oft sehr ausgedehnten Netze von dichten, im Allgemeinen ziemlich regelmässigen Maschen gebildet, die sich überall mit einander verbinden und zusammenschliessen. Die Breite der Netzbalken (Maschen) ist etwas verschieden, ihre Begrenzung erscheint bei guter Färbung scharf, wenn auch zart gereichnet. Bei Kantenansicht stellt man fest, dass das Net/ abgeplattet ist und die Maschen sehr dünn sind, so dass das Ganze eine zarte, dünne, netzförmig durchbrochene Membran von der Ausdehnung der elektrischen Platte bildet. Die Liicken, welche von dem Netzbalken begrenzt werden, sind meist etwas unregelmässig und von verschiedener Grösse. Gewöhnlich sind sie nahezu kreisrund oder länglich oval oder rhombisch mit abgerundeten Winkeln, häufig auch unregelmässig. Bisweilen ist ihre Grösse und Gestalt aber mehr regelmässig. Ich denke mir, dass diese Ungleichheiten zum Theil von dem Spannungsgrade der dünnen elektrischen Platten abhängen. In Folge der vorhergegangenen Behandlung sind die zarten Platten wohl oft unregelmässig gefaltet, hier gespannt, dort entspannt, meist auch wohl etwas geschrumpft. Es ist daher leicht möglich, dass hierdurch die Form und Breite der Maschen und der davon umschlossenen Lücken beeinflusst wird und dieselben im Leben noch weit regelmässiger sind. Dass mannigfache Faltungen der Platten bestehen und die Färbung beeinflussen können, werden wir noch sehen.. Hiervon abgesehen, kann man sagen, wie die Abbildungen auch beweisen, dass das Netz ein recht regelmässiges und vor allen Dingen ein vollkommenes ist. Nur hier und da habe ich gefunden - stets natürlich eine durchaus gelungene und vollständige Färbung vorausgesetzt -, dass in die Lücken stumpfe, blind endigende Fortsätze der Netz- 
balken wie kurze Sprossen frei hineinragen. Nur am Rande der gefärbten Stellen waren diese Seitensprossen häufiger, ebenso wie hier die Maschen unvollkommener und die Lücken oft grösser wurden (vgl. Fig. 1-3). Dies erklärt sich aber durch die am Rande der Flecken weniger vollkommen ausgefallene Tinktion.

Dic Färbung der Netzmaschen ist für je eine braun tingirte Stelle gewühnlich eine gleichmässige. Meist sind die Netze schön hellbram gefürbt and zeichnen sich scharf von den hellen, farblosen Lücken zwischen den Maschen ab. Bisweilen ist die Färbung weniger intensiv, so dass die Maschen nur sehwer sichtbar sind, ja sie kamn so schwach ausfallen, dass man kaum noch ctwas davon wahrnimint und der Verlanf der Maschen nur noch durch die intensiv gefübten Stäbchen angedentet ist.

Diese Stäbchen sind das Auffälligste und Merkwiurdiosste an den Netzen (Fig. 1-3 ker Tafel XXIX). Dieselben stellen längliche, schmale, stäbchenartige, in ihrer Form Bacterien ähnliche Gebilde mit wenig verdickten, leicht abgestutzten Enden lar, von im Durchsehnitt 0,0009-0,0014 $\mathrm{nm}$ Lïnge. Sie sincl in grosser Zahl in ziemlich regelmässigen Abständen über das Net\% hin ansgestrent. Neist liegen die Stäbehen isolirt. Häufig beobachtet man indessen, dass je 3 oder 4 sich mit einem ihrer Enden vereinigt haben, so dass drei- resp. vierstrahlige Gebilde entstehen. Bisweilen scheinen sich noch mehrere Stäbchen verlinden zu können, so dass kleine unregelmässige Figuren daraus hervorgehen, z. B. zweig- oder stemartige Bildungen (vgl. z. B. die Stäbcheneinlagerungen der Fig. 2). Am häufigsten sind stets die einfachen Stäbchen, dann werden oft die dreistrahligen oder Y.-artigen Formen beobachtet, die übrigen Combinationen treten schon seltener auf. Die Lage der Stäbchen ist stets nur auf den Maschen des Netzes, niemals beobachtet man in den Lïcken freie Stäbchen, so dass die Stäbchen als ein integrirender Bestandtheil des Netzes selbst angesehen werden müssen. Sie liegen dabei meist am Rande der Maschen in der Nähe der Liicken; die Mitte der Maschen bleibt gewöhnlich frei.

An solchen Stäbchennetzen, welche sich umgebogen haben oder etwas gewölbt sind (Fig. 1, rechter Rand der Netzplatte), erkennt man die Stellung der Staibachen lauf dem Netz. Ein Theil der Stäbchen steht senkirecht auf den Maschen; das eire Enđe wurzelt im Netz, während das andere Ende zapfenartig emperragt 
Ueber den Bau des elektrischen Organes von Torpedo etc. $\mathbf{4 6 5}$

und frei endigt. Stellt man ein horizontal ausgebreitetes Net\% mit nach oben gerichteten Stäbchen oberflächlich ein, so erscheinen zuerst diese vertikal stehenden Stäbchen als dunkele, stark lichtbrechende Punkte. Bei etwas tieferer Einstellung gehen dann diese Punkte in kleine Kreise mit hellem, stark lichtbrechendem Innern über, die Querschnittsbilder der stark lichtbrechenden Stäbchen. Die vertikal stehenden Stäbchen sind aber meist in der Minderzahl; bisweilen wollte es mir scheinen, als wären sie ziemlich regelmässig vertheilt. Der andere Theil der Stäbchen und Stäbchenkombinationen befindet sich in liegender Stellung auf dem Netz, so dass die beiden Enden des Stäbchens mit dem Netz in Berührung resp. in Verbindung stehen. Die Stäbchen sind dabei nicht gerade gestreckt, sondern etwas gekrümmt, so dass die Convexität von dem Netze ab frei nach oben hinsieht Dasselbe gilt auch für die Stäbchenkombinationen. Diese Krü̈mmung der Stäbchen ist sehr schön an gewölbten oder umgebogenen Netzen zu sehen: der Rand der Falte erhält in Folge der vorragenden Stäbchen und Stäbchenkrümmungen ein eigenthümlich zottiges Aussehen (vgl. in Fig. 1 den rechten Rand der Netzplatte).

Die Stäbchen fürben sich bei Anwendung der Golgi'schen Wethode leicht und intensiv. Wie erwähnt, kommt es nicht selten vor, dass nur sie gefarbt sind, nicht oder nur sehr wenig dagegen die Netze. Bei vollständiger Färbung erscheinen die Stäbchen intensiv dunkelbraun tingirt, stark lichtbrechend und heben sich sehr scharf von der Umgebung ab. Ist die Färbung keine sehr intensive, so erkennt man bei genauer Einstellung an jedem Stäbchen deutlich, dass die wenig verdickten Enden derselben in Gestalt intensiv dunkel gefärbter, stark lichtbrechender Pünktchen hervortreten, die sich von dem übrigen braun gefärbten Theil der Stäbchen deutlich abheben. Jedes Stäbchen besitzt also an jedem Pole ein von seiner übrigen Substanz differentes, in Gestalt eines dunklen Endpunktes erscheinendes Endkügelchen (vgl. die Stäbchen der Figuren 1-3). Bei den gebogenen Stäbchen ruhen beide Endkügeichen auf oder wohl richtiger im Netz. Auch die Stäbchenkombinationen lassen diese Endkügelchen erkennen, dieselben finden sich aber hier uur an der Spitze der frei vorragenden Aeste. Dort, wo die Aeste mit einander verbunden sind, fehlen sie. Ist die Färbung der Stäbchen nur gering, so 
treten die Endkügelchen sehr deutlich und scharf hervor. Aber auch bei intensiver Färbung lassen sich die dunklen Endkügelchen an den meisten Stäbchen bei genauer Einstellung noch gut erkennen. Alle Endkïgelchen haben gleiche Grösse und gleiches Aussehen.

Die Stäbchen ragen nur nach der einen (oberen) Seite hin vor, die andere Seite des Netzes ist, wie man an entsprechenden Faltungen sieht, ziemlich glatt.

Unwillkürlich drängt sich die Frage auf: Sind die Stäbchen vielleicht beweglich, können sie sich vom Netz erheben und aufrichten? Es wäre eine interessante Aufgabe, dieser Frage durch genaue Untersuchungen näher zu treten.

Dahingestellt sein lasse ich es iibrigens, ob und in wie weit die vorausgegangene Behandlung auf die Krümmung der Stäbchen eingewirkt liaben mag.

Die geschilderten Eigenthümlichkeiten, sowie die Verschicdenlseit der Reaktionen und Färbungen beweisen, dass einerseits. das Netz aus einer anderen Substanz besteht als die Stäbchen, andererseits die letzteren in ihrer Zusammensetzung wesentlich von ihren Endkügelchen verschieden sein müssen. Wir haben es hier also mit drei substantiell verschiedenen Bildungen zu thım: nämlich dem Netz, den Endkügelchen und den diese letzteren verbindenden und auch einschliessenden Stäbchenstïcken.

Diese so ansserordentlich scharf und deutlich hervortretenden Stäbchennetze setzen sich num zu den Nervenendästen in Beziehung, aber niemals direkt und so ohne Weiteres; vielmehr tritt an den Netzen regelmässig eine Veränderung der Färbung ein, wenn ein Nervenfaden herantritt (vgl. Fig. 2 und 3 der Tafel XXIX). Niemals habe ich in meinen Präparaten gesehen, so oft ich auch daranfhin untersuchte, dass ein Nervenfaden einfach in das typisch gefürbte hellbraune Stäbchennetz überging.

Von den Nervenveriastelungen finden sich übrigens nur die feineren Aeste mit den Wagner'schen Geweihfasern gefärbt, wie es scheint, von der Stelle ab, wo die äussere Nervenscheide mit dem von Ranvier beschriebenen scharfen Rande aufhört (vergl. unten Literaturübersicht). Ich habe diese Nervenbäumchen sehr häufig tingirt erhalten (Fig. 4, 5 u. 7 der Tafel XXX). Besonders schön waren sie sichtbar in einigen Stückchen, die nur 12 Stunden in Argentum nitricum gelegen hatten (Fig. 4 und 5 der Tafel XXX). Die 
Nerven waren hier scharf gezeichnet, glattrandig und mit fast sämmtlichen Aesten auf grosse Strecken hin zur Darstellung gekommen. Varikositäten, tröpfchenartige Anschwellungen, wie sie sonst bei Anwendung der Golgi'schen Methode an den feinsten Nervenzweigen regelmässig auftreten, wurden an denselben niemals beobachtet, wohl ein Beweis, dass diese feinen marklosen Nervenäste noch von einer Nervenscheide ungeben sein müssen. Zur Färbung der typischen Stäbchennetze war es in diesen Präparaten, auf welche ich unten noch Berug nehmen werde, noch nicht gekommen. In den Figuren 4 und 5 der Tafel XXX habe ich die Ramifikationen der kleinen Nervenbäumchen genau wiedergegeben. Die charakteristische Art der Ramifikation dieser "Geweihfasern" (s. unt. Literaturübersicht) ist genau dieselbe, wie sie die nach den üblicben Methoden behandelten Präparate, besonders die Osmiumpräparate, erkennen lassen. Diese Uebereinstimmung dürfte beweisen, dass die Golgi'sche Methode im elektrischen Gewebe keine Trugbilder und Verzerrungen der feineren Strukturen hervorruft.

In den Präparaten, welche länger in Argentum nitricum gelegen hatten und die Stäbchennetze deutlich zeigten, waren zwar auch die Nervenbäumchen oft in grosser Zahl und in ganzer Ausdehnung intensiv gefärbt (vgl. die Fig. 7 der Tafel XXX) und zeigten alle Eigenthümlichkeiten der Verzweigung; indessen waren die Nervenfädchen hier meist nicht so scharf und glatt ausgeprägt, sie erschienen vielmehr meist ein wenig, wenn auch sehr unbedeutend, rauh und uneben, ein Unterschied, den ich nicht unerwähnt lassen möchte.

Gegenseitige Communikationen der Endbäumchen, sowie der Endzweige bis kurz vor der eigentlichen Nervenendigung kommen niemals vor, die Art der Verästelung ist stets eine dendritische, in seltenen Fällen eine dreitheilige. Dass sich auch die feineren Aeste der Ramifikationen noch aus mehreren Axenfibrillen zusammensetzen, liess die Golgi'sche Fürbung bisweilen hervortreten. Es wird zuweilen beobachtet, dass dort, wo die Nervenfärbung in der Continuität der Nervenfasern aufhörte, an den Enden kurze, gefärbte Stücke feinerer Fäden hervorragten (vgl. Fig. 6 der Tafel $\left.\mathrm{XXX}^{1}\right)$ ).

1) Dies steht im Einklange mit der Beobachtung Ranvier's, 
Die Veränderungen nun, welche an den Stäbchennetz-Zeichnungen auftreten, wenn die lctzten Endäste der Geweihfasern herantreten, sind folgende. (Vgl. Fig. 2 u. 3 der Tafel XXIX, Fig. 8 u. 9 der Tafel XXX.) Die mit den Nervenfüden in Zusammenhang stehenden Netzbalken fürben sich ü̈mlich intensiv dunkelbraun bis scliwarzbraun. Statt der zarten und dünnen Netzbalken des Stäbchennetzes findet nuan damn dunkle Netzmaschen, welche dicker und anch ein weniges breiter sind. Zuglcich erscheinen sie etwas ranh und uneben, fast höckerigo, hier und da eingeschnürt und von ungleicher Breite; an den Rändern gegen die Lïcken hin sind sie oft mit kleinen, rundlichen Buckeln versehen. Diese vorspringenden Buckeh vergrösser'n sich hier und da zukleinen, abgerundeten, frei in die Lücken vorspringenden Seitensprossen. Das Ganze macht nicht einen so zarten, zicrlichen und regelmässigen Eindruck, wie das Stäbchennet\%. Hicrdurch, sowic durch die dunkle Tinktion grenzen sich diese Stellen scharf von dem zarten Staibchennet\% ab (Fig. 2 und 3). Anfangs sind nun an diesen dunkel gefürbten Netzmaschen noch die Stäbchen, wenn anch sehr unleutlich, sichtbar. Erreicht aber die Färbung ihre volle Ausbildung, so sind in den dunklen Netrzügen die Stäbchen als solche nicht mehr zn erkennen; (las Stäbehennetz wird vollstaindig ïberlagert und verdeckt.

Ist dic Färbung nun cine vollkommene, so folgt dic dunkle Zeichnung ziemlich genau der Ausdehnung des Stäbchemnetzes und dem Verlanfe seiner Netrbalken. (Vgl. Fig. 3 und znm Theil Fig. 2.) Die letzte Endigung, in welche die Nerven ibergehen, ist demnach eiu ebenso vollkommenes, in seinen Maschen geschlossenes Netz, wie das Stäbchennetz selbst. Auch hier grenzen sich die Ränder der Maschen scharf von der Umgebung ab und bleiben die Lücken zwischen den Maschen als helle Räume frei. Blind endigende, in die Lücken hineinragende Seitensprossen sind spärlich; sie kommen aber hier und da vor. Die zu dem dunklen nNervenendnetz", wie ich es zum Unterschiede von dem nStäbchennetz" nennen will, hinzutretenden Axencylinder sind schmäler, als die Netzbalken; die Axencylinder erfahren demnach bei ihrem Uebertritt eine bemerkenswerthe Verbreiterung und Abplattung. (Fig. 3 auf 'Tafel XXIX und Fig. 8 u. 9 aut Tafel XXX.)

wonach die Axencylinder der feinen Nerven des elektrischen Organes nach mässiger Osmiumsaure-Einwirkung eine feine Liingsstreifung zeigen. Ranvier, Leçons sur l'Histologie du systeme nervenx, p. 126. 
Ueber den Bau des elektrischen Organes von Torpedo etc. 469

Dieses dunkle Nervenendnetz fand ich nicht selten in grosser Ausdehnung auf dem Stäbchennetz ausgeprägt. (Fig. 2 und 3.) Die Endnetze benachbarter Nervenäste gehen dabei continuirlich in einander über (Fig. 3), ohne dass auch nur die geringste Abgrenzung. in den Innervationsgebieten benachbarter Nerven aufgefunden werden könnte. Hieraus folgt, dass das Endorgan, die eigentliche Endigung der Nerven des elektrischen Organes, eine grosse, allen Nerven einer jeden Platte gemeinschaftliche Netzmembran ist, in welche alle Axencylinder der zu der Platte hinzutretenden Nerven ubergehen. Diese Membran stellt ein echtes Nervenendnetz dar, wie es schöner und vollkommener kaum gedacht werden kann; es besitzt die Ausdehnung der elektrischen Platte selbst. Innervationsgrenzen der einzelnen Nervenbüumchen lassen sich an der Netzmembran nicht nachweisen, vielmehr muss angenommen werden, dass alle Axencylinder der Platte in der Netzmembran als dem gemeinschaftlichen Endorgan endigen und hier unter sich in engster, ausgiebigster Communication steluen.

Wie ich nochmals hervorheben möchte und auch die Abbildungen auf Tafel XXIX zeigen, ist das Nervenendnetz nicht so zart und zierlich und gar so regelmässig, wie das Stäbchennet\%. Auch ist es gewöhnlich nicht in so grosser Ausdehnung in seinen Maschen vollkommen geschlossen zur Darstellung gekommen, wie das Stäbchennetz. Ist die Fürbung des Nervenendnetzes am Stäbchennetz nicht vollständig ausgefallen, so erscheinen in den Lücken desselben die Netzzüge des Stäbchennetzes. Stellt man eine solche Stelle ein, wenn die betreffende elektrische Lamelle mit ihrer ventralen Fläche nach oben gegen den Beobachter gewandt ist und bewegt dann den Tubus bei Immersion langsam nach abwärts, so wird zuerst das dunkle Nervenendnetz deutlich und scharf sichtbar. Erst wenn man die Mikrometerschraube ein wenig weiter bewegt, erscheinen die Züge des Stäbchennetzes scharf eingestellt. Hieraus folgt, dass beide in etwas verschiedenem Niveau liegen; das Nervenendnetz befindet sich mit seiner Hauptmasse unter dem correspondirenden Stäbchennetz, mit demselben nach oben hin unmittelbar zusammenhängend.

Aus Allem geht hervor, dass das "Stäbchennetz" und das dunkle "Nervenendnetz" zwei differente Gebilde sind; denn die Vermuthung, die man etwa a priori hegen könnte, dass es sich 
in dem Stäbchennetz etwa um ein erst schwach gefärbtes Nervenendnetz handeln könnte, ist uach den obigen Befunden absolut auszuschliessen. Dass das zarte Stäbchennetz nicht so ohne weiteres und ausschliesslich als Nervenendorgan aufgefasst werden kann, geht darans hervor, dass es sich niemals direkt mit den Nervenenden verbindet, diese Verbindung vielmehr nur unter Vermittelung einer sich dunkler färbenden Substanz eintritt. Es wäre nun zu entscheiden, was sich hier am Stäbchennetz dunkler färbt. Bei Beginn der intensiveren Färbung tingirt sich eine Substanz unmittelbar unterhalb der Netzbalken des Staibchennetzes, so dass die Netzbalken dunkelrothbraun hervortreten. Weiterhin scheint dann der Niedersehlag des doppelchromsauren Silbers sich an und auch oberhalb der Maschen des Stïbchennetzes zwischen den Stäbchen auszubreiten, so dass dic Balken des Stäbchennetzes und anch die Stäbchen durch die dunklen Netzzweige so gut wie ganz verdeckt und bis auf $A$ ndeutungen unsichtbar gemacht werden.

Ich halte es daher fiir das Wahrscheinlichste, dass das Stäbchennetz nicht ausschliesslich nervöser Natur ist und die eigentliche Nervenendigung der Nervenfasern in der Platte bildet. Viehmehr glaube ich, dass dieses Netz mit seinen Stïbchen eine mit der speeifischen Funktion des elektrischen Organes in engstem (wenn anch noch völlig dunklem) Znsammenhange stehende specifische Struktur ist. Das Stäbchennetz bildet gewissermaassen die Grundlage für die Substanz, in welebe die Axencylinder der Nervenfasim lirekt übergehen. Diese in Netzform ausgebreitete Axencylinder-Substanz, welche das dunkle Nervenendnetz der Präparate liefert, überzielit, besonders ventralwärts, das Stäbchennetz, sodass das letztere mit seinen Stäbchen dadurch in intimste Berührung, ja man muss wohl sagen, in engsten Zusammenhang mit der Nervensubstanz der Axencylinder kommt.

Ich neige mich daher mehr der Ansicht $z$, dass von diesen beiden in Netzform ausgebreiteten Substanzen das "Nervenendnetz" zunächst als die eigentliche Endigung der Nerven betrachtet werden muss. Jedenfalls handelt es sich hier um zwei differente Bildungen, welche sehr wohl auseinander gehalten werden müssen.

In Obigem wurden nur durchats gleichmässig gelungene und vollstïndige Fürbungen der Präparate berücksichtigt. So, wie dieselben in Vorhergehendem geschildert wurden, stellen sie gewissermaassen die letzte Stufe der Vollendung dar, die bei An- 
Ueber den Bau des elektrischen Organes von Torpedo etc. 471

wendung der Golgi'schen Methode in diesem Gewebe erreicht werden kann. Ich habe viele solche Präparate von gleicher Klarheit erhalten. Es kommen nun aber, wie iblberhaupt bei Anwendung dieser Methode, im elektrischen Organ sehr häufig unvollständige Färbungen vor, die sehr leicht zu falschen Anschauungen vom Bau der Nervenplatte Veranlassung geben können, bei richtiger Auffassung aber von grossem Werthe sind. Hier ist eine ganz besonders vorsichtige Kritik und eine sorgfältige Beobachtung geboten.

Dass gerade an dem Nervenendnetz so leicht mannigfache unvollständige Färbungen auftreten, erklärt sich durch die ausserordentliche Zartheit und Vergïnglichkeit dieses Nervenendapparates, ein Umstand, auf welchen bereits $\mathrm{v}$ on $\mathrm{K} \ddot{0}$ lliker mit Recht hingewiesen hat, der aber leider von späteren Untersuchern sebr ausser Acht gelassen wurde; ich werde hicrauf bei Besprechung der Literatur noch zurüickkommen. Diese Nervenendigungen veründern sich nämlich sehr bald nach dem Tode und werden anch durch Reagentien in ihrer Form leicht beeinflusst. Wenn die fixirenden Flïssigkeiten, besonders bei etwas grösseren Stiicken, nicht schnell genug eindringen, was bei dem Gemisch von Kali bichromicum und Osmiumsïure leicht der Fall sein kann, so können sich inzwischen die Endnetze schon postmortal verändert laben, indem einzelne Netzbalken der Axencylindersubstanz sich an dem Stäbchennetz von einander trennen, so dass das Netz hierdurch unvollständig wird und freie in die zwischen den Maschen befindlichen Lücken vorragende Enden entstehen. Es fixirt daher das später eindringende Reagens schon postmortal veründerte Strukturen. Die grosse Zartheit und leichte Vergänglichkeit des Nervenendnetzes lässt darauf schliessen, dass die Axencylindersubstanz desselben vollständig ohne Hülle frei in dem Gewebe liegt. Das Stäbchennetz, besonders die Stäbchen, erweisen sich weit resistenter und geben daher auch weniger $\mathrm{zu}$ abweichenden Färbungen Veranlassung.

So beobachtet man zunächst, dass anf dem Stäbchennetz oft die dunklen Färbungen der Netzbalken auftreten, obne dass die dazu gehörigen Nerven sich gefärbt haben und sichtbar sind. Es sind dann diese dunklen Netze, ebenso wie die Stäbchennetze, ohne allen Nervenzusammenhang. Wenn man die dunklen Zeichnungen aber sorgfailtig untersucht, so wird man oft noch aus 
dem dunkeln Netze hier und da hervorragende kurze Nervenstïcke antreffen. Auch in Fig. 2 der Tafel XXIX waren zwei kurze Nervenstümpfe, die aber in die Zeichnung nicht eingetragen wurden, um die Uebersichtlichkeit derselben nicht zu stören, noch im Zusammenhange mit dem Nervennetz.

Diese dunklen Nervennetz-Färbungen sind nun schon oft auf dem Stäbchennetz selbst unvollkommen (Fig. 2 zum Theil). Dann ist der dunkle Niederschlag nicht allen Maschen gefolgt, so dass kein in allen Maschen geschlossenes, regelmässiges Netz mehr zur Darstellung kommt. Man sieht damn, dass die Färbung gewissermaassen an einzelnen Netzbalken des Stäbchennetzes in mehr gerader Richtung entlang gelanfen und nur hier und da in die Seitenbalken eingedrungen ist ( $\mathrm{g}$ gl. Fig. 2). Hierdurch entstehen auf dem stäbchennetz mehr dendritische, mit kurzen Seitensprossen versehene dunkle Zeichnungen und unvollstïndige Netzbildungen (Fig. 2). Besonders am Rande der Flecken sind die Fürbungen unvollkommen, während in Innern derselben dic dunklen Netze meist völlig ansgeführt zu sein pflegen (Fig. 2). Die Netze werden dann durch die dazwischen gelegenen hell gefärbten Maschen des Stäbchennetzes ergänzt (Fig. 2), welche letzteren aber in etwas anderem Nivean liegen.

Ein anderes sehr wichtiges Bild giebt die Fürbung der Nervenramifikationen in Verbindung mit den dunklen Endnetzen, oline dass es hier zur Tinktion der Stäbchennetze kommt; die letzteren bleiben hier völlig unsichtbar, ihre Anwesenheit innerhalb der tingirten Nervennetze kann hier nur aus bestimmten Anzeichen geschlossen werden. Dieser Befund ist ein sehr häufiger. Ich habe sehr oft in etwas dickeren Schnitten diese Zeichnungen in mehreren auf einander liegenden elektrischen Platten in grösster Ausdehnung erhalten, so dass die dunklen Endnetze grosse zusammenbängende Membranen bildeten (Fig. 7 auf Tafel XXX). Sehr schön sieht man dabei, wie die Endbäumchen der Nerven mit ihren sämmtlichen Endzweigen in diesem gemeinschaftlichen Terminalnetz aufgehen. Meist allerdings ist der Niederschlag von den Nerven aus nur in die Anfänge des Netzes eingedrungen, so dass den Endästen gewöhnlich nur kleinere oder grössere Stücke des Netzes ansitzen. In Fig. 7 der Tafel XXX ist bei schwacher Vergrösserung ein Stück der Nervenplatte einer elektrischen Lamelle aus einem derartigen 
Ueber den Bau des elektrischen Organes von Torpedo etc. 473

Präparat abgebildet. Links unten ist ein grösserer Abschnitt des Terminalnetzes imprägnirt, während an den anderen Stellen nur kleinere Stücke des Nervennetzes mit den Endzweigen der zahlreichen Nerven im Zusammenhange stehen. Dass diese Färbung eine unvollständige ist, geht schon daraus hervor, dass viele der imprägnirten Endfäserchen der Nerven frei aufhören.

Untersucht man diese dunklen Netzzeichnungen bei stärkerer Vergrösserung (Fig. 8 und 9 der Tafel XXX), so erkennt man eine überraschende Mannigfaltigkeit in der Anordnung und Verbindung der Netzbalken, die aber bei näherer Prüfung bald ihre Erklärung findet. Häufig trifft man allerdings echte, engmaschige Netze an, welche genau so beschaffen sind, wie die oben beschriebenen dunklen Netzzeichnungen auf den Stäbchennet\%en und sich in Nichts hiervon unterscheiden. Dies wird besonders in der Mitte der gefärbten Stellen und im Innern der grösseren Netzmembranen beobachtet.

Sehr lehrreich ist in dieser Beziehung Fig. 3 auf Tafel XXX. An drei Endästen eines Nervenstammes hängen isolirt gefürbte Stïcke des dunklen Nervenendnetzes, dessen Maschen recht regelmässig geschlossen sind. Das eine grössere Netzstïck geht noch an zwei Stellen in das Stäbchennetz direkt iiber. Zwei andere Endäste desselben Nervenstammes setzen sich mit regelmässig geformten, dunklen Nervenendnetzen in Verbindung, welche auf dem hier zur Darstellung gekommenen Stäbchennetz liegen.

Weit zahlreicher sind aber die unvollkommenen Netzzeichnungen, besonders an den kleineren dunklen Stellen. Das Bild, welches dieselben darbieten, ist sehr mannigfach und im Allgemeinen folgendes (vgl. Fig. 8 und 9 der Tafel XXX). Man erkennt unregelmässig gebogene oder auch streckenweise mehr gerade verlaufende dunkle Netzbalken, welche sich hier und da durch Aeste mit einander in Verbindung setzen. Hierdurch entstehen zwischen weiten Maschen unregelmässige Lücken von sehr verschiedener Grösse. In dieselben ragen nun Seitensprossen hinein, die meist abgerundet frei endigen und häufig mit einem gewissen Schwung umgebogen sind. Derartige Seitensprossen kommen sich oft von benachbarten Netzbalken entgegen. Die Netzbalken, sowie die grösseren Seitensprossen sind oft mit niedrigen, abgerundeten Buckeln besetzt oder bisweilen auch perlschnurartig eingeschnürt. Kurz und gut, es besteht eine 
eigenthümliche, sehr wechselnde, nicht unschönc Zcichnung, die man am besten als "Arabeskenzeichnung " benennen könnte. Die Figuren 8 und 9 sind bei Immersion von mir genall nach dem Präparat gezeichnet und geben eine Anschaumug dieser sehr wechselnclen "Arabeskenzeichunng".

Diese Arabeskenzeichnung ist eine unvollkommene Färlung, an welcher das Nervennetz nicht vollständig zur Ausprägung gokommen ist. Dies lässt sich aus folgenden Befunden bewcisen.

Häufig findet man zwischen zwei sich entgegenstehenden Arahesken oder Seitensprossen oder auch zwischen zwei vorspringenden Buckeln eine schmale helle Verbindungsbrüicke als cinen Theil des schwach gefärbten Stäbchennetzes. Bisweilen sind diese Verbindungsbriicken so zahlreich, dass eine Auszeichnung derselben aus der Arabeskenzeichnung ein vollstindiges Netz herstellen wïrde. Dies ist z. B. in Fig. 8 der Fall. Die lıellen Verbindungshrüicken in den Liicken zwisehen den dunklen Zïgen sind Netzhalken des Stäbehennetzes, anf welehen die Fïrhumg des Nervenendnetzes nicht erfolgt ist. Bisweilen sind anch grö̈ssere Stellen hell geblieben, selten nit schlecht gefüil)ten Stähelien besetzt (Fig. 8, links). Die Imprägnation ist an diesen Stellen nicht erfolgt, obwohl die färbbare Nervensulstanz sich hicr ebenso, wie an den dunkel tingirten Stellen vorfindet oder doch vorgefunden hat. Yon der Anwesenheit der Stäbchen in diesen Nervennetzen geben nur helle, krcisrunde kleine Punkte Nachricht. Wenigstens erkläre ich mir diese im dunklen Nervennetz oft zu beobachtenden Punkte in der Weise, dass vertikal stehende Stäbchen nicht mit gefürbt sind und bei ihrem starken Lichtbrechungsvermögen daher als helle Punkte sichtbar werden (vol. Fig. 8 und besonders den oberen Theil der Netzrüge in Fig. 9).

Ausserdem sieht man in den hellen Lücken zwischen den dunklen Balken - auch dies ist ein wichtiger Beweis für die Unvollständigkeit dieser Färbung - meist in unmittelbarer Nähe der Netzbalken kleine dunkle Punkte von gleicher Grösse. Bisweilen macht es den Eindruck, als ob diese Punkte durch einen feinen Stiel mit den Netzbalken verbunden wären (Fig. 8 und besonders Fig. 9). Diese Punkte sind die Endkügelchen der Stäbchen, die sich vereinzelt hier mitfairben und dadurch die Lage der nicht gefürbten Netzbalken verrathen. Die Stäbchen selbst sind in diesen Präparaten nicht mitgefürbt und scheinen 
Ueber den Bau des elektrischen Organes von Torpedo etc. 475

geschrumpft zu sein; die dünnen Stiele, welche die Pünktchen mit dem Endnetz verbinden, sind die Andeutungen der Stäbchenkörper.

Daza kommt schliesslich die grosse Mannigfaltigkeit der Arabeskenzeichnung im Gegensatz zu der Einfachheit und Regelmässigkeit der Netzzeichnung. Im Allgemeinen kann man sagen: Je unvollkommener und mangelhafter die Färbung, um so weniger ausgeprägt sind die Netzbildungen. Trotzdem oder richtiger geradle deswegen, ist diese Arabeskenzeichnung, wie ich nochmals hervorheben möchte, so häufig, dass ein nicht kritisch verfahrender Beobachter versucht werden könnte, dieselbe als die eigentliche Art der Nervenendigung hinzustellen.

Oder würde man es für wahrscheinlich halten können, dass in manchen Bezirken der Nervennetzmembran vollständige, ganz regelmässige Netzverbindungen vorhanden sind, während an anderen Stellen ein unregelmässiges Arabeskennetz besteht? Der Befund am frischen and gut fixirten Object spricht dagegen.

Von diesen Bildern abgesehen, habe ich in einigen Stïcken, in denen auch die Wagner'schen Geweihfasern (siche oben) und die Gallertzellen (siehe weiter unten) deutlich waren und die sich durch eine diffuse hellbräunliche Fürbung auszeichneten, noch andere Befunde erhalten, nämlich blass gefärbte Netze mit hinzutretenden Nerven ohne Stäbchenfärbung. (Vgl. Fig. 5 n. 6 der Tafel XXX. Fig. 5 ist bei schwacher Vergrösserung [Zeiss Obj. A, Oc. 5] gezeichnet, Fig. 6 nach Winkels homogener Immersion 1/24.) Diese Färbung muss auch als eine unvollkommene, und zwar in den ersten Anfüngen unterbrochene, bezeichnet werden, zumal die Stücke nur 12 Stunden in der Silberlösung gelegen hatten.

Die Färbung der dünnen, abgeplatteten Netzbalken bestand hier nicht in einem schönen Hellbraun, wie bei dem Stäbchennetze, vielmehr waren die Netzzüge eigenthümlich matt braungrau gefärbt, grenzten sich aber immerhin schon deutlich von dem nicht gefärbten Gewebe ab. Wie bei der dunklen Arabeskenzeichnung, waren die Netze auch bier keine vollkommenen und regelmässigen, wenn sie auch oft auf grosse Flächen hin sichtbar wurden. In die unregelmässigen grossen Lücken des Netzes ragten kürzere oder längere Seitensprossen der Netzbalken hinein (Fig. 6). Bisweilen verliefen längere, mit den Sprossen und Buckeln besetzte Abschnitte der Netzzweige isolirt ohne 
weitere Netzverbindung, sich hier und da nur dichotomisch theilend. Mit anderen Worten: Es trat biel eine ganz ähnliche Arabeskenzeichnung hervor, wie bei dem dunklen, unvollkommen gefärbten Nervennetz (vgl. Fig. 6). Mit diesem blassen Arabeskennetz setzten sich gewöhnlich die letzten Verzweigungen der Nerven in Verbindung (Fig. 5 und 6), aber auch wieder nicht in der Weise, dass die dunkel gefärbten Nervenfaiden einfach in die hellen, breiten Netzzüge direkt übergingen; vielmehr trat an den Verbindungsstellen eine intensivere Färbung ein. Von der Stelle aus, wo die Nerven an das Netz herantraten, waren 1-2-3 Netzbalken in der Richtung des Nervenverlaufes intensiv braun gef:irbt, so dass dieselben auch bei schwacher Vergrüssermng deutlich wahrnehmbar waren (Fig. 5) und den Verlauf der Nerven in dem hellen Netz gewissermaassen fortsetzten (Fig. 6). Von diesen intensiv gefărbten Netzbalken gingen kurze, unregclmässig wie abgeschnittene Färbungen in die Seitensprossen und Netzverbindungen hincin, so dass die braun gefärbten Netzzïge wie mit Zacken besetzt erschienen (Fig. 6).

Aber anch andere Anzeichen bewiesen, dass hier gleichfalls cine defekte Färbung vorlag. Hier und da zeigten sich nämlich in dem matten Arabeskennetz kleinere Abschnitte und unregelmässige Stellen intensiv braun gefärbt (Fig. 6): hier war die Färbung weiter rorgedrungen. Während die Stäbchen hier nicht gefärht und unsichtbar waren, kamen doch die Endkügelchen derselben bisweilen, wenn auch selten, zur Darstellnng. Dieselben erschienen an den Netzbalken als dunkle, gleichgrosse kleine Punkte, die meist paarweise oder zu kleineren Gruppen zusammenlagen und dem hellen Netz eine zierliche regelmässige Punktirung verliehen. Von den die Pünktchen verbindenden Zwischengliedern der Stäbchen war aber Nichts zu sehen. In dem linken unteren Viertel des blassen Netzstückes der Fig. 6 ist diese feine, durch die tingirten Endkügelchen der Stäbchen hervorgerufene Punktirung sichtbar. (Vgl. unten in der Literaturïbersicht Boll's elektrische Punktirung.)

Damit ist die Reihe der unvollständigen Färbungen aber noch nicht erschöpft. So sah ich bisweilen, dass sich nur die Stähchen gefärbt hatten, ohne dass das Netz sichtbar war. Entsprechend den Stäbchenzügen konnten dann dunkle unvollstän- 
Ueber den Bau des elektrischen Organes von Torpedo etc. 477

dige Nervennetz-Zeichnungen auftreten mit oder ohne Nervenzusammenhang.

Aus Obigem folgt, dass die Erscheinungsformen, unter deneu die Endnetze in den Golgi'schen Präparaten auftreten, sehr mannigfach sind. Alle finden aber ihre Erklärung in dem von mir ' u Anfang beschriebenen, vollständig tingirten, resistenteren Stäbchennetz und dem hinfälligen, leicht veränderlichen Nervenendnetz.

Ganglienzellen wurden im elektrischen Organ von mir nicht gefunden.

Ausser diesen nervösen Elementen kommen bei Anwendung der Golgi'schen Methode noch andere Strukturen in dem elektrischen Gewebe zur Darstellung. Vor Allem ist es die zarte Gerüstsubstanz des dorsalen Abschnittes der elektrischen Platte, welche ausserordentlich deutlich und intensiv gefärbt wird (vgl. die Figuren der Tafel XXXI). Auch hier tritt die Färbung meist fleckenweise auf, in Gestalt oft sehr zahlreicher, unregelmässiger, bei schwacher Vergrösserung braunroth erscheinender Stellen. Sie gehören den verschiedenen übereinander gelegenen elektrischen Lamellen an. Fig. 13 zeigt bei schwachen Vergrösserungen in der Vitte eines Säulchens diese gefürbten Flitter. Oft sind aber auch grosse Abschnitte der elektrischen Lamelle tingirt (vgl. Fig. 14 der Tafel XXXI).

Untersucht man bei stärkster Vergrösserung, so stellt man fest, dass diese rothe Färbung bedingt wird durch die Tinktion vieler äusserst feiner Fädchen, welche sich unter einander verbinden und ein enges, feinstes Netzgerüst darstellen (Fig. 15-17). In diese Fädchen sind kleinste, dunkel gefärbte Körnchen der Reihe nach einander eingelagert, so dass die Fädchen alternirend hell und dunkel erscheinen (Fig. 15-20). Von einer eigentlichen Querstreifung ist aber keine Rede. Man erkennt, dass die dunklen Stellen kleinste, rundliche, in die Substanz der Fädchen eingelagerte Körnchen sind von ziemlich gleicher Grösse; geringe Grössendifferenzen der Körnchen werden beobachtet. In den Netzfädchen, welche man bisweilen eine Strecke weit verfolgen kann, ist der Abstand zwischen den Körnchen auch nicht immer derselbe.

Stellt man nun die eine und zwar ventrale Fläche dieses Netzgerïstes ein, so sieht man, dass sich die Fädchen hier zu rundlichen 
oder unregelmässig polygonalen Maschen zusammenlagern, so dass ein zierliches, ziemlich regelmäissiges, sehr zartes, etwas weiteres Netz entsteht (Fig. 15). Bewegt man den Tubus ein wenig nach oben, so schliessen sich diese Maschen allmählich zusanmen und ans dem weitmaschigen Notz wird das erwähnte äusserst engmaschige feinste Notzgerist, welches den dorsalen Theil des elektrischen Gewebes der Platte bildet. Die Maschen sind so fein und eng, dass man dieselben sowic die zwischen ihnen befindlichen hellen Lïcken nur bei Anwendung stärkster Vergrösserma mud bei guter Beleuchtung erkennt (Fig. 15, 18, 19, 20). In Folge dessen scheinen auch bei etwas schwächerer Vergrösserung die dhnklen Körnchen, welche in die Fädchen eingelagert sind, dicht nebeneinander zu liegen, so dass dieser Theil bei Hiichtiger Untersuchung feinkörnig aussicht. Hier und da lassen sich die feinen Fïdchen eine Strecke weit verfolgen.

Dieses enge Maschennetz, welches den Eindruck eines filzartig dichten Geriistworkes macht, ist schwer durch reichnung wieder\%ugeben. In den Zeichnungen Fig. 15 und auch Fig. 18-20 ist das enge Geriistnet\% in seinen Maschen viclleicht ein wenig zn regelmässig angegeben; auch dic feinen Fädchen sind vielleicht ein wenig zu geradrandig geworten.

Ist die Fithumg nur mangelhaft oder ist schon eine theilweise Entfärbung eingetreten, so werden zuerst die Fädchen unsichthar, so dass die Körnchen völlig isolirt zu liegen scheinen. In der Fig. 16, in weleher die feinen Fadchen nicht mehr sichthar sind, erkennt man nur die Körnchen, deren Lage den Verlanf der Färlehen zum Theil angiebt.

Diese Geriistsulsstanz färbt sich nicht immer in ihrer ganzen Dicke. Es kommt vor; dass nur der grobmasehige ventrale Theil als ziemlich regelmässiges Netz allein sichthar wird. In Fig. 17 ist cin Theil des Randes eincr gefürbten Gerüstlamelle gezeichnet, an welchem nur die Maschen des weitmaschigen Netzes sich durch Tinktion dargestellt haben. Die Körnchen führenden Netzfäden sind sehr schön sichtbar.

Ausser den kleinsten, in den Füdchen befindlichen Körnchen kommen noch andere intensiv gefürhte Körner von verschiedener Grösse vor, welche meistens wohl den Inhalt der von den GerüstMaschen amschlossenen Lïcken bilden. Besonders auffällig, wenn auch in den Golgi'schen Präparaten nicht häufig, ist der Befund 
grosser Körner von intensiv dunkelbrauner Färbung in den unteren Schichten der Gerüstsubstanz und an der unteren Grenze derselben; dieselben füllen die Liicken der Maschen zum Theil aus (Fig. 15). Diese Körner sind gewöhnlich ziemlich regelmässig. in Gruppen vertheilt und lassen oft eine seitliche Einkerbung. als optischen Ausdruck einer flachen Delle erkennen (Fig. 15 1. 16). Andere erscheinen wieder rundlich oder etwas unregelmässig mit stark glänzendem Innern. Die meisten besitzen jedenfalls eine napfförmige Gestalt. Bisweilen haben sich diese gröbberen Körner in der Umgebung tingirter Gerüstsubstanz isolirt gefärbt (Fig. 16).

Dass diese Gerüstsubstanz mit Körnchen und Körner'n dem dorsalen Abschnitte der elektrischen Platte angehört, beweist dic Anwesenheit der grosskernigen Zellen in derselhen. Man sicht nämlich, wenn die Gerïstsubstanz auf grössere Strecken hin gefärbt ist, in derselben in bestimmiten, nicht regelmässigen Abständen helle, elliptische oder ovale oder bisweilen mehr rundliche Lücken von wenig differenter Grösse, in welchen man bei mittlerer Einstellung, umgeben von einem hellen Hofe, einen grossen, runden, mit Kernkürperchen versehenen Kern erblickt (Fig. 14). Am Rande des hellen Zellkörpers dieser Zelle scheint sich die Geristsubstanz etwas zu verdicken und zu erheben, so dass die Begrenzung der Zelle kapselartig hervortritt (Fig. 18-20). Die Anwesenheit dieser hellen Liicken in der Gerüstsubstan\% (Fig. 20) bertut vielleicht auch wieder auf einer unvollkommenen Färbung. Denn sehr oft zeigt sich diese Lücke überdeckt von einer diunnen schalenartigen, convex ausgebuchteten Fortsetzung der Geriistsubstanz, so dass sie nur wenig auffällt (in Fig. 14 stellenweise; besonders vgl. Fig. 18). In der Concavität der Kapsel-Ausbuchtung ruht ein Theil des völlig homogen und hell aussehenden Zellprotoplasmas. In dieser Kapselwand nimmt man meist selı sehön und deutlich die Architektur der Fädchensubstanz wahr, da dieselbe hier nur in dünner Schicht vorhanden. ist. An der unteren Fläche markirt sich auch hier noch das. weitmaschige untere Netz in Gestalt niedriger polygonaler Leisten (Fig. 18). Fiel die Tinktion nicht vollständig aus, so sieht man oft, dass vom Seitenrande der Kapselwand aus mehr weniger isolirt verlaufende, unit Körnchen versehene Fädchen ausgebuchtet um die 
untere Fläche der Zelle herum gehen, um sich mit entgegenkommenden Fädchen der anderen Seite zu verbinden (Fig. 19).

Bisweilen kommt es vor, dass nur diese Zellkapseln sich färben, während die umliegende Gerüstsubstanz farblos bleibt oder nur in der näclsten Umgelung hervortritt (Fig. 18-20).

Ist die Gerüstsubstanz auf grösseren Strecken tingirt, so erscheinen in derselben meist dunkle, schmale, unregelmäissige Linien, welche sich oft verzweigen und wie blattrippenartige Verdickungen der Gerïstsulostanz aussehen (vgl. Fig. 14). Ich glaubte anfangs auch, dass es sich um Verdickungen der Fädchenmasse handele. Wenn man aber hinreichend diunne Stellen untersucht, so sielit man, dass an denselben meist eine schmale, rinnenartige Einfaltung der Geruistlamelle vorliegt, so dass diese dunklen Linien wohl nichts anderes, als Falten der Geriustlamelle darstellen. Merkwïrdig ist, dass die Färbung oft in der Richtung dieser Falten vorschreitet, so dass die rothen Stellen häufig mit spitzen Ausläufern versehen sind. Ja, es kann die Färbung nur auf solche Faltungen beschränkt bleiben.

Im Zusammenhang mit der gefürbten Gerüstsubstanz trifft man weiterhin oft vollständig braunschwar\% und gleichmässig. tingirte nndurchsichtige Stellen an, in welchen sich nur noch die soeben besprochenen Faltungen kennzeichnen. Diese Stellen sind so undurchsichtig, dass sie Einzelheiten nicht mehr erkennen lassen. Es kann daher nicht gesagt werden, wodurch die dunkle Färbung bedingt wird, ob der Niederschlag auch innerhalb der Lücken des Netzgerüstes erfolgt ist, so dass Alles gleichmässig. imprägnirt wurde, was wohl anzunehmen ist oder ob eine Imprägnation der Dorsalmembran vorliegt (vgl. in Fig. 14 den linken Rand der gefärbten Gerüstlamelle).

Diese Total-Färbungen treten übrigens noch häufiger isolirt und oft auf grosse Flächen hin auf.

Ohpe Zweifel haben wir wohl in dem soeben beschriebenen Gewebe das eigentliche Substrat zu suchen, in welchem die Elektricität erzeugt wird. Die ganze innere Struktur, das Fädchengerüst mit den Granulaeinlagerungen und dem Körnerinhalt erinnert sehr an das Bill, unter welchem man sich die innere Zusammensetzung des Protoplasmas vorstellt; man könnte versucht sein, dieses Geritstwerk als grob sichtbares Paradigma vom feineren Ball des Protoplasmas aufzufassen. 
Ueber den Bau des elektrischen Organes von Torpedo etc. 481

Es fragt sich nun, wie man dieses eigenartige Gewebe der dorsalen Schicht der elektrischen Lamelle histiologisch aufzufassen hat. Man könnte diese ganze Schicht als ein grosses, aus zahlreichen Zellen bestehendes Synzytium deuten. Das feinfädige, feinkörnige Gerüstwerk würde dam die allen gemeinsame Filarmasse im Sinne Flemmings oder das Protoplasma im Sinne Kupffers darstellen. Die helle Substanz zwischen den Gerüstmaschen, welche die Lücken des Gerüstwerkes ausfüllt, wäre die Interfilarmasse Fl e m mings oder das Paraplasma im Sinne K u pffers. Dieses Paraplasma, wenn man so will, kommunicirt durch die Lücken der Kapselwände mit der hellen Substanz, welche die Kerne in Gestalt der Höfe umgiebt und dasselbe helle, anscheinend homogene Aussehen besitzt, wie die helle Substanz in den Lücken der schwammigen Gerüstsubstanz. Diese helle Substanz ist nun jedenfalls wohl eine eiweissartige Flüssigkeit. Denn ich habe nicht den geringsten Anhaltspunkt dafür gewonnen, dass die Lücken der dorsalen Gerüstsubstan\% etwa mit Körnchen ausgefüllt seien. Wären Körnchen in denselben vorhanden, so hätten sie, von anderem abgesehen, auch wohl einmal hier oder da Färbung bei Anwendung der Golgi'schen Methode angenommen, wie es die grö̈beren, unregelmässigen Körnchen und Körner in den unteren Lagen und an der unteren Grenze der dorsalen Schicht thaten. Ich habe aber niemals in den sehr zallreichen Präparaten, die ich daraufhin genau untersuchte, auch nur die geringste Färbung solcher Körnchen gesehen. Die feinen Körnchen, welche sich färbten, gebörten den Fädchen an. Auch die anderen Methoden (siehe unten) haben mir keinen Anhaltspunkt von dem Vorhandensein regelmüssig vertheilter, die Lücken ausfüllender Körnchen gegeben.

Eine andere Auffassung wäre die, das spongiöse, feinste Netzgerust als eine specifisch umgeformte, protoplasmatische Zwischensubstanz zu betrachten, etwa zu vergleichen den specifisch umgeformten contraktilen Fibrillen in den quergestreiften Muskelfasern. Die hellen Höfe um die grossen Kerne wären dann die Reste der Bildungszellen, gleich den "Muskelkörperchen" der Muskelfasern, während die die Lücken des Netzgeriistes ausfüllende Substanz zu vergleichen wäre der Füllmasse zwischen den contraktilen Fibrillenbündeln, dem Sarcoplasma. Diese Annahme schiene fast mehr Berechtigung zu haben, wie die andere. Aller- 
dings habe ich in der die hellen Höfe bildenden Sulsstanz keinc weitere Struktur sehen können, die doch vorhanden sein müsste, falls sie noch wirkliches Zellprotoplasma ist. Indessen müssten dies noch genamere, speciell hieranf gerichtete Untersuchungen entscheiden.

Es sei noch bemerkt, dass sich Geriistlamelle, Stäbchennetz und Nervennetz häufig an denselben Stellen gleichzeitig färben, aber merkwürdigerweise wohl meist nicht in derselben elektrischen Platte, sondern in benachbarten, unmittelbar äber einander liegrenden. Wenn ich die Ränder solcher etwas undurchsichtiger Stellen genau einstellte, so konnte ich bei Bewegung. der Mikrometerschraube sicher feststellen, dass die Geriistlamelle mit dem Stäbchen- und Nerrennetz nienals in direktem Znsammenhange oder unmittelbarster Berührung steht; vielmehr befindet sich immer ein dünnes anscheinend homogenes Stratum dazwischen, in welchem, wenn die Färbung zweien benachbarten clektrischen Lamellen angehört, die Ramitikationen der zu dem Nervenendnetz tretenden Nervenfäden sichtbar werden.

Schliesslich lassen sich nach der Golgi'schen Methorle noch die Gallertzellen in dem interlamellären gallertigen Zwischengewebe impräigniren. Ich fand dieselben aber nur in den Priiparaten tingirt, welche 12 Stunden in Argentum nitricum gelegen hatten und welche auch die blassen Arabeskennetze, sowie die Wagner'schen Geweihfasern zeigten. Die dunkel gefürbten, sehr scharf' hervortretenden Zellen besassen eine sehr unregelmässige Form (vgl. die Figuren 10 u. 11 der Tafel XXX).

Von einer hellen, länglichen Verdickung, welehe den Kern repräsentirte, gingen g'ewöhulich nach beiden Seiten zwei meist ungleiche Fortsätze aus, welche sich in reicher Weise dichotomisch velzweigten. Bisweilen entsandte eine Zelle auch $3-4$ Fortsätze, welche sich meist weithin verfolgen liessen. Die Endverzweignngen wurden von äusserst feinen Fäserchen gebildet. Auch von den gröberen, zackigen Aesten gingen oft feinste Reiserchen $\mathrm{ab}$, welche nach kurzem Verlaufe frei endigten (vgl. Fig. 12, welche einen Protoplasmaast einer Gallertzelle mit den Ranifikationen und den feinsten Reiserchen bei starker Vergrö̈sserung zeigt). Es machte fast den Eindruck, als ginge die Substanz dieser Fäserchen in die Zwischensubstanz direkt über. Manche von diesen Zellverzweigungen verliefen auch längere 
Ueber den Bau des elektrischen Organes von Torpedo etc. 483

Strecken ungetheilt und waren mit kleinen varicüsen Anschwellungen besetzt, so dass ihr Aussehen sehr an Nervenfäden erinnerte. Solche, bisweilen auch verzweigte Fäden fanden sich in den bezüglichen Präparaten oft zwischen den Geweihfasern und auch dicht unter dem Nervennetz. Man könnte geneigt sein, dieselben, wenn sie sich nicht mehr im Zusammenhange mit den Gallertzellen befinden, für Nervenfüden zu halten (vgl. den sich verzweigenden varicösen Faden zwischen den 3 Nervenbäumchen der Fig. 4 anf Tafel $\mathrm{XXX}^{1}$ )).

1) Auf die iussere Aehnlichkeit dieser Zellauslïufer mit Nervenfädchen hat schon M. Schultze hingewiesen. Dieser Forscher sagt hierüber (16, pag. 24): „Zellige Anschwellungen kommen, wie ich mit anderen behaupten muss, nirgends im Verlaufe der Fasern vor. Zu einer Verwechselung mit solchen können Veranlassung geben, einmal die in der Scheide dünner, markloser Fïserchen liegenden Kerne, welche, wenn sie die Faser von oben oder unten decken, wie in ihr liegend aussehen, und ferner die Bindegewebszellen, welche gerade zwischen den feinen Nervenfasern ziemlich häufig vorkommen, und mit ihren feinen Fortsätzen über grössere Flächen sich verbreiten, sich mit Nervenfasern kreuzen oder ilmen anliegen, und bei oberfiichlicher Bctrachtung oft wie in anastomischer Verbindung mit ihnen zu stehen scheinen. Ein absolut sicheres Unterscheidungsmerkmal zwischen beiden Faserarten giebt es nicht. ..... Dennoch ist gerade in den elektrischen Organen eine Verwechselung viel weniger möglich als an anderen Orten aus dem einfachen Grunde, weil die Nervenfasern wenigstens bis zu ihrer, der unteren Fläche des homogenen Plättchens unmittelbar asliegenden Endausbreitung eine Starrheit und Resistenz besitzen, die den Bindegewebszellenausliaufern nicht zukommt. Diese Eigenschaft iiussert sich z. B. bei Wasserzusatz; nach welchem noch längere Zeit hindurch die Nervenfasern, soweit von ihnen hier die Rede gewesen, mit unver:inderten scharfen Contouren sichtbar bleiben, während die Bindegewebszellenausläufer schwinden, die Zellen ihre Sternform verlieren und in rundliche Körper übergehen. Aber auch im ganz frischen Zustande lassen sich beide unterscheiden. Die Nervenfasern zeigen, soweit sich eine bestimmte Breite an denselben überhaupt noch sicher messen lässt, stets vollkommen parallele Contouren, nirgends in Verlaufe findet sich eine Ungleichheit der Dicke, eine Unsicherheit in der Begrenzung, eine Andeutung von Varikositäten, wihrend von den Zellausläufern das Gleiche nicht ausgesagt werden kann. Diese sind in ihrem Verlaufe bald dicker, bald dünner, unregelmässige Vorsprünge und Ausbuchtungen, in welchen der liörnige Zelleninhalt sich deutlicher angehäuft hat, finden sich oft an ihnen, ihre Verästelungen endlich, welche nicht selten sind, haben etwas Unbestimmtes an sich, wiederholen sich nicht in so charakteristischem Typus, wie das an den Nervenfasern der Fall ist." 
Eine Verbindung dieser dunkel gefärbten Gallertzellen mit den Nervenfasern wurde niemals beobachtet.

Ich habe mich nun nicht darauf beschränkt, die elektrische Platte allein nach der Golgi'schen Methode zu untersuchen, vielmehr habe ich anch die anderen von den Autoren fur dieses Gewebe empfohlenen Methoden in Anwendung gezogen. Ich will aber hier nicht näher auf meine damit crhaltenen Resultate eingehen, da ich bei der Besprechung der Literatur wiederholt Gelegenheit haben werde, hieranf zurückzukommen. Anch wird aus dieser Kritik der Literatur mein Standpunkt hervorgehen, den ich in manchen in dem obigen Text nicht berïcksichtigten, den Bau des elektrischen Gewebes betreffenden Fragen einnehme. Es seien hier nur in aller Kür\%e die wichtigsten Ergebnisse anfgeführt and will ich nur gleich hervorheben, dass ich alle nach dem Golgi'schen Verfahren erhaltenen Resultate durch die anderen Methoden in vollem Umfange bestätigt fand; nur das zarte Stäbchennetz ist in Folge seiner Zartheit ohne die charakteristische, durch die Golgi'sche Behandlung erhaltene Tinktion als solches nicht mit Bestimmtheit zu erkennen.

Von den in Betracht kommenden Methoden erschien anch mir die Behandlung mit Osmiumsäure als die zuverlässigste. Kleine Stücke des lebensfrischen Gewebes wurden auf 1-2 Tage in $1 \%$ tige Osmiumsäurelösung gelegt und alsdann in Wasser übergeführt, das wiederholt gewechselt wurde. Die Lamellen isolirte ich sodann mit Nadeln; einzelne wurden auch zerzupft, um Rissstellen derselben zu erhalten. Die Untersuchang nahm ich in Wasser vor; ohne weitere vorhergegangene Behandlung. Die Untersuchung in Wasser ist von grosser Wichtigkeit, da Glycerin oder gar Balsam die feinsten Strukturen zu sehr aufhellt, so dass sie undeutlich werden oder ganz entschwinden. Bedingung ist ferner, dass die zu untersuchende elektrische Lamelle horizontal ausgebreitet ist, keine Faltungen besitzt und auch nicht einseitig gezerrt ist. Besonders der letztere Umstand wirkt sehr störend auf die Form der Nervenendigungen.

Wenn man nun in dieser Weise eine isolirte Lamelle zunächst ohne Färbung mit nach oben gewandter Nervenschicht einstellt, so erkennt man Folgendes: Zuvörderst bemerkt mau 
Ueber den Bau des elektrischen Organes ron Torpedo etc. 485

die Ramifikationen der anfang's noch markhaltigen, sodann marklosen Nerven, auf welche ich indessen nicht näher eingehen will, da dieselben schon genügend bekannt und richtig beschrieben sind (siehe unten die Literatur-Uebersicht). Zwischen den Nerven, denselben sich oft anschmiegend und sie bis an die eigentliche Nervenendplatte begleitend, trifft man die Gallertzellen, welche dieselbe Gestalt und den grleichen Verlauf ihrer Protoplasmafortsätze, wie in den Golgi'schen Präparaten, zeigen. Nur lassen sich die Verzweigungen ihrer Fortsätze lange nicht so weit rerfolgen, wie in den von mil beschriebenen Präparaten, man sieht nur die gröberen Aeste. An den isolirten, von der Endplatte abgerissenen Nervenverzweigungen habe ich, besonders an mit Anilinfarben tingirten Präparaten, oft feinste Fäserchen, jedenfalls bindegewebiger Natur gesehen. Auch konnte ich bisweilen spärliche feine Bindegewebszüge feststellen, welche, wie schon Fritsch angegeben hat, das interlamelläre Gallertgewebe durchsetzen. Hicraus folgt, dass das letztere doch nicht so ganz ohne Struktur ist.

Verfolgt man die marklosen Nerven nun weiter, so sieht man, wie dieselben plötzlich übergehen in die Nervenendausbreitung, welche mit einem Male sichtbar wird, falls der Theil der Lamelle horizontal ausgebreitet ist. Die letzten an das Nervenendorgan herantretenden Nervenenden sind nun in diesen Osmiumpräparaten so breit oder wenig schmäler als die Maschen des Endnetzes, ein Unterschied von dem Befund in den Golgi'schen Präparaten, wo die Nerven gewöhnlich schmäler gesehen werden. Dieses Nervenendorgan erscheint als eine aus äusserst zahlreichen, feinsten Ramifikationen bestehenden Platte, welche ein eigenthümliches, charakteristisches Aussehen darbietet. Die Färbung der Endramifikationen ist eine verschieden dunkle, je nach der Einwirkung der Osmiumsäure. Immerhin ist diese Osmiumsäurefärbung noch nicht intensiv genug, um ganz genau den Verlauf dieser feinsten Endäste verfolgen zu können. Nur soviel lässt sich bei genauer Einstellung mit Immersion meist schon deutlich feststellen, dass sehr zahlreiche, netzartige Anastomosen der zarten Verzweigungen bestehen. Wie in den Golgi'schen Präparaten sind die Bälkchen dieses Netzes nicht überall gleich breit, sind vielmehr etwas unregelmässig höckerig, mit Buckeln und hier und da mit kleinen Seitensprossen besetzt. Dieses Netz liegt 
in einer optischen Ebene, Ueberkreuzungen der Bälkchen sind nicht vorhanden. Bewegt man den Tubus wieder ein wenig nach oben, so dass die Netzmembran undeutlich wird und die zu derselben tretenden Nervenäste sich wieder scharf einstellen, so bietet die undeutliche Netzmembran ein wesentlich anderes Bild. Statt der etwas unregelmässigen hellen Lücken zwischen den Netzbalken erscheinen helle, mehr oder weniger kreisrunde regelmässige Stellen, die umgeben werden von verschwommenen, verwaschenen, dunklen Linien; hierdurch könnte man verleitet werden, Körnchen $z u$ sehen, doch ist dies nur eine optische Erscheinung, welche anf einer ungenügenden Einstellung der Netzinembran und der stark lichthrechenden Eigenschaft der Net\%balken beruht. Ich werde hierauf bei der Kritik der Fritsch'schen Untersuchungen zurückkommen.

Bewegt man nun, nachdem man das Nervenendnetz wicder scharf eingestellt hat, den Tuous sehr wenig nach abwärts (dorsalwärts), so taucht im Gesichtsfelde sehr bald, sowic das dunkle Nervenendnetz gerade anfüngt, undeutlich zu werden, eine grosse Anzahl dunkler, gleich grosser, sehr scharf und bestimmt hervortretender, runder Pünktchen auf, welche, wie man bei leichtem Spielen der Mikrometerschraube erkennt, den dunklen Netzmaschen ihrer Lage nach entsprechen, in den Lücken aber feblen. Diese Ptinktchen, welche die Boll'sche Punktirung darstellen (siehe unten die Literatur-Uebersicht), liegen nicht alle genau in einer einzigen optischen Ebene, der grösste Theil derselben befindet sich mehr ventralwärts. Hier erkenut man bei genauester Einstellung, dass die Pünktchen oft zu zweien oder dreien oder mehreren gruppenweise zusammenliegen. Diese Pünktchen sind stark lichtbrechend; unwahrscheinlich wird hierdurch hauptsä chlich bedingt, dass bei einer gewissen Einstellung des Nervenendnetzes, meist entsprechend den Pünktchen, so lange dieselben noch nicht eingestellt sind, in den Balken des Nervenendnetzes häufig helle, kreisrunde Stellen sichtbar sind, in ähnlicher Weise, wie sie auch in den Golgi'schen Präparaten beobachtet wurden.

Schraubt man den Tubus noch weiter nach abwärts, so werden die Boll'schen Pünktchen undentlich. Sehr bald treten grössere, unregelmässig gestaltete Körner hervor, die sehr zahlreich und meist in unregelmässigen Gruppen uiber das ganze Gesichtsfeld ausgestrent sind. Diese ninterstitiellen Körner", wie 
Ueber den Bau des elelitrischen Organes von Torpedo etc. 487

sie von den Autoren auch wohl genannt werden, lialte ich für wichtige Bestandtheile des elektrischen Gewebes, obwohl sie ron den meisten Autoren sehr vernachlässigt sind und nur nebenbei erwähnt werden. Sie sind von verschiedener Grösse und Form, viele rundlich, andere napfförmig; häufig sind mehrere zu bisweilen etwas gebogenen kurzen Fäden, gleich Bakterienketten, zusanmengelagert. Durch Osmiumsäure haben sie einen leichten grauschwarzen Farbenton angenommen, welcher aber nur der peripheren Schicht anzugehören scheint; das Innere tritt stark lichtbrechend und hell hervor. Sie sind es, welche bei Anwendung der Golgi'schen Färbung sich bisweilen intensiv schwarzbraun fürben.

Im Niveau der am meisten rentralwärts geleg’nen Körner, bisweilen ein sehr weniges höher, tritt nun ein Gewebe an den Osmiumpräparaten in die Erscheinung, welches merkwürdigerweise den meisten Beobachtern ganz entgangen ist, wohl deshalb, weil immer zu stark aufgehellte Präparate antersucht wurden.

Dieses Gewebe besteht aus einem teinen Netzwerk feinster Fïlchen, welche kleinste rundliche Lücken von ziemlich gleicher Grösse zwischen sich fassen. Die Knotenpunkte dieses Netzgerüstes erscheinen wie dunkle Punkte, so dass die Schicht bei oberfliichlicher Untersuchung fein granulirt aussieht. Am deutlichsten nimmt man diese feinsten Gerüstmaschen wahr, wenn die dorsale Schicht isolirt, d. h. von der Nervenendplatte befreit ist. Dies tritt häufig an den Rissstellen ein. Man beobachtet an den Risslinien oft, dass die dorsale Schicht resistenter ist als die Nervenendplatte; letztere ist häufig eingerissen, während die dorsale Schicht noch intakt bleibt. Stellt man die ventrale Oberfläche dieses dorsalen Gerüstwerkes ein, so blitat bei einer gewissen genauen Einstellung eine zum Gerüst gehörige dünne Schicht auf, welche aus grösseren, ziemlich regelmässigen Netzmaschen besteht und genau dasselbe gefelderte Aussehen zeigt, wie die grossmaschige Gerüstschicht, die ich an den Golgi'schen Präparaten beschrieben und abgebildet habe. Es ist also das in den Golgi'schen Präparaten so ausserordentlich scharf hervortretende Gerüstwerk in allen Theilen schon an den Osmiumpräparaten gut zu erkennen; nur treten die Körnchen der Fädchen hier nicht so deutlich hervor, wie an jenen.

Bewegt man den Tubus weiter nach abwärts, so währt es 
eine Zeit, bis der Focus dieses feine Gerüst in den Osmiumpräparaten durchwandert hat. Alsdann hört dasselbe plötzlich auf; in einer hellen Ebene tauchen zahlreiche, sich durehkreuzende Bindegewebsfibillen und feinste Bindegewebsbündel auf. Damit haben wir die elektrische Lamelle ihrer Dicke nach durchmustert.

Diese Strukturen werden um vieles deutlicher, wenn man die mit Osmiumsäure belıandelten Platten mit stark färbenden Inilinfarben, z. B. Gentianaviolett färbt und sodann in Wasser untersucht. Vor allem treten die Ramitikationen der Nervenendmembran schärfer hervor, weil sie die Farbe annchmen. Man sieht dann die zahlreichen netzförmigen Anastomosen und kamm feststellen, dass die Netzbalken verschiedene Breite haben. Abcr auch frei endigende Seitensprossen sind lier und da zu crkennen. Bei genauem Hinsehen findet man aber oft, dass von der Spitze dieser Seitensprossen feine schmale Communikationsfiden zu den benachbarten Netzbalken hingehen. Hier und da scheint es, dass die Seitensprossen etwas zahlreicher werden. Das hängt wohl von einer verschiedenen Einwirkung der Osminmsäure auf dieses zarte Netz ab. Immer aber sind sie gering im Vergleich zu den sehr zahlreichen Netzverbindungen. Das Ganze bietet denselben eigenartigen, im Allgemeinen gleichmässigen Aublick dar, wie in den Golgi'schen Präparaten, nur dass in den letzteren die Bilder un vieles schürfer, wie mit der Feder gezeichnet, hervortretell, so dass sich die Netabalken auf das genaueste verfolgen lassen. Wenn auch die Anilinfärbung schon recht intensiv ist, so sind die Umrisse dieser feinsten Zeichnungen doch dabei noch zu weich, als dass man nicht wünschen müsste, dass diese Färbung noch deutlicher wäre, um genauer sehen zu können. Dasselbe gilt für die Hämatoxylin-Färbungen der Osmiumpräparate.

Bei etwas tieferer (dorsalwärts gerichteter) Einstellung der Anilinpräparate nimmt man sodann die Boll'schen Pünktchen sehr scharf und deutlich wahr. Häufig ist es mir nun begegnet, dass bei genater Einstellung der Pünktchenschicht je rwei oder mehr Pünktchen durch schmale, schwach gefärbte Linien verbunden wurden. Hier kamen also die Stäbchen und Stäbchenkombinationen zur Wahrnehmung, wenn auch die Fürbung eine recht schwache und zarte blieb. Immerhin kann man doch schon an diesen mit Anilinfarben tingirten Osmiumpräparaten den Beweis liefern, dass die Stäbchen und Stäbchenkombinationen auch hier 
Ueber den Bau des elektrischen Organes von Torpedo etc. 489

vorhanden sind und die Boll'sche Punktirung hauptsächlich durch die Endkïgelchen der Stäbchen bedingt wird. Durch diese Stäbchenverbindung der Kügelchen erhielt die Schicht dann eine Art Netzzeichnung, doch war es mir nicht möglich, das Stäbchennetz selbst wahrzunehmen; das nimmt mich bei der Zartheit desselben auch nicht wunder.

Auch das feinste Gerüstwerk der Dorsalschicht färbt sich mit Anilinfarben, aber nur die Fädchen und die denselben eingelagerten Körnchen. Die rundlichen Maschenlücken dagegen bleiben hell, wie man am besten an isolirten Dorsalschichten und den Rändern der Risslinien sieht. Dies spricht dagegen, dass die Lücken dieses Netzgerüstes von runden kleinen Körnchen ansgefüllt sind, die sich bei Anwendung der ziemlich Alles färbenclen Anilinfarben doch auch hätten mitfürben müssen. Die gröberen Körner der Grenzschicht z. B. sind intensiv gefärbt. Auch die Lichtbrechungsverhältnisse müssten andere sein, falls in den Lücken der Maschen Körnchen gelagert wären. Die kreisrunden Liicken müssten heller, stärker lichtbrechend, anch an dem ungefürbten Präparat, hervortreten; sie erscheinen indessen matt, während die Gerïstfädchen, besonders bei Tinktion, scharf sichtbar sind. Kurz und gut, ich habe nicht den geringsten Anhaltspunkt dafür gewinnen könuen, dass hier in der Dorsalschicht regelmässig angeordnete kleinste Körnchen (abgesehen von den Körnchen der Fïdchen selbst) vorhanden sind. Vielmehr glaube ich, dass die Lücken der Gerüistsubstanz durchtränkt sind von derselben, wohl flüssigen Masse, welche auch die eingelagerten Kerne umgiebt. Die hellen Höfe, welche die Kerne umsäumen, werden abgeschlossen von membranartig erscheinenden, oft wie zerknittert (in den Osmiumpräparaten) aussehenden Theilen der Gerïstsubstanz, welche dieselben kapselartig umgeben, wie ich dies in den Golgi'schen Präparaten festgestellt habe. Das zerknitterte Aussehen beruht jedenfalls auf einer durch Schrumpfung des Gerïstwerkes bedingten Verunstaltung der Kapsel. Dass die hellen Höfe um die Kerne aber einer durch Schrumpfung des Gerïstwerkes bedingten Retraktion ihre Existen $z$ verdanken, erscheint mir nicht wahrscheinlich.

In gleicher Weise stehen die Befunde, welche mir vertikale Durchschnitte der elektrischen Platte ergaben, durchaus im Einklange mit den bei Anwendung der Golgi'schen Methode erhal- 
tenen Resultaten. Ich benutzte hicrzu vorwiegend Material, welehes in der oben angegebenen Weise mit Osmiumsäure fixirt wurle. Die kleinen Stücke wurden in Paraffin, das einen Sclmolzpmukt von 56-58 Grad hatte, eingebettet. Es ist von grosicer Wichtigkeit, ganz feine und genau vertikale Schnitte anzufertigen. Ich stellte mit dem J ung'schen Mikrotom Sehnitte von $0,001-0,00: 3 \mathrm{~mm}$ Dicke her, welche mit Eiweisslösung auf dem Objectträger antscklebt und ungefärbt oder nach vorausgegangener Färlung mittelst Anilinfarben oder Hämatoxylin in Wasser bei Immersion und guter Belenchtung untersucht wurden. Ich betone, dass die Untersnchung in Wasser sehr wesentlich ist.

Von der Vertheilung der Nerven in den breiten interlamellären Ränmen will ich hier abschen; es sci nur erwähnt, dass die Durchschnitte der feinsten marklosen Aeste, kur\% bevor sie an das Netz herantreten, dem letzteren dicht an, aber ausserhalh desselben liegen.

Wenn man nun ganz dünne und genau vertikal ausgefülnte Schnitte untersucht, so fällt am unteren (ventralen) Ramle dis Plattendurchschnittes eine breite dunkel-schwarzgrane schicht sofort auf, welehe sich sehr deutlich und scharf von der Umgebung abhebt. Diese Schicht besteht aus einer einfachen Reilic etwas ungleich grosser würfelförmiger oder anch etwas länglicher Stulcke. Diese abgeplatteten Stücke sind durch helle Zwischenrïume von einander getrennt; die Breite der Zwvisehenrinme schwankt etwas. Diese Schicht, welche in dem Durchschnitt "/1 unterst in der Lamelle gelegen ist, stellt den Durchschnitt durch das Nervenendnctz dar.

Unmittelbar obcrhalb dieser Lage dunkler Stiickchen findet sich eine ganz schmale helle Linie, vielleicht nur eine optische Erscheinung, welche bedingt wird durch das starke Lichtbrechungsvermögen der Stïckchen. In dieser hellen Saumlinie oder ununittelbar darüber sieht man nun bei genauer Einstellung sehr deutlich und scharf eine einfache Reihe gleich grosser, dunkler Pünktchen, welche nicht alle genan in gleicher Höhe liegen; ein Theil derselben befindet sich in unmittelbarer Nähe der Oberfläche der dunklen Stückchen. Von den entfernteren Pünktchen geht num -ein feiner, sehr wenig scharf hervortretender, fast schattenhafter kurzer Strich aus, welcher die Pünktchen mit den Nervennetz in Verbindung setzt. Hierdurch wird eine kurze vertikale 
Ueber den Bau des elektrischen Organes von Torpedo etc. 491

Strichelung dieser Schicht bedingt, welche aber an dïnnen Schnitten durchaus nicht so regelmässig und dicht ist, wie sie von den Autoren beschrieben wird. Als sogenannte "Palissadenzeichnung" (siehe unten die Literaturübersicht) erscheint sie nur an dickeren Schnitten oder an optischen Durchschnitten bei Faltung isolirter Lamellen. Ich glaube auch, dass an etwas dickeren Schnitten die Pünktchen selbst das Bild der Strichelung wesentlich verstärken und in Folge ihrer starken Lichtbrechung in denselben als kurze Striche imponiren können. An den dünnen Schnitten kann man auch feststellen, was an dickeren nicht hervortritt, dass entsprechend den hellen Lücken zwischen den dunklen Nervennetz-Stiickchen auch die feinen kurzen Striche fehlen, dieselben mithin nur mit den Nervennetz-Stïcken korrespondiren. Die dunklen Pünktchen sind natürlich die Stäbchen-Kügelchen, welche in der Flächenansicht die Boll'sche Punktirung bedingen. Die Stäbchen selbst werden durch die zarten, undeutlichen, kurzen Striche repräsentirt. Bei den ausserordentlich kleinen Dimensionen und der äussersten Zartheit dieser Gebilde gelingt es auf dem Durchschnitt nicht, näheren Aufschluss über die Kritmmungen und Zusammenlagerungen der Stïbchen zu gewinnen, wie es die Golgi'schen Priiparate so ausserordentlich deutlich zeigten.

Sehr merkwürdig erscheint es mir; dass die Boll'schen Pünktchen auf dem vertikalen Durchsehnitte allen früheren Beobachtern entgangen sind, obwohl sie doch so scharf hervortreten; nur Ciaccio erwälnt in seiner letzten Mittheilung (33), dass er die Pünktchen auch auf dem vertikalen Durchschnitte wahrgenommen hat.

An diese Pünktchen- und Stäbchenschicht schliesst sich nun in den Durchschnitten eine breitere Schicht an, welche ein gleichmässig graues, wie es auf den ersten Blick scheinen möchte, gleichmässig fein granulirtes Aussehen besitzt. Der Anschluss findet aber nicht unmittelbar statt, sondern wird gewöhnlich vermittelt durch eine sehr schmale helle Linie. In dieser grauen Dorsalschicht erkennt man nun bei genauer Untersuchung dasselbe Gewebe, wie es an den Golgi'schen Präparaten und den Osmium-Zupfpräparaten von mir beschrieben wurde. Man sieht zahlreiche kleinste, meist kreisrunde helle Stellen, welche von dunklen, sehr schmalen und zarten netzartigen Zeichnungen begrenzt werden; die Knotenpunkte der Gerüstnetzmaschen erscheinen 
als dunkle Punkte, sodass hierdurch das fein granulirte Ausselıen bedingt wird. Dorsalwärts ist die Färbung dieser Schicht eine Nuance dunkler, es scheint hier das Gerüstwerk etwas dieliter gewelt zu sein. Ventralwärts, gegen die Ptinktchenschicht hin, wird es ctwas lockerer; hier an der Grenze zwischen dorsaler und ventraler (Nerven-)Schicht finden sich die schwarzgrau gefürbten, bei Schilderung der Flächenansicht näher beschriebenen, ungleich grossen Körner. Diesclben sind am zablreichsten an der Grenze und in der untersten Lage der (lorsalen Geriistsubstanz, erstrecken sich aber auch häutig vereinzelt bis gegen die Mitte ibrer Dicke lin. Diese Köruer und Körnerreihen erweisen sich auf den Durchschnitten als vollkommen isolirt liegende Gebilde, die mit keinem anderen Gewebsbestandtheil in sichtbaren Zusammenlang treten.

Auch die vertikalen Durchschnitte ergaben mir, sellost bei Anwendung verschiedener Färbungen, keinen Anhaltspunkt dafiur, dass die feinsten Nischenlïcken der Gerüstsubstanz von kugeligen Körnchen ausgefüllt sein könnten.

Sind die Lamellen geschrumpft, so beobachtet man bisiveilen, dass in dem unteren Theil der dorsalen Schicht eine Verdichtung hervorgerufen wird, welche als dunkle breitere Linie erseheint, die noch verstairkt und verbreitert wird durch die eingelagerten runklen Körner. Diese mehr unregelmässige Linie zieht parallel der Nervennetzschicht, von der letzteren nur getrennt durch den hellen Streifen, in welchem dic Pünktehen und vertikalen Stäbchen gelegen sincl.

Die Gerïstsubstanz wird dorsalwärts abgeschlossen durch eine schmale, stark lichtbrechende, sehr deutliche Linie, welche den Durchschnitt durch die dünne Dorsalmembran darstellt. Dorsalwärts davon, dieser schmalen Saumlinie dicht anliegend, trifft man auf dem vertikalen Durchschnitt zahlreiche durchtrennte feine Bindegewebsbündel an.

In Betreff der Kerne, welche die Lamelle dorsalwärts etwas vorbuchten, sei noch erwaihnt, dass dieselben auf dem Durchschnitte durch Präparate, die mit Osmiumsäure oder Flemming'scher Lösung fixirt waren, ausser den 3-4 häufig ungleich grossen Kernkörpern, oft ein grobes Netz mit Verdickungen der Knotenpunkte desselben erkennen liessen. Hierdurch erhiclten die Kerne oft ein grobkörniges Aussehen, was auch an den 
Ueber den Bau des elektrischen Organes von Torpedo etc. 493

Golgri'schen Präparaten nach Färbung derselben mit Alaunkarmin und Hämatoxylin häufig hervortrat.

Schliesslich will ich noch hervorbeben, dass in den Zupfpräparaten nach Osmiumsäurebehandlung sich die dorsale Schicht, besonders an den Rissstellen der Lamellen, häufig von der Nervenschicht trennt. Dabei bleibt stets die Püntchenschicht in innigem Zusammenhange mit dem Nervennetz, diese beiden lassen sich nicht von einander trennen. Mehrmals beobachtete ich aber, dass anch ein Theil der „Körner" der isolirten Nervenschicht anhaftete, während der andere Theil derselben in der Dorsalschicht verblieb. Die gegenseitige Verbindung der beiden Schichten ist demnach nur ein lockere. Es wollte mir indessen nicht gelingen festzastellen, wodurch und wie diese Verbindung vermittelt wird. Vielleicht treten die nach unten vorspringenden weiteren Maschen der Geriistsubstanz, welche ich oben beschrieben habe, in Beziehung zu den gleichfalls in Maschen angeordneten. Stäbchen des Stäbchennetzes, obgleich ich in den Golgi'schen Präparaten niemals eine direkte Verbindung beider Schichten gesehen habe.

Nach Allem kann man also in der elektrischen Lamelle eine ventrale und dorsale Schicht unterscheiden. Die ventrale setzt sich aus dem Nervenendnetz und dem Stäbchennetz mit den Stäbchen zusammen. Die letzteren liegen mit ihren Endkügelchen in dem sogenannten „Palissadensaume“. Die aus dem elektrischen Netzgerïst-Gewebe bestehende dorsale Schicht wird dorsalwärts abgeschlossen durch die dünne Dorsalmembran, der aussen noch Bindegewebszüge aufgelagert sind.

Die Behandlung des frischen elektrischen Gewebes nach anderen Methoden, z. B. die Fixirung mittelst Flemming'scher Lösung, Palladiumchlorür, Salpetersäure von $3-5 \%$, leisteten mir nun durchaus nicht mehr als die Fixirung kleinster Stlickchen durch Osmiumsäure, im Gegentheil muss ich der letzteren Methode in jeder Beziehung den Vorzug geben.

Auch das lebensfrische Gewebe habe ich in indifferenten Flüssigkeiten untersucht, wenn mir auch za einem eingehenderen Studium desselben das genügende Material fehlte. Doch konnte ich mich auch hier auf das bestimmteste von der Existenz des Nervenendnetzes, welches das oben beschriebene Aussehen zeigte und von dem Vorhandensein der Boll'schen Punktirung, die an der frischen elektrischen Platte sehr deutlich ist, überzeugen. 
Bei ungenïgender, nicht scharfer Einstellung, besonders an etwas dickeren Gewebsschichten bietet das Nervenendnetz häufig das oben bereits erwähnte Trugbild dar, als bestände hier eine Znsammensetzung aus hellen, durch undeutliche, verschwommene Grenzlinien getrennten Kügelchen; eine genate Einstellung an isolirten Lamellen zeigt aber sofort, dass es ein Trugbild ist, dias Nervenendnetz tritt dann stets sehr dentlich hervor. Bei einigem Verweilen der Präparate in der Zusatzflüssigkeit fand ich, dass die Stäbchenschicht ein eigenthümlich zottiges Aussehen erhielt.

Versuche mit Methylenblau nach dem von Dogiel angegrebenen Verfahren wollten mir noch nicht giücken, wohl aus dem Grunde, weil mir nicht hinreichend Naterial \%ur Verfïgung stand. Methylenblan färbte iibrigens die 1-4 oft ungleich grossen Kernkörperchen sehr intensiv und liess dieselben in dem blass bleibenden Kerne schr scharf hervortreten.

\section{Literatur - Uebersicht.}

Die Literatur über das elektrische Organ der Fische ist sehr umfangreich. Ich werde sie nur soweit beriicksichtigen, als sie den Zitterrochen (Torperlo) betrifft und mit den von mir mitg'ctheilten Thatsachen in unmittelbarer Beziehung steht. Bei der Beurtheilung der Resultate, welche andere Forscher nach anderen Methoden erhalten haben, muss ich von den nach der Golgi'schen Methode von mir erhaltenen Befunden ausgehen; denn es kann der Golgi'schen Methode, wie die Erfahrung gelehrt hat und allgemein anerkannt ist, nicht der Vorwurf gemacht werden, Kunstprodukte und Zerrbilder su liefern, wenn die damit erhaltenen Strukturzeichnungen so konstant auftreten und so scharf und bestimmt ausgeprägt sind, wie es im elektrischen Organ der Fall ist. Ich habe dabei alle Cautelen beobachtet, die ein so uberaus zartes und vergängliches Gewebe, wie das elektrische, erfordert. Kleine Stücke des Gewebes wurden in der oben geeschilderten Weise den lebenden Thieren ausgeschnitten and sofort in eine reichliche Menge des Gemisches von Osmiumsäure und doppeltchromsaurem Kali gebracht, so dass die fixirenden Flüssigkeiten auf das lebensfrische Gewebe einwirkten. Ich glaube 
Ueber den Bau des elektrischen Organes von Torpedo etc. 495

daher zu der Annahme berechtigt zu sein, dass die von mir erhaltenen Befunde in allen wesentlichen Punkten den Strukturen entsprechen, wie sie im lebenden Gewebe wirklich vorhanden sind. Man muss nur bei Beurtheilung der Golgi'schen Präparate vorsichtig. sein und stets daran denken, dass sich nicht Alles gleichzeitig fürbt und die Färbungen meist unvollständig ausfallen. Der letztere Umstand tritt besonders im elektrischen Organ hervor. Im Uebrigen habe ich, wie oben bereits erwähnt, auch die anderen Methoden nicht vernachlässigt; ich werde bei Besprechung der einzelnen Arbeiten darauf zurïckkommen.

Um dem Leser bei der von mir geiibten Kritik ein unbefingenes Urtheil zu gestatten, will ich die Arbeiten der Autoren meist wörtlich citiren. Diese Zusammenstellung kann zugleich cinen Ueberblick über die interessante Geschichte unserer Kenntniss vom Bau der elektrischen Organe geben.

Die älteren Arbeiten von Jo hn Hunter (1), Delle Ch i aje (2), Valentin (3) und Savi (4) können unberiicksichtigt bleiben, da sie nur die gröberen Bauverhältnisse des elektrischen Organes behandeln. Es sei nur erwähnt, dass Savi zuerst die Zusammensetzung der elektrischen Prismen aus Lamellen ("Diaphragmes“) erkannt und die Nervenverästelungen auf den durchsichtigen Lamellen entdeckt hat.

Die grundlegenden Arbeiten über den feineren Bau des elektrischen Organes heben an mit den Untersuchungen R. Wagner's $(6,7,8,9)$, deren Resultate hauptsächlich in den Abhandlungen der Königlichen Gesellschaft der Wissenschaften zu Göttingen 1847 veröffentlicht wurden (9). Wenn auch die Anschauung, zu welcher R. Wagner über die Anordnung und den Bau der

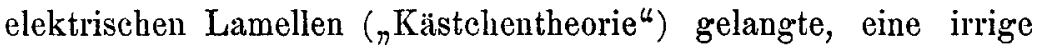
var, so sind doch die Mittheilungen, welche dieser Forscher über den Verlauf und die Verzweigung der Nerven machte, um so werthvoller gewesen.

R. Wagner berichtete in seiner Arbeit (9) zuerst von dem merkwürdigen Zerfall der an jedes Prisma herantretenden Nerven in ein Büschel zahlreicher noch markhaltiger Aeste ("Wagner'sches Büschel"; "Bouquet de Wagner" [Ranvier]). (1. e. p. 154): „Plötzlich an einer Stelle verliert das Mark seine doppelten Contouren und es entspringen hier eine grössere oder geringere Anzahl Aeste mit ganz feinen Würzelchen aus der Marksubstanz 
und bilden hier ein Büschel, der sich jedoch durch seitliche Ausbreitung der Aeste, welche mit dem Stamm der Fibrillen verschieden grosse, zum Theil rechte Winkel bilden, bald zu einer Art Krone oder Dolde ausbreitet, von einer Seite gesehen auch oft ein kammförmiges Aussehen gewinnt. Die Zahl dieser Aeste ist verschieden; meist gegen fünfzehn, zuweilen zwölf. Weniger habe ich nicht gezïhlt, wohl aber öfters mehr, achtzehn, ja zwanzig, seltener noch mebr, bis auf fünf und zwanzig, welches die höchste von mir beobachtete Zahl war."

Sodann wurden von $R$. Wagner die weiteren Verzweigungen der Nerven und die eigenthimlichen, hirschgeweihartigen Ramifikationen ibrer Endäste sehr genal verfolgt, "Wagner's Geweihfasern". L. c. p. 157:

„Bei grosser Sorgfalt gelingt es, einzelne Aeste der Primitivfasern bis in alle ihre Endzweige zu verfolgen, und man überschaut dann die ganze Ramifikation allmählich mit der grössten Klarheit..... Man bemerkt, dass jeder Hauptast eine Strecke verlänft und sich dann zuerst immer dichotomisch theilt. In jeder solchen Theilungsstelle wird die Markmasse des Astes dünner, blasser, verliert die doppelten Contouren und theilt sich in zwei diunne Schenkel, welche kurz darauf wieder dicker werden, ja den Durchmesser ihres Stammastes erreichen und wieder die zwei Contouren zeigen. Jeder solcbe Theilast theilt sich dann nach einiger Zeit wieder dichotomisch; die Aeste gehen unter mancherlei Winkeln ab, bald V-förmig;, bald sehr gespreizt, und vertheilen sich in langen Bogen und wurzelförmigen Auslänfern auf die zierlichste Weise. Ueberall, wo Aeste abgehen, theilt sich auch die Scheide und bildet für jeden weiteren $Z$ weig derselben einen weiten Ueberzulg, durch welchen das Mark vom Muttergewebe des elektrischen Organes isolirt wird. Ueberall nimmt man auch Kerne wahr. Hier und da, aber doch selten, kommen auch dreifache Theilungen der Aeste vor, sonst ganz mit ähnlichen feinen Wurzeln, wie die zweifachen Theilungen entstehend.

Ich nenne diese Aeste, welche büschelförmig alle aus dem Terminalpunkt der Primitivfaser entspringen: Primitiväste oder Aeste erster Ordnung. Nachdem sie sich vielfach gespalten und verzweigt haben, wobei sie nur wenig im Durchmesser verlieren, gehen aus ihnen zuletzt dünnere Aeste hervor, an denen die 
Ũeber den Bau des elektrischen Organes von Torpedo etc. 497

Scheide sich.pplötrlich enger anlegt und verschwindet. Von ihnen entspringen, gewöhnlich sehr gespreizt, viel feinere, blassere Aeste. Ehe noch dieselben abgehen, hat das Mark mit seinen doppelten Contouren aufgebört, ohne dass diese ubber einander zusammenfliessen. Ich nenne diese Aeste oder vielleicht besser Zweige: Aeste der zweiten Ordnung, Sekundäräste. Sie sind blasser, haben auch scharfe, aber feine Begrenzungen, die niemals doppelt, immer einfach erscheinen ..... Diese Aeste verzweigen sich sogleich hirschgeweihartig, werden sehr fein und enden, wie es scheint, frei und offen, entziehen sich aber bei einem Durchmesser von $1 / 800-1 / 1000$ Linie der weiteren Beobachtung ....... Jeder Sekundärast hat sein eigenes Gebiet und bleibt in einiger Entfernung von den Endverzweigungen der Sekundäräste anderer Primitivfasern."

Diese Art der Ramifikation hat $R$. Wagner sehr naturgetreu auf der bekannten, oft citirten Abbildung Fig. IIIB seiner Tafel zur Darstellung gebracht; sie ist in zablreichen Abbildungen späterer Autoren (von Kölliker, M. Schultze, Boll, Ranvier und andere) stets bestätigt worden. An jedem frischen Präparat, deutlicher noch an Osmiumpräparaten ist es leicht $\mathbf{z u}$ sehen. Der gespreizte Verlauf, die bisweilen rückläufigen Bicgungen der Sekundäräste auf dieser Abbildung verhalten sich genau so, wie in den Figuren 4,5 und 7 meiner Tafel XXX, nur sind auf letzterer die Verzweigungen der Sekundäräste noch vollständiger zur Darstellung gekommen. Auf der Abbildung Wagner's erkennt man auch schon die Kerne der Zellen der Dorsalschicht und eine leichte Granulirung zwischen den Nervenisten.

Ueber die Enden der Sekundäräste hinaus vermochte $R$. Wagner die Nerven nicht zu verfolgen.

Hervorbeben muss ich noch, dass schon $R$. Wagner betont, dass diese Nervenramifikationen niemals unter sich Anastomosen bilden. L. c. p. 159: „Sie bilden, so wenig als die Aeste der ersten Ordnung; ein Netzwerk; sie kommuniciren weder unter sich, noch mit den benachbarten Endzweigen." Wagner berichtigt hiermit die gegentheilige Behauptung Savi's (4), welcher sich dadurch täuschen liess, dass er keine völlig isolirten Lamellen, soudern übereinander geschichtete untersuchte und die letzteren für isolirte Lamellen nahm. Die Kreuzungen der überein- 
ander gelegenen gröberen Nerrenausbreitungen hatte $S$ a vi für wahre Auastomosen gehalten und ein Nervennetz der gröberen Nervenzweige als letzte Endigung angenommen.

Die Mittheilungen von A. Ecker (10) und H. Müller (11) bestatigten bald daranf dic Angaben Wagner's iiber die Nervenverzweigungen, olme Nenes zu enthalten.

Die unrichtige Anschaung. $\mathrm{R}$. Wagner's ron der Anordnung der elektrischen Lamellen wurde von Pacin i 1852 korrigirt. Pacini (12) stellte zuerst die wahre Zusammensetzung des Inhaltes der Prismen in den Grundzilgen fest. Nach seiner Beschreibung sind die Schichten der Gefiss- und Nerven-haltigen Flüssigkeit und die festeren Lanellen in einfacher Wechselfolge ïbercinander geschichtet. Die Nerven treten nur an die Unterseite der jedesmal näichst höheren Lamelle, um hier zn endigen, so dass jede elektrisehe Lanelle zwei Flächen besitzt, eine freie und eine mit Nerven in Verbindung stehende. Diese Flächen sind in jedem Prisma stets gleich gerichtet; die freie Scite sieht dorsalwärts, die mit Nerven versehene ventralwärts.

Wahrscheinlich ohne die Arbeit Pacini's zu kennen, veröffentlichte Remak im Jahre 1856 eine Abhandlung über dic Nervenendigung im elektrischen Organ des Zitterrochcus (13), welche, wenn auch kurz und ohne Abbildungen, so doch reich an trefflichen Beobachtungen ist. Remak hat eigentlich schon die meisten wesentlichen Bestandtheile des elektrischen Gewebes wenn auch nicht klar erkannt und nicht in jeder Hinsicht richtig erklärt, so doch in Andeutungen wahrgenommen. Es ist erstannlich, dass dieser Forscher mit den damaligen Hilfsmitteln soweit vorgedrangen ist. Mit Recht zollt Ranvier diesen Beobachtungen Remak's Bewunderung, indem er sagt (l.c. p. 144): "Quand j'ai pris connaissance du travail de Remak, j'ai admiré plus que jamaị la finesse et la sûreté d'observation de cet histologiste remarquable. Je ne comprends pas comment, sans objectifs suffisants, sans bons réactifs, malgré les nombreuses causes d'erreur qu'il avait à èviter, il a pu reconnaître $\ldots$... u. s. w.

Remak berichtigte zunächst, wie Pacini (12) schon vor ihm, die Auffassung Valentin's (3) und R. Wagner's (9) ron der Zusammensetzung der elektrischen Prismen aus Kästchen. Nach Remak besteht das Prisma im Innern ans zahlreichen quergestellten Blättchen, welche sich wieder ans Schichten zll- 
Ueber den Bau des elektrischen Organes ron Torpedo etc. 499

sammensetzen. An jedem Blattchen ist cine dorsale und eine ventrale Schicht zu unterscheiden; die letrtere wird von den Nervenverzweigungen gebildet. 13, p. 469: „Nan sieht klar, dass an jedem Blïttchen, welches kaum 1/500 L. in der Dicke messen dürfte, eine glatte und eine rauhe Seite zin miterscheiden ist. Die Blätchen liegen dicht auf einander, sodass immer die glatte Seite eines Blättchens der rauhen Seite des anderen mugewendet ist. Wenn ich nicht irre, ist die glatte Seite nach oben gewendet ${ }^{1}$ ). Sie wird durch eine durchsichtige, beinalıe glashelle Membran gebildet, welche in grossen regelmässigen Entfernungen runde, kernhaltige Höhlen enthält. Diese Mcmbran ist der festeste Theil des Blättchens: denn sie erhält sich, auch wenn durch schlechte Maceration die Nervenschicht verloren geht, welche die rauhe Seite des Blaittehens bildet."

Möglicherweise hat $\mathrm{Remak}$ schon etwas von den gröberen Maschen der von mir beschriebenen Gerüstsubstanz in dieser dorsalen Membran gesehen, denn er sagt p. 471: „Beachtenswerth ist jedenfalls, dass ich zuweilen auch auf der glashellen Membran, nach Ablösung der Nerven- und Stäbchenschicht, eine feine matte Zeichnung von kleinen unregelmässigen Ringen oder eckigen Figuren unterscheide. ${ }^{\prime}$

Ferner stellte Remak fest, dass sich die Nerven noch über die Enden der Wagner'schen Geweihfasern hinaus verästeln, indem er jedenfalls schon das Nervenendnetz wahrnalim; doch deutete er das Gesehene als einen Nervenplexus und schloss eine anastomosirende Verbindung der Nervenenden aus. L. c. p. 469 : „Wagner's Beschreibung und Abbildung ist richtig, soweit sie die stärkeren Fasern betrifft. Allein die blassen Fasern brechen nicht so plötzlich ab, wie Wagner angiebt, sondern sie verästeln sich weit feiner, wie man an allen meinen Präparaten anf den ersten Blick sieht, und die Aeste werden so fein, dass man wohl versucht wird, zu sagen, dass sie dem Auge sich entziehen, und dass zwischen ihnen doch noch ein, wenn auch kleiner von

1) In diesem Punkte war Pacini (siehe oben) schon weiter gekommen. Auch hatte Pacini schon richtig erkannt, dass die Blättchen nicht ,dicht auf einander liegen“, sondern durch eine Flüssigkeit von einander getrennt werden, deren gallertige Natur von von Kölliker später festgestellt wurde. 
Nerven freier "körniger" ${ }^{1}$ ) Raum übrig bleibt. Allein es bedarf nur eines günstigen Lichtes, $u m$ an gut ausgespannten Stiicken zu erkennen, dass der ganze scheinbar freie Raum vou Nervenverästelungen a sgefült ist. Man sieht nämlich kleine runde oder eckige Figuren von kanm $1 / 800$ L. und darunter. Verfolgt man die zarten Contouren dieser Figuren, so sieht man, dass sie Aeste der Nervenfasern sind und dass sie nicht geschlossene Ringe bilden, sondern offene, indem die Füserchen, deren Durchmesser ich auf weit weniger als $1 / 1500 \mathrm{~L}$. schätze, einander ebenso kreuzen, wie es die starken thun, und daher die ähnliche Täuschung hervorbringen, als bildeten sic netzförmige Anastomosen. An den Präparaten, welche ich mit doppeltchromsaurem Kali eingekittet habe, erscheinen die Zwischenräume zwischen den feinsten Fäserchen stellenweise wie helle runde Bläschen."

Bei dieser Sehilderung des so genauen und sorgfältigen Beobachters kann man sich einer gewissen Verwunderung dariber nicht erwehren, dass $R$ emak bei diesen äusserst feinen, dünnen, in einer optischen Ebene liegenden Bildungen schon so sicher entscheiden will, dass die feinen Fäserchen sich kreuzen, also olne gegenseitige Verbindung über einander und unter einander vorbeigehen, etwa wie die Rohrstreifen in dem Geflecht eines Rohrstuhles. Wie aus den Worten Remak's hervorgeht, gründet er sein Urtheil auch nicht auf optische Argumente, die durch Drehung der Mikrometerschraube geliefert würden und die gerade an diesem Objekt des elektrischen Nervennetzes beste Linsen und äusserst subtile Handhabung voraussetzen. Vielmebr kann es nur eine Annabme Remak's sein, zu welcher ihn wohl hauptsächlich die Geschichte des S a vi'schen Nervennetzes (siehe oben) veranlasst hat.

Mag dem sein, wie ihm wolle, jedenfalls hat Remak schon die eigentlichen Nervenendigungen an der elektrischen Lamelle gesehen, wenn auch seine Deutung des Gesehenen eine nicht richtige war.

Ja noch mehr! Remak hat sogar schon die elektrischen Stäbchen und möglicherweise auch die Endkügelchen derselben

1) Vgl. Fig. IIIB der Abhandlung R. Wagner's, wo dieses „körnige" Aussehen der Lamelle andeutungsweise schon angegeben wird. 
Ueber den Bau des elektrischen Organes von Torpedo etc. 501

wahrgenommen, wenn es von ihm auch nicht klar ausgesprochen wird. Doch konnte Remak über ihre Bedeutung und ihr Verhäiltniss zu den Nervenendigungen keinen Aufschluss erlangen. Die sehr beachtenswerthe Angabe lautet folgendermaassen, l. c. p. 470: „So wird die ganze rauhe Seite des Blättchens durch eine Nervenfaserverästelung von einer Feinheit und Dichtigkeit gebildet, wie sie bisher nirgends angetroffen worden ist. Es fragt sich aber nunmehr, wie die feinen Spitzen dieser Fäserchen enden. Zunächst ist zu beachten, dass in dem Maasse, als dic kleinen eckigen Ringe, welche den Zwischenräumen zwischen den Endästen entsprechen, deutlicher hervortreten, auch der Anschein von "Körnchen", welche man sonst $\varkappa u$ sehen glaubt, schwindet. So gelangt man schon durch die Flächenansicht zu der Vermuthung, dass das Ansehen von Körnchen entstehe durch kniefürmige Umbeugungen der Endfäserchen, welche in senkrechter Richtung der glashellen Membran zustreben. Diese Deutung gewinnt an Boden, sobald man ein Blättchen faltet; alsdann bekommt die Falte den Anschein, als wenn feine Cylinderchen die Dicke des Blättchens bis zur glashellen Membran hin durchsetzten. Hier ist zwar leicht eine Täuschung möglich, insofern die in der Fläche laufenden Fäiserchen bei einer gewissen Richtung der Falte ein älnnliches Anschen werden bedingen können. Allein es scheint die pallisadenähnliche Stellung feiner Stäbchen nach der Dicke des Blättchens zu deutlich und zu beständig, um eine solche Täuschung zuzulassen. Doch bekenne ich, dass mich schon hier meine Mikroskope im Stiche lassen. Denn es handelt sich nunmehr noch darum, zu entscheiden, ob die feinen Stäbchen nichts weiter sind als Fortsetzungen der feinsten Nervenreiser, oder eine neue differente, etwa der Muskelsubstanz ähnliche Masse. Diese Frage muss ich deshalb aufwerfen, weil es mir zuweilen gelingt, die feinen Nervenreiser im Zusammenhange sich ablösen zu sehen und weil alsdann kurze in Körner zerbrechende Stäbchen herausfallen, welche in Festigkeit und lichtbrechenden Eigenschaften sich von den Reisern unterscheiden und wegen ihrer Leichtigkeit zuweilen Molekularbewegung zeigen. Andererseits habe ich die feinsten Fäserchen mit stösselförmigen Anschwellungen und abgestutzten Enden aufhören sehen."

Schliesslich fand Remak auch die Zellen des allerdings von ihm nicht erkannten interlamellären Gallertgewebes auf und 
schloss mit Recht eine Verbindung derselben mit den Nerven-

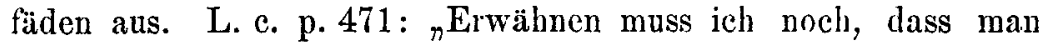
bei Verfolgung der feinsten Nervenreiser stellweise anf sternförmige oder spindelförmige, mit grossen Kemen versehene Zellen stösst, welche dem Anscheine nach im Laufe der Nervenfasern sich finden. Die feinen fadigen, zuweilen verästelten Ausläufer jener Zellen hängen nicht mit den Nervenfasern zusammen, und unterscheiden sich überdies zuwcilen von ihnen durch grössere Dunkelheit, ja sogar durch variköse Gestalt! Sie scheinen Bindegewebszellen zu sein."

Das Verdienst, die wichtigste Entdeckung in der Anatomie des elektrischen Organes gemacht zu haben, gebührt lier, wie :uf so manchem anderen Gebiete, A. von Kölliker (14); ich meine die Entdeckung des Nervenendnetzes. Es gereicht mir zu besonderer Freude, dies aussprechen zu können, da gerade dieses Nervenendnetz ein merkwürdiges Schicksal gehabt hat; nur von wenigen Forschern wurde es anerkannt, die meisten Untersucher, vor Allem die neueren, haben es in Abrede gestellt.

Die von von Kölliker (14) entworfene Schilderung dieses Nervenendnetzes, welches von Remak allerdings schon gesehen, aber als solches nicht erkannt wurde, lautet folgendermaassen, 14, p. 8:

${ }_{n}$ Nachdem die Nerven der Septa die von Wagner so gut beschriebenen und so huibsch abgebildeten Verzweigungen eingegangen sind, enden sie keineswegs, wie es Wagner schien, frei und offen oder doch so, dass sie bei einem Durchmesser von $1 / 800-1 / 1000$ "' der Beobachtung sich entziehen, vielmehr lassen sich dieselben noch viel weiter verfolgen. Indem nämlich die Wagner'schen blassen Nervenenden an die granulirte Lage Remak's oder meine Tunica nervea herantreten und in dieselbe sich einsenken, lösen sie sich in ihr unter fortgesetzten dichotomischen Theilungen noch viel weiter auf, bis sie schliesslich nur noch 0,0005-0,0008 "/ messen und diese feinsten Fäserchen treten dann endlich zu einem wirklichen Netzwerke zusammen, das die zierlichste und zugleich zarteste Bildung darstellt, die mir bis dahin im Bereiche der thierischen Gewebelehre vorgekommen ist. Man denke sich ein Netz von blassen, zarten Fïserchen von nieht mehr als $0,0005-0,0008^{\prime \prime}$, selbst darunter, 
Ueber den Bau des elektrischen Organes ron Torpedo etc. 50:

dessen dunkler aussehende rundlicheckige Maschen so eng sind, lass sic die Breite der Fasern nicht übertreffen, in dieses Net\% iiberall cine sehr grosse Zahl von zarten Nervenbäumchen ausstrahlend, ron denen jedoch keines die anderen beriihrt und anders als durch das Netz selbst mit ihnen zusammenhängt, endlich das Net\% in der ganzen Ausdehnung einer Scheidewand ausgebreitet und die Nervenhant derselben darstellend und man wird einen etwelchen Begriff von einem Verhalten haben, das keine Beschreibung und kaum eine bildliche Darstellung rollkommen wiedergeben kann. Dieses Netz ist num aber auch so zart und vergïnglich, dass dasselbe fast nur an eben getödteten oder wenigstens an ganz frischen Thieren (untersucht wurden von mir Torpedo narce und Galvani) vollkommen und rein zur Anschaumng kommt, was mir denn auch zu erklären scheint, warum Remak lasselbe nicht gesehen hat und von freiem Auslaufen der let\%ten Nervenenden spricht. Remak nämlich, der, obschon er im Jahre 1853 in Triest Torpedines untersuchte und sammelte, loch erst im Jahre 1856 seinen Fund von einer noch weitergehenden Verästelung der Nerven in den Septis des elektrischen Organes bekannt machte, mochte denselben doch vorzüglich an den $n$ in Triest in Sublimatlösung von $0,2 \%$ und Chromsäure von $0,2 \%$ macerirten und seitdem theils in Alkohol, theils in einer Mischung von doppeltchromsaurem Kali und Sublimat aufbewahrten Stïcken" gemacht haben, von denen er angiebt, dass sie das von ihm Beobachtete fast ebenso klar, wie die frischen Stücke zeigen. Ist diese Vermuthung richtig, so hätte ich dann zu bemerken, dass Reagentien eine sehr verderbliche Einwirkung auf die beschriebenen Endnetze haben und dass selbst die gelungensten Chromsäure- und Sublimatstücke nur selten eine schwache Andeutung von dem zeigen, was man frisch sieht. Solche Andeutungen scheint in der That auch Remak gehabt zu haben, wenigstens spricht er von einem Anscheine von netrförmigen Anastomosen der feinsten Nervenenden, welchen er dann aber für eine Täuschung: erklärt. Sollte Remak seine Anschauungen in der That vorzüglich an Chromsüure- und Sublimatstücken gesammelt haben, so finde ich es ganz begreiflich, dass er sich nicht anders ausspricht, denn ich weiss aus eigener Erfahrung, dass es an solchen fast unmöglich ist, die Ueberzeugung von dem Dasein von Endnetzen zu gewinnen und wäre ich anch selbst nie dazu gekom- 
men, dieselbe bestimmt $\mathrm{zu}$ vertreten, wenn ich nicht meine $\mathrm{Be}$ obachtungen an ganz frischen Organen angestellt hätte."

Von Kölliker knüplt an dicse Ausfïbrung, welche ich absichtlich in ganzer Breite citirt habe, noch eine Bemerkumy. über die Zartheit und grosse Vergänglichkeit dieses Nervennetzes, eine Bemerkung, welche sehr zu beachten ist und ron den Nachuntersuchern leider $\mathrm{zu}$ wenig berücksichtigt wurde. L. c. P.9: „Es verändert sich nämlich - und das bitte ich alle die wohl zu beherzigen, die diese Verhältnisse nachuntersuchen werden - die Nervenhant oder die Endnetze änsserst leicht in der Art, dass einzelne Theile der feinsten anastomosirenden Fasern zerfallen und aus der Verbindung mit den anderen sich lösen, und damm erhält man ein Bild von frei endenden Fäserchen, wie es Remak beschreibt."

In Fig. 1 der Tafel I seiner Abhandlung hat von Kölliker das Nervennetz mit einer himzntretenden, sich verzweis'enclen Nervenfaser sehr zierlich bei nicht starker Vergrössermug abgebildet. Nerven und Nervennetz sind hell gezeichnet, die Zwischenräume zwischen den Maschen dunkel. Bei scharfer Einstelluug mit starker Vergrösserung sehe ich aber das mikroskopische Bild gerade ungekehrt: die Maschen dunkel und die Lücken hell. Auch könnte in der Zeichnung der Anschein erweckt werden, als ob die Nervenveristelungen in dem Netz liegen, dasselbe unterbrechend, während in Wirklichkeit das Netz nicht unterbrochen ist und continuirlich über den Nerven hinzieht. Im Uebrigen würde sich diese Abbildung, falls man sie entsprechend vergrösserte, ziemlich genau mit meinen Zeichnungen lecken, auch was die etwas verschiedene Grösse und Form der Lücken zwischen den Maschen anbetrifft. Nur sind die buckelförmigen Hervorragungen der Netzbalken und die hier und da auftretenden Seitensprossen nicht angegeben; es würde dafiur anch die angewandte Vergrösserung nicht genügt haben.

Von den Stäbchen dagegen hat von Kölliker Nichts gesehen, wie er ausdrücklich hervorhebt. Pag. 10.

Was nun die weitere Zusammensetzung und Anordnung der elektrischen Lamellen betrifft, so unterscheidet vou Kölliker an jeder Säule, abgesehen von den dickeren bindegewebigen, die ganzen Prismen umgebenden und dieselben von einander trennenden Hüllen: 
Ueber den Bau des elektrischen Organes von Torpedo etc. 505

1. die Scheidewände, Septen (die elektrischen Lamellen),

2. die seitlichen Wandung'en,

3. die von je zwei Septen und den betreffenden Seitenwänden umschlossenen, einen mebr flüssigen Inhalt fïhrenden Räume, die Fäicher, Alveoli.

Der Inhalt der Alveolen ist eine fast flüssige Gallerte, in der ausser den Nervenverïstelıngen und den feinsten Blutgefässen keine weiteren Elemente als vereinzclte spindel- oder sternförnigre Sattzellen (Bindegewebskörperchen) mit langen, feinen Anslänfern sich finden; die Saftzellen liegen hauptsächlich längs den nahezu feinsten, woch nicht anastomosirenden Nervenästchen, in der Nähe der Septen.

Die Höhe der Fächer orler der Abstand zweier Septen ist sehr niedrig.

Die Scheidewände (Septa) bestehen nach von Kölliker aus zwei dünnen Lagen, einer Haut, welche dieser Antor noch für bindegewebiger Natur bält, und einer Nervenhaut. Beide Häute sind schon an frischen Priparaten leicht zu unterscheiden und lassen sich an Chromsäure- und Sublimatpräparaten olne Schwierigkeit in grosser Ausdehnung isoliren. Sie liegen an frischen Präparaten dicht beisammen und sind mit einander verklebt, ohne jedoch irgend eine Verbindung mit einander einzugehen. Die Nervenhant besteht aus dem erwähnten Nervenendnetz und findet sich stets an der unteren (ventralen) Seite der Septen. Die obere Haut erschien von Kölliker noch strukturlos; sie schien ihm nur die von allen Autoren erwähnten, als Kerne oder Zellen bezeichneten Gebilde zu enthalten. Ueber die letzteren sagt der Autor, 1. c. 1) 5: „Man findet diese Gebilde regelmässig. in jedem Septum als runde oder länglich runde, in grösseren Abständen befindliche Körper von 0,003$0,005^{\prime \prime /}$ Grösse, die offenbar nichts als Kerne sind und auch neben einem hellen Inhalt ein deutliches Kernkörperchen fïhren. An frischen Septis sah ich nichts von Zellenwänden ansser an diesen Kernen, dagegen bemerkte ich solche ganz deutlich an Sublimatpräparaten in Gestalt lichter Höfe mit deutlichen Contouren, die jedoch lange nicht an allen Kernen deutlich waren, so dass ich vorläufig nicht wage, alle diese Gebilde als Zellen zu bezeichnen. Was nun die Lage dieser Elemente anlangt, so sieht man an Flächenansichten frischer Präparate so viel mit 
Sicherheit, dass sie nicht in einer Ebene mit den feinsten Nervenausläufern, mithin nicht in der Nervenhaut liegen, und an Falten der Septa ergibt sich oft deutlich, dass sie in der Bindegewebslamelle ihre Lage haben, so dass sie an derselben leichte Verdickungen erzengen." Doch stiegen von Kölliker hicrgegen noch Bedenken auf.

Die von Kölliker'sche Entdeckung des Nervenenrlnetzes crhielt zwei Jahre später (1860) durch M. Schultze (15, 16) eine glänzende Bestätigung. Dies ist allerdings bis auf den hentigen Tag fast die einzige riickhaltlose Bestätigung geblieben. M. Schult \%e untersuchte gleichfalls das lebensfrische Gewebe und kam daher zu demselben Resultate wie A. von Kölliker. Der herühmte Autor sagt hierüber wörtlich 16, p. 25 :

„Die Endver\%weigungen sind nur im frischen Zustande des Organes zu sehen, lösen sich unter Quellungserscheinungen sehr bald nach dem Tode mehr oder weniger vollständig auf, und lassen sich, wie ich mit v. Köll i k e r bebaupten muss, in keiner der bisher gebräuchlichen conservirenden Flïssigkeit in voller Integrität erhalten. Diese Endverzweigungen bestehen in einem dichten Netz anastomosirender Nervenfäden, welches in einer ununterbrochenen Schicht die Bauchscite der homogenen Plättchen bedeckt und anch mit dieser innig verbunden ist ${ }^{1}$ ).

In der That ist das von v.Kölliker an dieser Stelle entdeckte und vollkommen naturgemäss beschriebene Nervennetz so fein, dass unsere besten Mikroskope kaum ansreichen, dasselbe mit aller wünschenswerthen Schärfe zu stndiren. Nur der höchsten Durchsichtigkeit des Objectes, welches so günstig zum Studium der Nervenendigung ist, wie nur möglich, und dem gänzlichen Mangel störender anf- oder untergelagerter anderer Elemente, vorausgesetzt, dass ein Plättchen vollkommen isolirt worden, ist es zu verdanken, dass wir hier im Stande sind eine Nervenverbreitung in situ und ohne künstliche Präparation so weit, als der jetzige Zustand unserer Mikroskope überhaupt erlaubt, zu verfolgen. Dennoch gelingt es auch bei Anwendung guter 400 bis

1) M. Schultze wollte es noch nicht gelingen, die beiden Schichten der elektrischen Lamellen $z u$ isoliren, was z. B. an Osmiumsäurepräparaten sehr leicht ist. 
500maliger Vergrösserung nur mit einer gewissen Anstrengung, die netzförmige Verbinduug der Einzelfädcnen und den Zusammenhang des Netzes mit den etwas dickeren Nervenfasern, welche alle ausserhalb der Ebene des Netzes, der Bauchseite des Fisches zu, liegen, deutlich wahrzunehmen. Nach längerer Vertiefung in den Gegenstand labe ich es dann unternommen, eine Abbildung des Netzes zu entwerfen und zwar der grösseren Deutlichkeit halber etwa drei Mal so gross, als ich es gesehen, also bei 1500maliger Vergrösserung gedacht, und vertraue ich, dass dereinst die Richtigkeit der Zeichnung bestätigt wird. An dieser ist das Nervennetz in der Ebene des Papiers gedacht, die eintretenden Nervenfasern ausserhalb derselben, dem Beobachter zugekehrt. Die an das dargestellte Stückchen Netz herantretende Nervenfaser ist eine marklose, an welcher schon keine vom Inhalte abstehende Scheide meh" wahrzunehmen ist. Dieselbe theilt sich in einen dickeren und einen dünneren Ast, deren jeder weiter sich verästelt in leicht gebogenem Verlaufe der Theilfasern, bis diese endlich mit ihren Endausläufern in das Netz ïbergehen."

Die von M. Schultze ausgeführte Zeichnung Fig. 3 auf der beigelegten Tafel I stellt das Netz mit ausserordentlich regelmässigen Mascheu dar, ein Schematismus, welcher wohl dadurch bedingt wird, dass M. Schult\%e das Netz dreimal grösser gezeichnet hat, als er es wirklich gesehen. Fast alle Maschen sind gleich gross und gleich gestaltet, so dass das Ganze sehr steif und eckig aussieht. Nach meinen Untersuchungen muss angenommen werden, dass das Netz in dem lebenden Gewebe nich t so regelmässig und abgezirkelt ist. Auch habe ich an der Zeichnung auszusetzen, dass die Netzbalken im Verhältniss zu den Lïcken zu schmal sind. Ebenso, wie von Kölliker, dessen Zeichnung meiner Ansicht nach dem natürlichen Verhalten näher kommt, hat M. Schultze die Netzbalken hell und die Zwischenräume dunkel gezeichnet, während ich es bei genauer Einstellung des frischen Gewebes bei starker Vergrösserung umgekehrt sah. In die Maschenlücken vorspringende Enden und Buckel erwälnt M. Schultze ebensowenig wie von Kölliker; auch die Abbildungen lassen nichts davon erkennen.

Jedenfalls ist das von von $\mathrm{Kölliker}$ entdeckte und von M. Schultze bestätigte Nervennetz identisch mit dem von mir 
beschriebenen, nach der Golg. i 'schen Methode sich schwarz färbenden "Nervenendnetz", welches aber noch das von diesen Autoren nicht gesehene "Stiibchennet " " umfasst.

Ausser dieser Bestätigung entbält die Arbeit M. Schult\%e's noch Angaben tiber den feineren Bau des elektrischen Organes, welche mit mcinen Ergebnissen durchaus im Einklange stchen.

Was zunächst die gröberen Verzweigungen der Nervenfasern anlangt, so berichtet M. S ehultze dariuber Folgendes: 16, p. 23: „Eine auffallend dicke bindegewebige Scheide mit hie und da eingebetteten längsovalen Kernen, wie sie $R$. W a g n e r schon abbildet, umhïllt die Fasern und findet sich, wenn auch allmälig. bedentend verdiunnt, noch vor, wenn die Markscheide im weiteren Verlanfe der Fäserchen allmälig geschwunden ist. Dic marklosen Fasern, welche aus den markhaltigen hervorgehen, sind in rer That noch mit einer zarten Hülle versehen, an deren innerer Oberfläche auch noeh hie und da längrsovale Kerne vorkommen, wic A. Ecker znerst beschrieb. Die Scheide gibt den Fasern cine Resistenz gegen den Einfluss macerirender Flüssigkeiten, welche marklosen Fasern an anderen Orten nicht zukommt." „Dic Nervenfasern zeigen, soweit sich cine bestimmte Breite an denselben überhaupt noch sicher messen lässt, stets rollkommen parallele Contouren, nirgends im Verlaufe findet sich eine Ungleichheit der Dicke, eine Unsicherheit in der Begrenzung, eine Andeutung von Varikositäten." „Die in Rede stehenden marklosen Nervenfäiserchen können aber auch künstlich nicht in variköse Fasern umgewandelt werden. Weder in Chromsäurelösungen verschiedener Concentrationsgrade, noch in Lösungen von doppeltchromsaurem Kali, Sublimat, Holzessig zeigen sie nach längerer oder kürzerer Autbewahrung die Erscheinungen, durch welche die marklosen Fasern der Retina und anderer Sinnesorgane so ausgezeichnet sind, jene in verschiedenen Abständen sich wiederholenden spindelförmigen Anschwellungen, welche man auch an kiunstlich aus markhaltigen Fasern isolirten Axencylindern unter gewissen Umständen hervorrufen kann. Das Fehlen derselben an den marklosen Fäserchen der elektrischen Organe gibt mir einen Beweis mehr für die Annahme, dass diese auch in den feineren Zweigen noch eine Scheide besitzen, auch wenn cine solche nicht mehr als deutlich rom Inhalt abstehende Hülle erkannt werden kann. 
Eine solche Scheide scheint nun aber an den letrten Endverzweigungen auch zu schwinden, wie wenigstens aus der bis dahin nicht vorhandenen, diesen letzteren allein eigenthimlichen höchsten Zartheit und Vergänglichkeit geschlossen werden muss." Hiermit stehen meine nach der Gol $\mathrm{gi}$ 'schen Methode erhaltenen Befunde durchaus im Einklange und kann ich diesen Ausfuhrungen M. Schult ze's nur beistimmen. Auch ich sah bei Anwendung der Golgi $\mathrm{i}$ 'schen Methode selbst an den feinsten Aesten der Geweihfasern niemals Varikositäten auftreten, die sonst gerade bei dieser Nethode doch so regelmässig an den feinsten Nervenfälen beobachtet zu werden pflegen. Ich glaube daher, dass dies nur durch das Vorhandensein einer zarten Scheide bedingt wird. Dagegen labe ich nicht den geringsten Anhaltspunkt dafür, dass den Netzbalken des Nervennetzes eine solche Hïlle zukommt, vielmehr schliesse auch ich aus der äusserst leichten Vergänglichkeit des Nervennetzes, dass hier die Nervensubstanz ohne jede Umhüllung im Gewebe liegt.

Die Dorsalschicht hält M. Sch ultze noch für homogen, doch konnte er eine membranartige Verdichtung ihres oberen Theiles nachweisen; wahrscheinlich ist dies schon die Dorsalmembran gewesen. Es gelang nämlich durch Maceration in Wasser von der Lamelle eine ganz feine persistirende Haut \%u erhalten, welche, wie der Autor selbst sagt, „der dorsalen Oberfläche des Plättchens entspricht". L. c. p. 28: „Ausser den Kernen oder Zellen scheint der Platte jedes geformte Element abzugehen und die Intercellularsubstanz eine vollkommen homogene zu sein. Doch erkennt man bei aufmerksamer Beobachtung bald dunklere, bald hellere Molekularkörnchen in ihr zerstreut, doch nicht in grosser Zahl und auch nicht in bestimmter Anordnung, wie etwa in der elektrischen Platte von Malapterurus, wo solche Körnchen vornehmlich um die Kerne angehäuft liegen." Diese ,Molekularkörnchen", welche M. S c h ultz e zuerst ausdrücklich erwähnt, sind die sogenannten interstitiellen Körner der Dorsalschicht.

In Betreff der Kerne, welche in die Dorsalschicht eingebettet sind, wird bemerkt, dass sie in einem und demselben Plättchen oft etwas verschieden gross sind und der Abstand der einzelnen von einander etwas variirt. Nach M. Schultze liegen alle innerhalb der dorsalen Schicht, was von Kölliker noch 
nicht mit voller Sicherheit entscheiden konnte. Da der Durchmesser der Kerne grösser als die Dicke der Lamelle ist, vertrsachen die eingelagerten Elemente kleine hügelartige Auftreibungen der Lamelle. H. Schultze spricht aber noch nicht klar aus (p. 27), dass es sich hier um Zellen handelt; er bezeichnet den ,scharf begrenzten lichten Hof" um den Kern, den er an mit Reagentien behandelten Präparaten in vielen Fällen wahrnahm, als ,Zellenhöhle". P. 35 heisst es allerdings, dass in der Grundsubstanz der elektrischen Platten von Torpedo ,zum Theil wenigstens wirkliche Zellen liegen". Interessant ist die Bemerkung (p. 28), dass , die Kerne oder Zellen dieser Membran ihre Lage bei Druck, Zerrung oder bei Verletzungen der letzteren nicht verändern", eine Beobachtung, welche sich dadurch erklärt, dass die Zellen in den von mir nacligewiesenen Kapseln des Netrgeriistes lagern.

Wie in einer Anmerkung p. 30 und 31 ansdriicklich gesagt wirl, gelang es auch M. S chultze nicht, die von Remak beschriebenen Stäbchen wichler aufzufinden.

Dagegen geht M. S ch ultze einen wichtigen Schritt weiter, indem er nachweist, dass die dorsale Schicht der elektrischen Lamelle nicht, wie A. von $\mathrm{K} \ddot{0} l \mathrm{i} \mathrm{ker}$ noch wollte, bindegervebiger Natur ist, sondern vielmehr aus Eiweisssubstanzen besteht; er kommt zu dem wichtigen Resultat, dass seine ,honrogene Membran" (Dorsalschicht der Lamelle) als der wirksamste Theil des elektrischen Organes betrachtet werden muss. Indessen erkenut M. S chultze in ihr noch nicht ein specifisches Gewebe, hält dieselbe vielmehr, durch noch ungenügend bekannte Verhältnisse bei ancleren Fischen verleitet, für ,homogene Nervensubstanz".

Ueber Lage und Verlauf der Capillar-Gefässe innerhalb der Prismen wird schliesslich bemerkt, dass dieselben sich nur in dem interlamellären Gallertgewebe vorfinden; sie sind hier so vertheilt, dass sie nur neben den gröberen Nervenfasern, nicht aber in der Ebene der feinsten Endausstrahlungen und des Nervennetzes vorkommen. Dagegen bleiben die Capillaren bei der Isolirung der elektrischen Plättchen bisweilen arif der Rückenseite der letzteren haften.

Von den der Abhandlung beigegebenen Abbildungen auf Tafel I sind die Figuren 1, 3 und 5 sehr schematisch gehalten. 
Ueber den Bau des elektrischen Organes von Torpedo etc. 511

Das Schema der Figur 5 ist überdies nicht richtig, weil es auf der falschen Annahme beruht, dass die Nerven von dem Net\% aus direct in die "hypothetische homogene Nervensubstanz" der dorsalen Schicht übergehen sollen.

Erst viele Jahre nach dem Erscheinen der Monographie MI. Schultze's, im Jahre 1874, wurde durch die Untersuchungen von Fr. B oll $(17,18)$ unsere Kenntniss des elektrischen Organcs wieder um eine nene interessante Thatsache vermehrt: die sogenannte elektrische Punktirung. Ihr Fntdecker, welcher die Beobachtung an frischem und mit Osmiumsäure behandeltem Gewebe machte, berichtet dariuber Folgendes, 18, p. 110: „Das von mir entdeckte Strukturverhältniss der elektrischen Platte liegt unmittelbar unter diesem Terminalnetz, d. h. betrachtet man (natiirlich mit Immersionslinsen) eine elektrische Platte von der Bauchfläche und hat allmälig von oben her durch die gröberen Verästelungen der Nerven hindurch das Terminalnet\% in den Focus gestellt, so genitgt eine minimale Drehnng der Mikrometerschraube, das Terminalnetz verschwinden $z \mathfrak{n}$ machen und an die Stelle desselben die von mir entdeckte Struktur treten zu lassen. Es besteht diese Struktur in einer rollkommen regelmässigen und gleichartigen Punktirung; die ganze Fläche der elektrischen Platte erscheint in fast gleichen Abständen von feinen runden Punkten durchsetzt, die im frischen Präparate glänzend, im Osmiumpräparat dunkel gefärbt erscheinen. Man kann diese vollkommen regelmässige Punktirtng lange völlig übersehen und unbeachtet lassen. Hat man sie aber einmal gesehen, so wird man in jedem Präparat auf's neue über die vollkommene Regelmässigkeit und Schönheit dieser Bildung, der ich aus dem ganzen Gebiet der Histiologie kein Analogon an die Seite zu setzen weiss, erstaunen.

Die Anordnung der dunklen Punkte, die im Allgemeinen durch gleichmässige $Z$ wischenräume getrennt sind, scheint auf den ersten Blick eines bestimmten Princips zn entbehren, und es vergingen einige Tage, ehe ich das in dieser scheinbar gan $\%$ gleichmässigen Vertheilung der Punkte waltende Gesetz auffinden konnte. Der Grund hiervon lag darin, dass ich die erste Bekanntschaft dieses Netzes an solchen Osmiumpräparaten machte, an denen das Kölliker'sche Terminalnetz nur unvollkommen und schlecht $z u$ sehen war. Als ich mich aber dem Studium frischer und der Untersuchung besser conservirter Osmiumprä- 
parate, an denen das Terminalnetz erhalten war, zuwandte, wurde ich alsbald auf eine höchst interessante Beriehung meiner Punkte zu dem Terminalnetz anfmerksam. Um es ku\% zu sagen: die Anordnumg der Punkte reproducirt getreu die Configuration des über der punktirten Schicht gelegenen Terminalnetzes, so dass die Punkte den Balken des Netzes folgen und den Verlauf derselben nachahmen. Und wwar geschieht dies in der Weise, dass den einzelnen Netzbalken in der punktirten Schicht nicht eine einzelne Reihe oder Zeile von Punkten, sondern mehrere, meist 2 oder gar 3, nnregelmässig gestellte Reilien von Punkten entsprechen."

Boll kommt Anfangs zu einer Erklärung der Punktirung, welche sich an die von Remak (siehe oben) beobachtete Palissadenzeichnung eng anlehnt. P. 112: „Auf Grund dieser Bilder gelangte ich gleich beim Beginn meiner Untersuchmgen zu folgender Vorstellung iiber den Zusammenhang beider Bildungeu, des TerminaInetzes und der von mir entdeckten Pünktchenreilicn. Die einzelnen Balken des flächenhaft die Bauchseite der elektrischen Platte iber\%iehenden Terminalnetzes tragen an ihrer unteren (đl. h. dem Rücken zugekehrten) Seite ein System zarter stiftförmiger Fiserchen, welche senkrecht in die Substanz der elektrischen Platte eindringen und somit alle frei auflören. Ich deutete mithin die Pïnktchen als Querschnitte feinster Fiiserchen."

Eine Stütze für diese Deutung suchte Boll in dem Querschnittsbilde der elektrischen Lamelle, in welchem er, gleich Remak, eine Streifung oberhalb der Nervennetzschicht wahrnahm. P. 114: „Durch meine Querschnittsbilder wird die Thatsache zur Gewissheit erhohen, dass die elektrische Platte (Dorsalschicht) nicht homogen ist, sondern zwei deutlich geschiedene Schichten besitzt, von denen die der Bauchfläche zugekehrte in ihrer ganzen Ausdehnung feingestreift erscheint, während die der Rückenfläche zugekehrte keine Spur der Streifung zeigt. Diese beiden Schichten sind an Dicke sehr verschieden und zwar beträgt ganz konstant die feinstreifige Schicht ein Sechstel der ganzen elektrischen Platte."

Fünf Seiten später in derselben Arbeit (p. 117) widerruft indessen Boll diese Dentung, bestimmt durch Einwände, welche M. Schultze ihm machte. Boll lässt es jetzt unentscheiden, 
Ueber den Bau des elektrischen Organes von Torpedo etc. 513

„ob die an der dem Rücken zugekehrten Fläche der Balken des Nervennetzes in so eigenthümlicher Regelmässigkeit angeordneten Elemente Pünktchen (feinste Kürnchen) oder ob sie feinste stiftförmige Fïserchen sind, ob sie reine Kugelform oder die Form eines kuzen mit seiner Längsaxe senkrecht auf die Fläche der elektrischen Platte gestellten Cylinders besitzen". "Auch ïber" die Art und Weise, wie diese Elemente mit den Balken des Kölliker'schen Terminalnetzes in Verbindung stehen", fährt der Autor fort, "wage ich keine Vermuthung und will auch die transscendentale Frage nicht weiter erörtern, ob diese Elemente nin" oder nan" dem Nervennetz, d. b. ob sie noch in der Substanz des Nerveunetzes selbst oder bercits ausserhalb derselben an der unteren Flaiche des Nervennetzes gelegen sind. Auf dem engen Raume von $0,0016 \mathrm{~mm}$, um den es sich hier handelt und auf welchem durch eine einzige Drehung der Mikrometerschraube lic Bilder des Terminalnetzes und der von mir entdeckten Punktstruktur in einander schwimmen, ist für eine motivirte Entscheidung dieser Frage in der That kein Raum."

Die Fig. 5 auf Tafel VIII der Boll'schen Arbeit (18) und Fig. 10 auf' Tafel XV einer späteren Abhandlung (19) geben eine leidlich gute Anschaumg dieser Punktirung, die von Boll zutreffend, so wie ich sie an frischen und mit Osmiumsäure behandelten Präparaten anch sehe, beschrieben wird.

Wie aus meinen obigen Untersuchungen hervorgeht, wird diese Punktirung ganz hauptsächlich hervorgernfen durch die gleichgrossen, runden Endkügelchen der freien Enden der elektrischen Stäbchen und Stäbchenkombinationen im Stäbchennetz. Bei weitem die meisten dieser Endkügelchen befinden sich im Niveau des Stäbchennetzes, weil die Stäbchen gebogen sind, sodass die meisten „Pünktchen" bei ein und derselben Einstellung gleichzeitig deutlich werden. Nar die Endkügelchen an den frei nach oben (dorsalwärts) gewandten Enden der vertikal gestellten Stäbchen befinden sich in etwas anderem Niveau, wovon man sich bei genauer Einstellung überzeugt. Die Niveaudifferenz beträgt die Lünge der vertikal gestellten Stäbchen; die letzteren müssen bei etwas tieferer Einstellung als Querschnitte, also auch als Pünktchen, erscheinen. Da nun das Nervenendnetz mit seiner Hauptnasse unter (ventralwärts ron) dem Stäbchenneiz gelegen ist und mit den Netzbalken des letzteren uber- 
einstimnt, erklärt sich hieraus einerseits, dass die Boll'sche Punktirung bei etwas anderer (dorsalwär's gerichteter) Einstellung, als das Nervenendnetz scharf sichtbar wird, andererseits, dass die "Piinktehen" immer nur mit den Net\%balken des Nervenendnetzes korrespondiren, niclit aber in den Lüeken desselben vorkommen. Es wäre hiermit also endlich eine zutreffende und geniigende Erklärung der so viel besprochenen und mannigfach gedenteten "elektrischen Prunktirung" gegeben. Bei den folgenden Besprechungen werde ich daher anf diese Ansfïhringen mich nur zu beziehen nöthig haben.

Eine wichtige Bemerkung über den imnigen Zusammenhang awischen Terminalnetz und Pünktchenstruktur macht Boll noch in einer Anmerkung anf p. 117, indem er sagt: "Ganz besonders muss ich betonen, dass bei diesem Zerfall der elektrischen Platte in \%wei Blätter (wie es schon von von Kölliker [siehe oben] beschrichen ist) ganz ausnahmslos die punktirte Schicht dem Kölliker'schen Terminalnetz folgt und niemals die Spaltung der elektrischen Platte etwa zwischen Terminalnety und punktirter Schicht stattfindet, was gewiss anf einen sehr innigen Zusammenhang beider Bildungen hindeutet." Hieraus folgt, dass die Stäl,chenschicht dem ventralen (nervösen) Theil der elektrischen Lamelle zuzurechnen ist.

Ueber die Struktur der dorsalen Schicht der elektrischen Platte bringt Boll nichts Nenes, erwälnt aber schon die Bindegewebsfasern, die der dorsalen Fläche derselben ausserhalb dicht anliegen; nur verlegt er sie irrthümlich in das Innere der dorsalen Schicht. Die betreffende Stelle lautet: „In der fein granulirten Substanz des der Rückenfläche zugekehrten Blattes labe ich, wo dasselbe von dem Nervenblatt befreit zu Tage lag, bei sehr starken Vergrösserungen in der Fläche desselben sparsame, selı feine, blasse, geschlängelte Fasern von dem Aussehen gewöhnlicher Bindegewebs fibrillen verlanfen sehen, ein Befund, der darauf hinweist, dass das Ritckenblatt doch vielleicht nicht so ganz jeder differenzirten Struktur entbehrt, wie man bisher angenommen hat."

In seiner ersten Abhandlung (18) würdigt Boll anch das von Kölliker'sche Nervennetz einer eingehenden Besprechung und schliesst sich hier zunächst noch vollständig der Deutung an, welche sein grosser Meister, M. Schultze, demselben gegeben 
Ueber den Bau des elektrischen Organes von Torpedo etc. 515

hat. Auch erkennt Boll sehr richtig die Ausstände, welche an der schematischen Zeichnung M. Schultze's (siehe oben) gemacht werden müssen, indem er sagt (1. c. p. 109): „Nur das eine möchte ich in Bezug auf die Abbildung M. Schultze's hervorheben, dass die Maschenräume niemals so quadratisch erscheinen, wie M. Schultze sie gezeichnet, sondern durchwer verzogene und unregelmässige Rhomben mit spitzen und stumpfen Winkeln darstellen; auch sind die Balken des Netzes dicker und die Maschenräume im Verhältniss kleiner, als M. Schultze sie gezeichnet hat. Die Balken sind ganz allgemein ebenso breit, wie der schmale Durchmesser der rhombischen Maschen, sodass die ganze Bildung eine hohe Aehnlichkeit mit gewissen Formen der sogenannten gefensterten Häute der Arterienwandungen zeigt, Netzen, in denen Substanz und Lïcken ungefïhlı den gleichen Raum einnehmen.

Diese beiden an der Idealabbildung. M. Schultze's zu rïgenden Fehler sind in der ïlteren und bei schwächerer Vergrösserung gezeichneten Abbildung Kölliker's vermieden. Hier ist die Flaichenansicht der elektrischen Platte in der That genau so chagrinirt dargestellt, wie sie bei einer Vergrösserung, wic etwa Hartnack's VII und etwas darunter, erscheint, nicht regelmüssig quadratisch gefeldert, sondern unregelmässig gefleckt. Auch ist die Chagrinirung insofern naturgetreu gebalten, als die hellen Maschenräume und die dunklen, dieselben umgrenzenden Netzbalken auch die gleiche Breite zu besitzen scheinen."

Entsprechend dieser Schilderung sind anf Tafel VIII der Boll'schen Abhandlung in den Figuren 2,3,4 und 7 Stücke des Terminalnetzes abgebildet, doch sind anch diese Netzzeichnungen noch $\mathrm{zu}$ regelmässig gehalten; anch sind in den Abbildungen noch keine vorspringende Buckeln und blind endigende Seitensprossen der Netzbalken zur Darstellung gekommen, die Boll im Texte auch nicht erwähnt. Indessen sind die Begrenzungen der Netzbalken in der Fig. 3 schon etwas nnregelmässig angegeben.

Während Boll hier also noch ganz für die Existenz des Terminalnetzes eintritt, wideruft er einige Jahre später $(20,21,22)$ diese seine Ansicht vollständig und bekehrt sich $\mathrm{zu}$ der gerade entgegengesetzten Meinung. In der späteren Abbandlung (1876) lengnet er auf Grund ernenter Untersuchungen die Existenz jeg- 
licher Anastomosen der Nervenendverzweigungen und stellt die Behauptung auf, dass alle Nerven in der Nervenplatte mit freien Endästen aufhören. 21, p. 470: „Zunächst ist alzuerkemnen, dass es sich in dieser Terminalverästelung des $N$. electricus nicht um ein greichmässiges geschlossenes Netz, bestehend aus regelmässigen Balken und ebenso regelmässig geformten Maschen handelt, wie M. Schultze es beschrieben lat und auch ich noch in meiner letzten Arbeit es angenommen hatte, sondern dass die bier vorliegende Bildung einen von der eigentlichen Netzform sehr abweichenden Charakter trägt, indem die Nerren durclaus nicht regelmässig mit einander anastomosiren, sondern allenthalben mit freien Enden aufhören. Hierdurch wird es bedingt, dass von irgend einer bestimmten Form der Maschen, die M. Schultze als quadratisch und ich als verzogene Rhomben beschrieben habe, gar nicht die Rede sein kann, sondern dass diese, die nichts weiter sind als die zwischen und neben der Nervenverästelung ausgesparten Räume, eben jede mögliche Formı werden annehmen können."

Wäbrend für Boll früher die Untersuchung des lebensfrischen Objectes und des Osminmpräparates maassgebend war, stützt er seine neue Ansicht auf Silber- und Goldpräparate, bei deren Deutung er mit grosser Willkür verfährt.

Es dürfte hier am Platze sein, mein Urtheil über die Brauchbarkeit dieser beiden Methoden für die Untersuchung der elektrischen Platte abzugeben. Beide Methoden in mannigfachen Abänderungen oder auch deren Combinationen: erst Versilberung und dann Vergoldung und umgekehrt, sind ja auch von späteren Untersuchern vielfach in Anwendung gezogen, sodass ich nicht wieder darauf zur ückzukommen nöthig habe. Ich halte diese beiden Methoden bei ibrer Anwendung auf das frische elektrische Gewebe nicht gerade für geeignet, die natürlichen Verhältnisse zur Demonstration zu bringen. Ganz besonders gilt dies für die Silbermethode. Es scheint ein zu starker Eingriff zu sein, lässt man Argentum nitricum in Lösung, oder in Substanz (Lapis-Stift), wie es von Ranvier (siehe unten) geübt wurde, auf das frische elektrische Gewebe einwirken.

Ick denke mir, dass in Folge der Einwirkung des ungeeigneten Reagens die Netzbalken am Stäbchennetz gerinnen und sich dabei aus ihrem gegenseitigen Zusammenhange zum Theil 
Ueber den Bau des elektrischen Organes von Torpedo etc. $\mathbf{5 1 7}$

lösen, sodass die mehr oder weniger zahlreichen freien, häufig abgerundeten und etwas angeschwollenen Enden entstehen. Ganz. dieselbe Erscheinung tritt, wie es scheint, ein, wem das leicht vergängliche Gewebe des Nervennetzes abstirbt. Man weiss daher nicht recht, ob manche Forscher nicht schon bei ihrer vermeintlichen Fixirung spontan aufgetretene postmortale Gerinnungen der zarten hüllenlosen Axencylindersubstanz des Nervenendnetzes zul Darstellung gebracht haben. Aus diesen Gesichtspumkten betrachtet, erklären sich die abweichenden Angaben der Forscher ïber freie Nervenendigung in der elektrischen Platte.

Um nun auf dic Silbermethode zurückzukommen, so bemerkt Boll schon mit Recht (1. c. p. 469) „dass die reine Silbermethode insofern wenigstens absolut mzuverlässig ist, als niemals die Garantie einer wirklich naturgetrenen (negativen) Wiedergabe des Kölliker'schen Terminalnetzes besteht." Boll illustrirt dies an den Figuren 1,2 und 3 der Tafel VIII seiner Abhandlung (21), welche nach verschieden gelungenen Silberpräparaten gezeichnet sind. Fig. 1 zeigt noch sehr reichliche netzartige Anastomosen der hell gebliebenen Netzbalken des Nervennetzes; in Fig. 2 sind die Anastomosen schon weniger reichlich, um cndlich in Fig. 3 sehr spärlich zu werden. Mit Recht erklärt Boll diese Verschiedenheiten als bedingt durch die Reagenswirkung and bemerkt sehr richtig, 1. c. p. 468: „Es ist sicher, class die Configuration der Balken des Terminalnetzes iiberall in len elektrischen Platten eine vollkommen gleichartige ist und nirgends Verschiedenheiten zeigt, welche für das Zustandekommen so verschiedener Silberbilder verantwortlich gemacht werden können. Wenigstens ist es mit den zuverlässigsten Methoden Untersuchung in Liquor cerebrospinalis und Osmiumsäure - niemals gelungen, irgendwelche lokale Verschiedenheiten im mikroskopischen Bilde der elektrischen Platten nachzuweisen, welches iiberall durchaus gleichartig erscheint."

Wenn Boll nun aber die Untersuchung in Liquor cerebrospinalis und Osniumsäure, die ihn zu der Erkenntniss der Existenz eines Endnetzes geführt hat, für die zuverlässigsten Methoden erklärt, warum lässt er sich durch die mit denselben erhaltenen Resultate nicht bei der Deutung seiner Silberbilder bestimmen? Boll erklärt vielmehr die negativen Silberbilder für nm so „vollkommener" (naturgetreuer), je weniger Netzverbin- 
dungen und je mehr freie Enden sie aufweisen. Das „vollkommenste" Silberbild würde also dasjenige sein, in welchem niemals eine wirkliche Anastomose, niemals eine geschlossene Masche sich vorfände. B oll bemerkt aber selbst (l. c. p. 473), dass ,derartige vollkommene negative Bilder mittelst der reinen Silberimprägnation niemals von ihm erbalten wurden."

$\mathrm{Zu}$ dieser willkürlichen Deutung der Silberbilder wurde B o 11 veranlasst durch die Resultate, welche ibm die Goldmethode lieferte. Was diese letztere anbelangt, so ist dieselbe ja weniger eingreifend, als die Silbermethode, indessen kann ich auch ihr nicht einräumen, dass sie geeignet ist, an dem zarten elektrischen Gewebe die feinste Struktur der Nervenendplatte naturgetreu zu konserviren, zumal wenn bei Ausübung derselben eine Säure angewandt wird und anf das frische Gewebe einwirkt. Denn schon von Kölliker hat nachgewiesen, dass Säurezusatz auf das Nervenendnetz sehr deletär wirkt. Dort, wo die Netzbalken am dïnnsten sind, wird zuerst eine Continuitätstrennung derselben entstehen, die fortschreitet, je mehr und je intensiver das Reagens einwirkt, sodass schliesslich zahlreiche blind endigende Seitensprossen und nur wenig Anastomosen vorhanden sind. In der Nachbarschaft der zum Netz tretenden Nervenäste scheint die Continuitätstrennung der Maschen am wenigsten leicht zu erfolgen. Boll bediente sich nun einer schwach durch Essigsäure angesäuerten $1 / 2$ procentigen Goldchloridlösung und erbielt daher in seinen Präparaten theilweise zerstörte Terminalnetze. Die Abbildungen $4-8$, die theilweise sogar noch schematisch gehalten sind, stellen meist frei endigende Nervenverästelungen dar. Doch hat B o 11 jedenfalls auch in den Goldpräparaten oft genug Anastomosen der Nervenenden gesehen, wie z. B. Fig. 4 noch zeigt. Trotzdem will er eigenthümlicherweise Nichts davon wissen und möchte die Anastomosen gerne aus der Welt schaffen, ohne auch nur den Versuch zu machen, ibr Vorkommen in den Präparaten zu erklären. Boll scheint sogar seine Ansicht nur auf ein einziges Präparat zu stützen, was bei der so überaus unzuverlässigen Goldmethode unter Berücksichtigung meiner obigen Ausführungen wenig zu bedeuten hätte. L. c. p. 472: „Je vollkommenere und intensiver gefärbte Präparate ich erhielt, desto seltener konnte ich die Anastomosen nachweisen, sodass ich bald dazu gekommen bin, ihre Existenz völlig za bestreiten und in den elektrischen 
Ueber den Bau des elektrischen Örganes von Torpedo etc. 519

Platten von Torpedo ganz ausschliesslich die zuerst von Remak behauptete freie Endigung der Nervenfasern anzunehmen. Das entscheidende Präparat, welches mir jeden $Z$ weifel in dieser Hinsicht benahm, ist in Fig. 7 wiedergegeben worden. An den tief braumroth gefärbten Nervenfasern sind ganz ausschliesslich nur freie Endigungen und niemals Andeutungen einer Verschmelzung mit einer benachbarten Faser wahrzunehmen."

Alles in Allem ist an dieser Arbeit Boll's befremdend, dass der Autor ohne genïgende Motivirung und mit grosser Willkür bei Deutung der Thatsachen sich der seiner früheren Ansicht diametral entogengesetzten Anschaumg zuwendet. Dies ist $\mathrm{zu}$ bedauern, da $\mathrm{B}$ oll in seinen ersten Arbeiten schon weiter gekommen war. Der Umschwung findet vielleicht dadurch einigermaassen seine Erklärung, dass Boll im Jahre 1875 in Viareggio eine Zeit lang mit dem italienischen Forscher Ciaccio, welcher auf Grund der Goldmethode schon vor Boll die Existenz des Kölliker'schen Terminalnetzes in Abrede gestellt hatte, zusammenarbeitete und von demselben vielleicht beeinflusst wurde.

Ciaccio hat eine Anzahl von Abhandlungen (27-34 des Verzeichnisses) über den feineren Bal des elektrischen Organes von Torpedo veröffentlicht, von denen ein Theil theils früher, theils gleichzeitig mit den Publikationen Boll's erschien. Leider waren mir nur zwei davon zugänglich, da die übrigen in den dentschen Bibliotheken nicht vorhanden zu sein scheinen. Es sind dies die beiden letzten und jedenfalls wichtigsten Arbeiten (31 und 33) Ciaccio's, auf welche ich näher eingehen muss. Die früheren Aufsätze dieses italienisehen Forschers enthalten, nach den Referaten Boll's über dieselben, welcher sie zum Theil bereits einer berechtigten Kritik unterworfen hat, und nach den Auszügen in den Jahresberichten zu urtheilen, jedenfalls nicht wesentlich von dem Verschiedenes, was die beiden von mir eingesehenen Arbeiten bringen. Besonders ist es die grössere in den Berichten der Akademie der Wissenschaften zu Bologna 1877 erschienene Arbeit Ciaccio's (31), welcher durch zahlreiche Abbildungen ein grösserer Werth verliehen wird. Indessen kann ich mich durchaus nicht mit Allem, was dieser Forscher berichtet hat, einverstanden erklären.

Nach Ciaccio soll sich die elektrische Platte aus 3 von 
einander trennbaren Schichten zusammensetzen, einer zarten Stuitznembran, einer Gefässschicht und einer Nervenlamelle. L. c. p. 387: „Per ciò che si appartiene alla piastra elettrica, io per ne credo, secondo le mie osservarioni, ch'ella consti di tre parti differenti e separabili l'un dell' altra, cioè di una sottilissima lamina di sostegno, di vasellini capillari sanguigni e di una fitta intrecciatura nervosa."

Was zunächst die Gefässschicht anbetrifft, welche nach Ciaccio von den der dorsalen Fläche der Stützlamelle unmittelbar anliegenden Blutcapillaren gebildet werden soll, so muss ich dieselbe als Bestandtheil der elektrischen Platte entschieden in Abrede stellen. Wie schon M. Schultze (siehe oben) festgestellt hat, liegen die Gefüsse ausserhalb des Gewebes der elektrischen Platte; sie werden von demselben getrennt durch die dümne Dorsalmembran, welche $\mathrm{Ciaccio}$ noch nicht kennt. Ich habe niemals imnerhalb der elektrischen Platte selbst Capillaren angetroffen und kann daher richt zugeben, die Gefässe als besondere Schicht der elektrischen Platte aufzufassen.

Es blieben daher nur die beiden Schichten der Stützlamelle und der Nervenschicht ibrig.

Die Bezeichnung Stützlamelle ("Lamina di sostegnQ") ist uu auch zu verwerfen. Wie oben von mir hervorgehoben wurde, ist es ein Verdienst von M. Schultze, nachgewiesen zu haben, dass die dorsale Schicht der elektrischen Lamelle nicht bindegewebiger Natur ist und einfach die Funktion einer "Stützlamelle" hat; vielmehr ist dieselbe als ein specifisches (elektrisches) Gewebe aufufassen.

In der dorsalen Schicht will Ciaccio nun zwei verschiedene Arten von Zellen gefunden haben. Die eine Zellart sind die längst bekannten, schon von $R$. Wagner (siehe oben) abgebildeten, grossen, rundlichen oder elliptischen Kerne. Bei Bellandlung des Gewebes mit Miuller'scher Lösung sah Ciaccio, wie schon viele Beobachter vor ihm, helle Räume anftreten, die von einer feinen Membran begrenzt wurden.

In Betreff der zweiten Zellart sagt Ciaccio l. c. p. 388: "Quelli della prima specie hanno diversa figura, alcuni essendo fusati, altri triangolari, altri quadrangolati, altri in foggia di una pera, altri di figura irregolari. $\mathrm{E}$ in eiascuno di essi vi ha un 
Ueber den Bau des elektrisehen Organes von Torperlo etc. 521

nucleo, più di sovente grosso, con entrovi un piccolissimo nucleolo, e intorno al nucleo, ora più, ora meno, ora appena un ombra di sostanza cellulare che si stende in lunghi fili o processi, via facendo, si partiscono varie volte, e quelli di un corpuscolo non di rado si veggono congiungersi con quelli di un altro. Il sito de' detti corpuscoli non è solamente nella lamina di sostegno, perochè ve n' ha di parecchi que son situati o nel medesimo piano o inmediatamente sopra le fibre nervose pallide, alla cu' guaina sovente stanno attaccati talora con solo il loro corpo, tali altra con soli i loro processi e tal' altra con quello e questi insieme; altri ma assai di rado, rasentano qualcuna delle fibre nervose midollari, alla cui seconda guaina aderiscono per via de' loro suddetti processi; altri, da ultimo fiancheggiano i vasi capillari sanguigni distribuiti per la piastra elettrica."

Ohne Zweifel sind dies die zelligen Elemente des interlamellären Gallertgewebes, die, wie schon $R$ em ak (siehe oben) erwähnt, oft den Verzweigungen der Nerven sich anschmiegen. Entschieden in Abrede stellen muss ich aber, dass diesc Gallertzellen sich in der dorsalen Schicht („Lamina di sostegno" ) der elcktrischen Platte zum Theil befinden, diese Schicht bleibt vielmehr gänzlich frei ron ihnen! Es ist demnach durchaus irrthämlich von $\mathrm{Ci}$ a e eio, wenn er diese Elemente als Bestandtheile des elektrischen Gewebes der Platte selbst aufführt, in demselben kommt nur die eine Art der grosskernigen Zellen vor.

In Betreff der Textur der ,lamina di sostegno" äussert Ciaccio (l. c. p. 388): "La Lamina di sostegno è fatta di una particolare sostanza granosa e di sottilissime fibre di tessute connettivo, le quali tibre io le ho trovate tanto pin numerose e manifeste, quanto più grandi erano le torpedini, da cui toglieva le piastre elettriche."

Diese ,sottilissime fibre di tessute connettivo" sind jedenfalls die feinen Bindegewebsfibrillen und Fibrillenbündel, welche der Dorsalmembran aufliegen, sich aber schon ausserhalb der elektrischen Platte befinden, mithin derselben nicht mehr zugerechnet werden können.

Ciaccio macht aber weiterhin eine beachtenswerthere Bemerkung iiber die ,particolare sostanza granosa“, welche erkennen lässt, dass er das von mir beschriebene feine Netzgerüist wohl schon wahrgenommen hat. Die Stelle lautet (l. c. p. 390): 
„Oltre di che nelle piastre elettriche tenute lungamente in una soluzione acquosa di acido picrico satura, ed anche in quelle colorate a fresco col carminio o con la friesina, io ho osservato più di una volta tra $i$ suddetti spazj albicei un reticolamento di fili delicatissimi o fibre che siano; le quali fibre insieme co' corpuscoli e i loro particolari spazii albicei, io credo che siano una particular sorta di tessuto mucoso o gelatinoso, il quale entra nella composizione della lamina di sostegno e si continua d'altra parte a quell' altra sostanza, ancor essa di natura gelatinosa, que riempie lo spazio che è tra l'un diaframma elettrico c l'altro."

Wie vorher schon von mir betont, darf dieses Gewebe aber nicht einfach als ein Schleimgewebe bindegewebiger Natur angesehen werden, sondern es stellt vielmehr ein eigenartiges, specifisches Gewebe dar. Auch muss ich in Abrede stellen, dass dasselbe mit dem interlamellären Gallertgewebc zusammenhängt; dagegen sprechen schon rlie so ausserordentlich bestimmten Fïrbungen dieses Netzgerüstes bei Anwendung der Golgi'schen Methode, die sich scharf nach oben und nach unten hin von der Umgebung absetzen.

Es erübrigt schliesslich noch, auf die Mittheilungen Ci accio's ïber die Nervenschichte der elektrischen Platte einzugehen. $\mathrm{Ci}$ a c c i o nimmt in so fern einen eigenen, gewissermassen vermittelnden Standpunkt ein, als er netzartige Anastomosen der Netzbalken der von Köllike r'schen Terminalverüstelung zugiebt, ausserdem aber zahlreiche, in die Liicken des Netzes hineinragende, blind endigende Nervenenden findet. Es scheint geboten, seine Ausführungen iiber diese ,intrecciatura“ (intextus der Lateiner), wie er die Nervenverästelung nennt, wörtlich zu citiren. L. c. p. 395 heisst es: "Cosi fatto intreccio, che non ha veruna somig-lianza con ciò che volgarmente si denomina rete, ma piuttosto rassembra quelle capricciose e bizarre figure 0 pitture 0 lavori di rabesco, che gli vogliano dire, si compone di soli cilindri dell' asse più o meno appianati, i quali cilindri dell' asse serpeggiando e partendosi reiteratamente e a distanze brevissime finiscono parte con unirsi l'un l'altro insieme, e parte con estremità libere più o meno bitorzolate."

$\mathrm{Ci}$ a c cio sieht aber nicht dieses Arabeskennetz, sondern die Boll'sche Punktirung als eigentliche Nervenendignng an: 
Ueber den Bau des elektrischen Organes von Torpedo etc. 523

„E ancorchè l'universalità degli odierni osservatori tenga questı) intreccio come veramente finale, nondimeno io dalle mie osservazioni sono necessitato a non crederlo; ma credo invece che l'ultimo termine delle fibre nervose distribuite nella piastra elettrica è quella regolarissima punteggiatura, che constantemente si vede nella faccia di sopra del detto intreccio. La quale punl teggiatura, scoperta e minutamente descritta dal Bol, ma nè dir lui, nè da altri stata finora chiarita che cosa la sia, non è nelvero che una infinità di minutissime palline o bottoncelli, ciascuna delle quali sta attaccata all' estremità di una sottile e corta fibra che s'innalza dal piano de' cilindri dell' asse che compongono l'intreccio nervoso."

In Betreff dieser Kügelchen macht $\mathrm{C}$ i a c c i o einen Vergleich, den ich wenigstens nicht unerwähnt lassen will : „E queste palline, che semplicemente toccano la superficie inferiore della lamina di sostegno, per la similitudine che, al parer mio, elleno hanno co' bottoni della bottiglia di Leyda, fanno si, che come in quella, cosi l'elettricità, che si genera nell' organo elettrico delle torpedini si manifesti interrotta ed instantanea, anzi che in modo lento e continuo; la qual cosa forse averrebbe, se le dette fibrille, in lnogo di essere terminate nelle loro sommita da piccole palline, terminassero nella medesima guisa che i denti, onde sono armati i pettini o mascelle della commune macchina elettrica."

$\mathrm{C}$ i a c c i o meint mit Recht, dass die Kügelchen von anderer Beschaffenheit sind, als das Netz, weil sie sich anders färben und resistenter erweisen.

Für das Verständniss dieser Mittheilungen sehr werthvoll sind die Abbildungen, welche der Autor auf Tafel VI seiner Abhandlung in den Figuren 1-11 gegeben hat, worin seine „,intrecciatura“ der Nerven zur Darstellung gebracht wird. Wir müssen auf dieselben näher eingehen.

Die Abbildungen sind nach Präparaten gezeichnet, welche nach verschiedenen Methoden behandelt wurden. Fig. 1 entstammt einem einfachen Osmiumpräparat, Fig. 2-4 ist nach Osmiumbehandlung mit daranffolgender Hämatoxylinfärbung, Fig. 5-9 nach Behandlung mit Goldchlorid mit nachfolgender Imprägnation mit Argentum nitricum gewonnen; Fig. 10-12 endlich geben Negativbilder nach einfacher Silberimprägnation. Diese letzteren kann ich hier unberücksichtigt lassen, da ich die 
Unzuverlässigkeit derselben bereits oben hervorgehoben habe. Dass es sich hier hauptsächlich um Zerrbilder handelt, zeigt ein Vergleich der Fig. 10 mit der Fig. 4.

Das meiste Vertrauen verdienen mithin die Abbildungen Fig. 1-4, weil sie nach der zuverlïssigsten Methorle (Osmiumbehandlung) gewonnen sind. Auffällig ist aber auch hier in den Präparaten, welche nach derselben Methode gewomnen sind, die Verschiedenheit in der Vollständigkeit der Netzbildung. Wie erklären sich diese Differenzen? Denn es ist wohl sicher, wie schon Boll (siehe oben) hervorgehoben hat und wie in meinen Golgi'schen Präparaten die Gleichartigkeit der Net\%zeichnung des Stäbchennetzes und Nervenendnetzes bei gelumgener Tinktion beweist, dass in der ganzen Nervenendplatte jeder elektrischen Lamelle die Art der Nervenverästelung und Nervenverbindung eine gleichartige ist. Ich erkläre mir dies durch die verschiedene Einwirkung der Reagentien. Ciaccio betont auch nicht, dass $\mathrm{el}^{\circ}$ das elektrische Gewebe stets dem lebenden oder doch frisch getödteten Thiere entnommen hat, was bri der Zartheit und leichten Vergänglichkeit der nackten Axencylindersubstanz sehr von Bedeutung ist. Ich babe dies oben schon mehrfach hervorgehoben.

Am vollständigsten gefärbt und meinen Befunden am nächsten kommend ist die Fig. 4 der Abbildungen von $\mathrm{Ciaccio}$ und zwar der ganze rechte Theil derselben. Dieser Theil zeigt ganz dasselbe regelmässige und vollkommene engmaschige Netz, wie ich es oben beschrieben und als dem Verhalten in vivo entsprechend erklärt habe. Nur in 3 Luicken dieser Netzmaschen ragt hier je ein kleiner, sprossenartiger, kurzer Fortsatz hinein; die blinden Endigungen sind also in dieser Zeichnung im Vergleich zu den geschlossenen Maschen sehr spärlich, ein Verhalten, wie es auch von mir gefunden wurde. Dass aber auch dieser Theil nicht mehr gan\% rollkommen zur Darstellung gekommen ist, zeigen die schmalen Fäden, welche an 3 Stellen dieser rechten Hälfte der Zeichnung von einenı Höcker durch die Maschenlücke zu einem anderen bingehen. Nach links hin in derselben Zeichnung werden diese Fäden zahlreicher, zum Beweise, dass hier das Netz schon etwas alterirt ist, nicht mehr ganz dem Verhalten in vivo entspricht. Diese Fäden sind nun zum grössten Theil entweder alterirte Netzbalken meines Stäbchennetzes oder dünn ausge- 
zogene Netzbalken der Axencylindersubstanz des Nervenendnetzes, denen noch die Balken des Stäbchennetzes zu Grunde liegen; alterirt entweder dadurch, dass das Reagens nicht genügend eingewirkt hat oder dadurch bedingt, dass diese Netzbalken postmortal bereits verändert waren, als das eindringende Reagens sie erreichte. Dass diesen feinen Fädchen in der That mein Stäbchennetz, das nach den von $\mathrm{Ci}$ a $\mathrm{c}$ e i o angewandten Methoden nicht zur Darstellung gebracht werden kann, zu Grunde liegt, beweist der Umstand, dass bisweilen die Endknöpfchen meiner Stäbchen (Boll's Pünktchen) darin angetroffen werden, wie $\mathrm{C}$ i a c c i o selbst hervorhebt und auch abbildet. In der Figurenerklärung zu Fig. 1 heisst es \%. B. von diesen Fädchen: „Congiunture lineari tra una espansione e l'altra del cilindro dell' asse, in alcune delle quali congiunture talvolta si osserva a metà lunghezza un puntino del Boll."

Diese feinen Verbindungstäden mit eingelagerten Endkügelchen der Stäbchen finden sich auch in den anderen Figuren derselben 'Tafel vor, welche mehr die "Arabesken"-Zeichnung aufweisen. Je weniger gut erhalten nun das Nervenendnetz in den Präparaten ist, um so reichlicher sind diese Fädchen; kommen auch sie nicht mehr zur Darstellung und fehlen ganz, so geht daraus die von $\mathrm{Ciaccio}$ beschriebene Arabeskenzeichnung hervor, wie ich sie auch in meinen nach der Golg i'schen Methode behandelten Präparaten oft angetroffen habe. Aus denselben wohl erwogenen Gründen wie dort, muss ich daher auch hier diese ausgeprägten Arabeskenzeichnungen Ciaccio's für unvollkommen conservirte, resp. unvollständig tingirte Nervenendnetze erklären.

Dass dem so ist, dass hier defect gewordene Nervennetze vorliegen, beweist schon die Figur 9 der $\mathrm{Ci}$ a c c i o'schen Tafel, welche einem Präparat entnommen ist, welches nach derselben Methode (Goldchlorid mit nachfolgender Argentum-nitricum-Behandlung) behandelt wurde, wie die vorhergehenden. Diese Figur zeigt genau dieselbe Arabeskenzeichnung, wie die anderen Figuren und auf den Maschen und Sprossen dieses Arabeskennetzes die tingirten Endkügelchen der Stäbchen. Ausser diesen auf den Ausbreitungen der Axencylindersubstanz vorhandenen Endkügelchen sind nun aber anch zahlreiche Stäbchenkügelchen in den grösseren Lücken wwischen den Maschen in Gestalt gleich 
grosser, isolirt liegender Ptinktchen sichtbar. Und doch sollen, wie schon B oll mit Recht hervorhebt (siehe oben) und wie man an dem frischen und dem tadellos conservirten Präparat sieht, diese Piunktchen ausschliesslich nur auf den Netzbalken und niemals in den Lücken dazwischen vorkommen! Wie erklärt sich nun dieser Befund in der betreffenden Zeichnung? Ciaccio macht anch nicht einmal einen Versuch, dies zu erklären. Unzweifelhaft liegt hier wieder ein unvollkommen erhaltenes Nervenendnetz vor, was nach der vorausgegangenen Behandlung mit Goldchlorid nicht befremden kann. Bei dieser Behandhung ist das Stäbchennetz ebenso wenig wie die Substanz der Stäbchen bis auf ihre Endkügelchen zur Darstellung gekommen; nur die letzteren geben die Lage des (unsichtbaren) Stäbchennetzes an. Von einem Theil der Maschen des unsichtbaren Stibchennetzes hat sich nun die zarte Axencylindersubstanz zurückgezogen, so dass die urspriingliche Ausdehnung des Nervenendnetzes nur noch durch die isolirt sichtbaren und wohl nicht mehr in ihrer vollständigen Zahl gefärbten Endkügelchen der Stäbchen angedeutet wird.

Wie Ciaccio ferner berichtet, werden diese scheinbar isolirt liegenden Knöpfehen hier und da mit den Netzbalken des Nervennetzes durch sehr feine, kurze Füden verbunden. In der Tafelerklärung zu Fig. 9 sagt $\mathrm{Ciaccio}$ von diesen isolirten Kügelchen (ppp der Zeichnung): Pontini di Boll, che in realtà non sono altro che piccolissime pallottoline attaccate alle punte di cortissime e sottilissime fibre." Ci a c ci o schliesst aus diesem Befunde, dass die Boll'schen Pünktchen Kügelchen darstellen, welche durch Vermittelung feinster Häärchen, wie Stecknadelköpfe, den Nervenendverzweigungen eingepflanzt sind. Nach meinen Untersuchungen ist diese Anschauung dahin zu verbessern, dass die B oll'schen Pünktchen die Endkügelchen der Stäbchen und Stäbchenkombinationen darstellen, welche einem besonderen Netz, dem Stäbchennetz, eingepflanzt sind. Die feinen kurzen Fädchen, an welchen $\mathrm{Ciaccio}$ die Pünktchen befestigt sah, wie auch ich es in den Golgi'schen Präparaten bei unvollständiger Färbung beobachtete, sind die geschrumpften, missgestalteten Mittelstücke der Stäbchen, welche weniger resistent und von anderer Beschaffenheit sind, als ihre Endkügelchen. Ich habe diese nicht unwichtigen Befunde $\mathrm{Ciaceio}$ 's so aus- 
Ueber den Bau des elektrischen Organes von Torpedo etc. 527

ftihrlich besprochen, weil auch andere Beobachter in die gleichen Irrthümer verfallen sind.

Nur eine Angabe des italienischen Forschers in dieser Arbeit muss ich noch erwähnen. Ci a c c i o berichtet nämlich, dass er auch netzförmige Anastomosen der Nervenverästelungen, bevor sie sich in das Endnetz auflösen, wenn auch sehr selten beobachtet hat (l. c. p. 394). Ich muss dies bestreiten. Nach meinen Beobachtungen, wie auch schon $R$. Wagner (siehe oben) hervorgehoben hat, verzweigen sich die Nerven innerhalb des Prismas bis zum Endnetz rein dichotomisch, oder höchstens selten durch Dreitheilung; Nervenanastomosen dieser Art kommen aber hier nicht vor.

Die letzte mir zugängliche Abhandlung (33) $\mathrm{C}$ i a c c i o 's über die elektrische Platte von Tor pedo (1888) ist mehr eine Wiederholung der Resultate seiner früheren Arbeit; ich brauche daher nicht so ausführlieh auf dieselbe einzugehen.

Der Autor definirt zunächst die Begriffe „Plexus" und „Netz", was bei der herrschenden Verwirung in der Auffassung der Nervenendausbreitung an der elektrischen Platte (vergl. unten W. Krause) gar nicht so überflüssig erscheint (33, p. 433):

$\pi \mathrm{Je}$ dis donc, que les histologistes modernes, principalement les Allemands, donnent le nom de plexus à cette terminaison des nerfs dans laquelle il y a seulement accollement des fibres et de réseau à celle dans laquelle il y a union des fibres entre elles."

In Betreff der Nervenendverästelung hält $\mathrm{C}$ i a c cio an seiner früheren, von mir besprochenen Anschauung fest. Nur mit Bezug auf die Verbindung der Netzmaschen unter sich fügt er noch etwas hinzu, was ich hier erwähnen muss. Es heisst dort: „Mais outre les filaments d'union, qui sont indubitablement de nature nerveuse, car ils montrent les mêmes granulations extrêmement fines, le pointillé que présentent les cylindres-axes, j'ai réussi à découvrir un autre mode d'union, qui se tait par l'intermédiaire de certains filaments, fins, arrondis et homogènes, lequels ne peuvent être vus que quand la susdite lamelle nerveuse a été séparée et isolée des plaques nerveuses préalablement colorées par l'acide osmique à 2 pour 100 et tenues en maceration pendant quelques jours dans l'alcohol au tiers.

Ce second mode d'union, qui n'a pas été vu par d'autres observateurs avant moi, je le crois d'origine et de nature con- 
nectives, parcequ'il se produit par des prolongements, qui naissent des cellules connectives que l'on voit souvent superposées aux fibres nerveuses pâles, soit avant, soit après que celles-ci se sont dépouillées de leur seconde gaîne. Ces prolongements, qui dans leur trajet se divisent et se subdivisent, viennent tantôt raser et tantôt embrasser clans une spirale les fibres pâles et les accompagnent jusqu'à leurs dernières ramifications."

Es ist ja richtig und schon lange bekannt, dass die feinsten, oft beträchtlich langen Ansläufer der interlamellären Gallertzellen die Nerven begleiten, denselben sich eng anschmiegend, wie schon Remak gesehen hat. Auch findet man die letzten Ausläufer oft unmittelbar unter dem Nervennetz. Dass die Ausläifer aber eine Beziehung zu dem Nervennetz selbst eingehen und Verbinrlungsfäden der Axencylinder-Netzbalken liefern, habe ich nicmals gesehen und auch keinen Anhaltspunkt dafür gewonnen.

Bald nach den ersten Publicationen Ciaccio's ersehien eine kure Nittheilung $R$ an $\mathrm{v}$ i e r's über die Nervenverästelungs in der elektrisehen Platte (1875, 3ã und 36). Dieser ausgezeichnete Forscher kommt hier zu dem Schluss, dass das v o n K ̈̈lliker'sche Nervennetz nicht cxistirt und die Nerven frei endigen $(35$, p. 1277): "On arrive à se convaincre que le réseau décrit et figuré par $K o ̈ l l i k e r$, par $\mathrm{M}$. S $\mathrm{ehultze}$ et par F. B o 11 n'existe pas, et que la terminaison des nerfs se fait dans la portion nerveuse de la lane électrique par une série de branches, à l'extrémité desquelles il existe des boutons, comme Rem a k l'a indiqué autrefois. Ces branches et leurs boutons terminaux dessinent d'élégantes arabesques couvertes d'un gra-

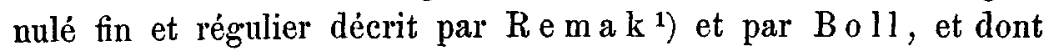
je ne dirai rien de plus dans ce travail."

In seinen so anziehend geschriebenen Vorlesungen über die Histiologie des Nervensystems (38, vgl. auch 37 und 39) entwirft Ranvier dann später eine ausführliche, sehr eingehende Schilderung des feineren Baues der elektrischen Platte, modificirt aber seine frühere Anschaung sehr wesentlich dahin, dass er neben freien Nervenendigungen Anastomosen der Nervenendäste zugibt.

1) Wie oben ausgeführt wurde, hat nicht $R$ emak, sondern Boll die Punktirung entdeckt; ein Irrthum, den Ranvier später bereits selbst verbessert hat (Leçons sur l'Histologie du système nerveux, 1878 , p. 103). 
Ueber den Bau des elektrischen Organes von Torpedo etc. 529

$\mathrm{Zu}$ dieser Einschränkumg wird $\mathrm{R}$ a $\mathrm{n}$ v i e r veranlasst durch Befunde, welche cr nach verschiedenen Methoden erhalten hatte. Zunächst zog er die Silbermethode in Anwendung, betont aber ausdricklich und sehr mit Recht die Unzuverlässigkeit derselben; er legt diesen Befunden anch nicht zu grosses Gewicht bei. Auf p. 143 ist ein negatives Silberbild dargestellt. Der Umstand, dass die Verzweigungen der Nerven sehr schmal sind, im Verhältniss zu den sehr breiten dunkel gefärbten, unregelmässigen Zwischenrïumen, beweist schon, dass diese Bilder dem natürlichen Verhalten nicht mehr entsprechen und die zarten Nervenendigungen durch die Einwirkung des Reagens auf das frische Gewebe wesentliche Veründerungen erfahren haben müssen. R a n v ie r sagt ïber diese Silberbilder (1. c. p. 144): "Quoi qu'il soit possible de suivre les contours d'arborisations terminales completes où toutes les mailles sont ouvertes, on en rencontre cependant d'autres où, en examinant attentivement, on distingue des mailles fermées, soit que le nitrate d'argent ait épargné une portion $d u$ fond située entre deux bourgeons libres, soit que réellement il y ait des anastomoses entre les rameaux de l'arborisation. Comme, d'autre part, il n'est pas absolument certain que le nitrate d'argent n'ait pas coloré quelques portions des terminaisons nerveuses et n'ait par conséquent pas interrompu des mailles fermées qui existaient réellement, il reste sur l'exactitude absolue de la disposition observée un certain doute, malgré que les préparations soient parfaitement nettes et claires. Pour écarter ce donte, nous ferons de nouvelles préparations au moyen de métlıodes différentes."

Die andere Methode, der R a n vi er mit Recht Vertrauen schenkt, ist die Behandlung mit 1-2procentiger Osmiumsäure. Indessen genügt die einfache Behandlung mit Osmiumsäure nicht; denn obwohl die Axencylinder-Verzweigungen bei den Rochen durch Einwirkung dieses Reagens gefärbt werden, so erscheint Ranvier diese Färbung nicht intensiv genug, um bei der Feinheit der Bildung mit voller Sicherheit zu entscheiden, ob Anastomosen vorliegen. Der Forscher nahm daher noch nachträgliche Färbung der fixirten Stücke mit Goldchlorid und Hämatoxylin vor.

Die nachträgliche Färbung mit Goldchlorid, welche auf dem Objectträger bewerkstelligt wurde, ergab in den Präparaten 
gleichfalls Anastomosen der Nervenenden. L. c. p. 150: ${ }_{n}$ Examinons une préparation faite suivant cette méthode, et portons notre attention sur les dernières ramifications nerveuses. Nous les verrons se terminer en boutons. Nous remarquerons aussi des anastomoses, mais plus rares que dans les préparations faites à l'aide du nitrate d'argent. Nous distinguerons sur l'arborisation terminale la ponetuation que nous connaissons, et en même temps nous observerons des points colorés par l'or disséminés entre les branches de l'arborisation."

Mit Recht bezweifelt $\mathrm{R}$ anvi er aber auch die Zuverlässigkeit dieser Goldmethode, indem er sagt: L. c. p. 150: „Nous trouvous done dans ces préparations la confirmation des résultats fournis par l'application du nitrate d'argent, mais elles sont encore sujettes à bien des objections. L'action des sels d'or cst en effet si variable que certaines parties pourraient avoir été colorées sans appartenir à l'arborisation nervẹse, tandis qu'inrersement des branches nerveuses de celle-ci seraient demeurées incolores. Par conséquent, les mêmes dontes dont je vous ai parlé à propos des préparations à l'argent persistent encore."

Ich möchte noch hinzufügen, dass das Goldchlorid wohl nur dann noch nachträglich die Osmiumsäurepräparate fürbt, wenn die Osmiunsäure nicht stark eingewirkt hat; eine schwache und langsame Osmiumeinwirkung garantirt aber keine gute Fixirung. Ranvier scheinen auch nur wenige Goldpräparate nach dieser Methode gelungen zu sein.

Aber anch die nachträgliche Färbung der Osmiumpräparate mit Hämatoxylin nach dem $R$ anvie r'schen Verfahren ist fïr dieses zarte Gewebe nicht einwurfsfrei. Man muss sich eben stets an die Methoden halten, um die unter sich abweichenden Resultate der Forscher richtig beurtheilen zu können, um so mehr, wenn es sich um so zarte Dinge handelt, wie es die nackten Axencylinderverzweigungen der elektrischen Platte sind. Die leichte Vergänglichkeit derselben ist $R$ a n vier anch sehr wohl bekanut, denn er sagt von derselben, l. c. p. 152: „Les liquides exercent une action perturbatrice sur les dernières ramifications nerveuses et altèrent la forme de ces organes délicats. Il n'y a guère que l'acide osmique qui conserve cette forme dans toute son intégrité."

R anvier verfuhr nun bei seinen Hämatoxylin-Färbungen 
Ueber den Bau des elektrischen Organes von Torpedo etc. 531

der elektrischen Platte in der Weise, dass er in das elektrische Gewebe eine interstitielle Injection von 1procentiger Osmiumsäure machte. Die schwer eindringende Osmiunsäure wird dann nur das Gewebe der nächsten Umgebung schnell und gut fixirt haben ${ }^{1}$ ). Die so behandelten Gewebstücke wurden dann einfach in eine 2procentige wässerige Lösung von Ammonium bichromicum anf mehrere Tage oder mehrere Wochen gelegt. $\mathrm{R}$ an vi e r benutzte nun für die Tinktion nicht die elektrischen Lamellen, welche durch intensive Schwärzung anzeigten, dass sie gut fixirt seien, weil sich diese mit Hämatoxylin nachträglich nicht färbten. Vielmehr benutzte er die Lamellen, welche an der Grenze des Bereiches der Osmiumsäureeinwirkung sich befanden. Es erscheint mir unwahrscheinlich, dass gerade diese gut fixirt gewesen sind, zumal bald nach der Injection die Stücke nicht weiter in Osmimmsäure, sondern in die Lösung von Ammonium bichromicum kamen. Man könnte nun ja allerdings auch mir den Einwand machen, dass die Lösung von Osmiumsäure und Kali bichromicum bei Anwendung der Golgi'schen Methode diese zarten Nervenendigungen nicht naturgetreu fixirt. Es wirkt aber hier die Osmiumsäure gleichzeitig mit der 3procentigen Kali bichromicum-Lösung, die ein besseres Reagens, als die 2 Procent-Lösung von Ammonium bichromicum, für diese Gewebe darstellt, allseitig auf kleinste Stäcke des elektrischen Gewebes ein. Durch diese Bedenken veranlasst, habe ich auch bei meinen Untersuchungen für den einen Theil der präparirten Stücke einen doppelt grösseren Zusatz der Osmiumsäure genommen. Wie die oben von mir genau analysirten, bei Anwendung der Golgi'schen Methode häufig auftretenden defecten Nervennetzzeichnungen in der That zeigen, erfolgt aber selbst dann nicht immer eine vollkommene Fixirung des Nervennetzes.

Schon diese Bedenken, welche gegen die hier angewandte Methodik Ranvier's zu erheben sind, lassen die Resultate dieses Forschers zweifelhaft erscheinen. Die Färbung mit Hämatoxylin ergab $\mathrm{Ranvier}$ ein ähnliches Ergebniss, wie die Goldmethode, 1. c. p. 153: ${ }_{n} \mathrm{~A}$ un grossissement de 500 à 600 diamètres, vous verrez l'arborisation terminale violette, très-nette-

1) Hierzu kommt, dass, wie Ewald $(48$, p. 5) feststellte, Injectionsmasse nux in die Räume zwischen den Säulchen eindringen, dagegen nicht zwischen die sie aufbanenden Plättchen. 
ment délimitée, se détacher sur les parties intermédiaires à peine colorées. En suivant les ramifications nerveuses, vous reconuâ̂trez que presque toutes se terminent librement, mais vous observerez aussi quelques anastomoses. Ces dernières sont moins nombreuses que sur les préparations au nitrate d'argent, mais elles existent réellement.

Les points, qui correspondent aux cils électriques vus de face sont colorés en bleu, et s'aperçoivent, de même que dans les préparations au chlorture d'or, non-senlement sur toutes les ramifications terminales, mais encore, en dehors de ces ramitications, dans la substance internédiaire."

Die volle Sicherheit, dass diese gefärbten Präparate $R$ a nvi er's ungenïgend fixirte, postmortal stark veründerte Nervennetze zur Anschauung gebracht haben, gibt ein Blick auf Fig. 4 der Tafel V des Ranvier 'schen Werkes (38), in welcher ein Stiick der elektrischen Lamelle nach Behandlung mit Osmium, Ammonium bichromicum und Hämatoxylin dargestellt ist. Abgesehen davon, dass sich die Nerven ans ihrer Continuitit bis auf wenige noch bestehende Anastomosen gelüst haben, sind die Nervenäste zu sehmal, mit zu regelmässigen Begrenzungen, die unregelmässigen Zwischenrïume zu breit gezeichnet, um nur einigermaassen dem Bilde gut fixirter Osmiumpräparate zu gleichen. Der sicherste Beweis, dass es sich hier um Entstellungen des Nervennetzes handelt, wird endlich dadurch geliefert, dass, wie Ranvier von diesen, wie von seinen Goldpräparaten ja auch hervorhebt, in den freien Räumen zwischen den Nervenverzweigungen zahlreiche B oll'sche Püuktchen zur Darstellung gekommen sind, eine Erscheinung, deren Bedeutung ich bei ler Kritik der Befunde Ciaccio's schon hinreichend besprochen habe.

Mehr Glück hat $R$ an vie r mit der Deutung der Boll'schen Pünktchen gehabt, die er nicht für den optischen Ausdruck aufrechtstehender Stäbchen oder Füserchen hält, wie Boll Anfangs anzunehmen geneigt war, vielmehr erklärt er sie sehr richtig als bedingt durch Endanschwellungen von Stäbchen; die letzteren, deren Existenz Ranvier wohl nur aus dem Durchschnittsbild der elektrischen Lamelle erschlossen hat, nennt der Forscher , cils électriques". L. c. p. 139: „Ils présentent un renflement terminal, et c'est à ce renflement bien plus qu'au corps même du cil qu'est due la ponctuation de Boll." Wenn Ranvier 
Ueber den Bau des elektrischen Organes von Torpedo etc. $\mathbf{5 3 3}$

aber sagt, dass diese ,cils électriques" auf dem verticalen Durchschnitte durch die elektrische Lamelle alle in gleichem Abstande stehen, so ist dies nicht richtig;, es erscheint nur an dickeren Schnitten so. Fertigt man aber hinreichend dünne Schnitte an, so sieht man, dass die Stäbchen nur den Nervennetzmaschen entsprechen, also nicht gleichmässig vertheilt stehen. Es ist dann in der That der Fall, was $\mathrm{R}$ a $11 \mathrm{v}$ i er postulirt, p. 154: „Or, s'il y avait des cils électriques seulement au-dessous des différentes ramifications nerveuses, ils devraient former des groupes, entre lesquels on pourmait distinguer des espaces intermédiaires qui en seraient dépourvus". Um nun zu erklären, dass die Endkügelchen der ,,cils électriques" auch in den Räumen zwischen den „arborisations“ in der Flächenansicht der elektrischen Platte sichtbar sind, greift $R$ anvier zu der gezwungenen und nicht richtigen Deutung, dass am Rande der Nervenäste die ,eils électriques" schräig eingepflanzt seien und mit ihren Endknöpfen in die freien Räume überhängen. „Il faut done admettre, pour expliquer la régularité des palissades, que les cils qui sont sur les bords et aux extrémités des ramifications nerveuses sont trèslégèrement obliques en dehors, de manière que leurs boutons terminaux, empiétant un pen sur les espaces intermédiaires toujours très-petits, arrivent à être aussi rapprochés de ceux de la branche voisine, qu'ils le sont les uns les autres..... et c'est ce qui explique pomrqui nous apercevons un certain nombre de points en dehors des arborisations terminales. Ils correspondent aux boutons des cils implantés obliquement." Dass dem nicht so ist, geht aus meinen obigen Ausführungen hervor.

Bei der Untersuchung der frischen elektrischen Platte hat Ranvier sich wohl zu sehr von seinen nach obigen Methoden erhaltenen Resultaten leiten lassen, constatirt aber auch hier das Vorhandensein von Anastomosen. Noch eine erwähnenswerthe Beobachtung machte $R$ anvier an den Verzweigungen der Nervennetzäste am frischen Präparat, l. c. p. 155: „On remarque qu'elles deviennent claires, quand on éloigne l'objectif, obscures quand on le rapproche. Elles se comportent donc comme des corps convexes plus réfringents dans un milieu moins réfringent." In der That sind die abgeplatteten Netzbalken auch etwas convex mit abgerundeten Seitenrändern.

Auf die umfassenden Beobachtungen $R$ anrier's über die 
gröberen Aeste der elektrischen Nerven will ich hicr nicht eingehen; es sei nur erwähnt, dass von ihm festgestellt wurde, dass die äussere Nervenscheide der Nervenäste mit einer ringförmigen Umbiegung plötzlich aufhört, nachdem die Myelinscheide schon vorher ihr Ende erreicht hat. Von hier ab scheint im elektrischen Organ bei Anwendung der Golgi'schen Methode die Färbung. der Nerven zu beginnen; centripetal davon habe ich niemals Nervenfärbungen in den Prismen gesehen (siehe oben den Text).

Was endlich die Zusammensetzung der elektrischen Lamelle ambelangt, so unterscheidet $\mathrm{R}$ anvier folgende Schichten, l. c. p. $1: 37:$

1. „Une première couche, que j'appellerai lamelle nerveuse, divisée elle-mêrne en deux portions: la superficielle formée par l'arborisation terminale, la profonde par les bâtonnets correspondant anx palissades de $\mathrm{Re} m \mathrm{ak}$, à la ponctuation de Boll; cils électriques.

2. Une seconde couche intermédiaire.

3. La troisième conche, anhiste et d'une grande mincenr, situce immédiatement au-dessous de la précédente, doit être désignée sous le nom de lamelle dorsale.

4. La quatrième conche, couche connective, n'appartient pas à la lame électrique proprement dite. Elle est constituée par des fibres lle tissu conjonctif très-grêles qui s'entre-croisent de manière a former un treillis resistent.

Bei dieser Unterscheidung ist es das Verdienst $R$ a $n \mathrm{v}$ i e r's, auf den dorsalen Abschluss des elektrischen Gewebes durch die "lamelle dorsale", Dorsalmembran, hingewiesen zu haben, eine Membran, welche schon von M. Schultze (s. oben) isolirt wurde.

Mit Bezug auf den zelligen Inhalt der zweiten Schicht trifft Ranvier aber wohl nicht las Richtige, indem er die hellen Räume um die Kerne für Kunstprodukte hält und die zellige Natur dieser Gebilde bestreitet. L. c. p. 134: „La zone claire qui parfois se forme autour des noyaux est due à un retrait de la substance qui les entoure." Ranvier wird zu dieser Annahme dadurch veranlasst, dass er bei Anwendung der unbeständigen Silbermethode um die Kerne herum keine hellen Höfe auftreten "sah. Im Widerspruch hiermit habe ich bei geringer Einwirkung der Silbernitratlösung in den Prïparaten öfters die hellen Höfe gesehen.

Gegenïber den Publikationen ron Boll, Ciaceio und 
Ranvier hatte $\mathrm{R}$ ouget $(41,42,43,44,45)$ einen schwierigen Stand, welcher ziemlich gleichzeitig mit den genannten Autoren für das von Kölliker'sche Terminalnetz sehr energisch eintrat und dasselbe auch zuerst auf photographischem Wege zur Darstellung brachte. Dieser französische Forscher bediente sich đlerselben Methoden, wie Ranvier, erkannte und vermied aber die Fehlerquellen, die zur Entstellung des Nervenendnetzes führen. Bemerkenswerth ist, dass ihn (in seiner ersten in den Comptes rendus, Paris, 1876 erschienenen Publication(42)) gerade die viel besprochene Silbermethode zu der Ueberzengung brachte, dass es sich um ein Nervennetz handelt. L. c. p. 918: „Les fibres nerveuses se dépouillent de toute enveloppe et ne sont plus constituées que par des cylindraxes nus, dont les éléments se dissocient pour constituer le réseaut. Celui-ci, dans son ensemble, présente une grande analogie d'aspect, avec une fenille d'arbre dépouillée de son parenchyme par maceration.

Quant aux terminaisons par des extrémités renflées en bouton, vues par M. Ranvier, on pent les observer, en effet tant sur des préparations traitées par le nitrate d'argent que sur celles qui ont été soumises à imprégnation par le chlorure d'or seul. Mais on a toujours affaire alors à des préparations défectueuses, dans lesquelles la continuité des mailles du réseau est interrompue."

In einer zweiten Mittheilung (43) in welcher über fortgesetzte Untersuchungen des frischen und mit Reagentien behandelten electrischen Gewebes von Torpedo berichtet wird, urtheilt Rouget über die Methodik Ranvier's folgendermaassen (p. 103): „Le procédé d'injection interstitielle employé par M. Rauvier ne m'a jamais donné, soit seul, soit suivi de l'imprégnation par le chlorure d'or, que des préparations défectueuses et impropres à déceler la véritable disposition de l'expansion terminale des nerfs électriques. L'immersion de petits fragments de l'organe électrique pris sur l'animal vivant dans des solutions d'acide osmique de $1-2$ pour 100 , où ils séjournaient pendant un ou deux jours, m'a permis an contraire d'obtenir des préparations où se montrent avec une netteté parfaite non seulement les terminaisons nerveuses en réseaux, mais tous les éléments constituants des disques électriques". Hierin kann ich Rouget nur beipflichten.

Auch in einer dritten Arbeit (44) kommt Rou get auf 
Grund zahlreicher angewandter Methoden zu dem Ergebniss, dass ein geschlossenes Terminalnetz besteht ( 39 p. 486) : "Les apparences de terminaisons en boutons ou extrémités libres, qui peuvent se montrer çà et là dans toutes les préparations, se rattachent manifestment au réseau, dans les photographies agrandies, par des prolongements qui échappent à l'observation directe. Les solutions de continuité des mailles que l'on observe dans les préparations traitées à l'état frais par l'azotate d'argent ou le chlorure d'or ne sont pas constantes et résultent de l'action nuisible ou irrégulière du réactif."

Was Rouget aber über weitere von diesem Nervennet\% ausgehende Nerrenfortsetzungen sagt, ist umichtig und auch sehr unklar (l. c. p. 487): „Vus par la face ventrale de la lamelle nerveuse, les filaments qui circonscrivent les mailles sont lisses et it bords régnliers: en examinant, au contraire, la lame nerveuse complétement isolée par sa face dorsale, ces mêmes filanents présentent une surface irrégnlière, hérissée de prolongements qui se montrent, dans certains cas, disposés en séries régulières sur les bords des filaments d'où ils se détachent comme les barbes d'une plume. Ces fibrilles font corps avec les filaments du réscau, elles émanent de sa substance: ce sont des fibrilles nerveuses ćlémentaires, qui, paralléles les unes aux autres, se dirigent perpendiculairement au plan de la lame nerveuse, de la face venttrale vers la face dorsale, et à ce niveau se réunissent en arcade et constituent un dernier réseau, véritablement terminal l'ume régularité admirable, dont les mailles et les filaments ont à peine le quart des dimensions du réseau d'origine de la face ventrale (réseau terminal de Kölliker). L'ensemble des deux réseaux nerveux et des prolongements qui les unissent constitne me couche spongieuse réticulée, à mailles de grandeur décroissante de la face ventrale à lá face dorsale, dans laquelle tous les éléments nerveux s'anastomosent en arcade et se fusionnent, sans qu'on y rencontre une seule extrémité libre."

Diese ,prolongements" oder ,fibrilles nerveuses élémentaire" Rouget's, die dem Nerrennetz aufsitzen, sind ohne Zweifel die elektrischen Stäbchen, die Roug et aber als solche, d. h. als besondere Bestandtheile, noch nicht erkannt hat, ebenso wie ihm die Endkiigelchen derselben, welche die Boll'sche Punktirung hervorrufen, entgangen sind. Die Angabe aber, dass sich diese „prolongements" " 
Ueber den Bau des elektrischen Organes von Torpedo etc. 537

vereinigen sollen, ist falsch und beruht auf einer Täuschung. Es scheint, mir, dass Rou get das feine Netzgerüst des dorsalen Abschnittes der elektrischen Platte gesehen und für eine zweite netzförmige Nervenendigung irrthümlich gehalten hat. Die Bezeichnung desselben als eine ,conche spongieuse réticulée, ì mailles de grandeur décroissante de la face ventrale à la face dorsale" lässt darauf schliessen.

Was Rouget sonst noch über diese dorsale Schicht (substance conjonctive) sagt (43 p. 805), ist zu unklar und anch zu wenig zutreffend, um darauf näher einzugehen.

$\mathrm{Zu}$ der genau entgegengesetrten Ansicht, wie Rougret, bekennt sich wieder Babuchin $(46,47)$, welcher gelegentlich seiner entwickelungsgeschichtlichen Studien über das elektrische Organ von Torpedo bemerkt, dass es sich in der elektrischen Lamelle um kein Netz, sondern ,um eine reiche Terminalverzweigung. der elektrischen Nerven" handelt. Indessen sagt $\mathrm{Babuchin} \mathrm{nicht,}$ auf welche Gründe er diese seine Ansicht stützt, seine Angabe kann daher hier auch keine weitere Berücksichtigung finden.

Yit dem Modus der Nervenverbreitung im elektrischen Or.gan beschäftigt sich eine Arbeit von Ewald (1881), welcher in der Art der Nervenverästelungen an den elektrischen Platten bestimmite, physiologisch wichtige Gesetzmässigkeiten sieht (48). Ueber seine physiologischen Schlussfolgerungen möge man die Kritik Du BoisReymond's in Carl Sachs' Untersuchungen am Zitteraal p. 416 vergleichen. In Betreff der Nervenendigung schliesst sich Ewald der Auffassung von Ciaccio und Ranvier an, ohne im iibrigen über die Struktur der Nervenplatte Neues beizubringen. Erwähnenswerth ist nur, dass Ewald in seinen Silberpräparaten, hei denen der richtige Grad der Silbereinwirkung getroffen war, nrecht bäufig" Anastomosen der Nervenenden beobachtete; er spricht die Vermuthung aus, dass die Zahl der Netzverbindungen im frischen Zustande eher noch grösser als kleiner gewesen sein muss.

In neuester Zeit hat W. Krause einige Abhandlungen über den feineren Bau der elektrischen Platte von Torpedo (49, 50, 51) publicirt.

In seiner ersten Arbeit (49) unterscheidet W. Krause an der elektrischen Platte:

1. Die elastische Dorsalmembran. 
2. Die Gallertsubstanz mit Kernen, Körnchen u.s.w.

3. Den Palissadensaum, in der Flächenansicht als Punktirung erscheinend, die ron ihm "Palissadenpunktirung" genannt wird.

4. Das (scheinbare) Net\% von Terminalfasern, von ihm als "Terminalplexus" bezeichnet.

5. Die von Adventitia und Neurilemm (sog. Schwann 'scher Scheide) bekleideten, blassen, marklosen Nervenfasern.

6. Die ebenso bekleideten aber markhaltigen, doppelt-contourirten Nervenfasern nebst den capillaren Blutgefiissen und sternförmigen Bindegewebszellen.

Wir mutssen auf die Ausfithrungen W. Krause's über diese cinzelnen Theile näher eingehen, da ich mich durchaus nicht mit Allem einverstanden erklären kann.

Vor Allem gilt dies fiil die Terminalverzweigung der Nerven. W. Krause kehrt zu der ursprünglichen Auffassung Remak's zurück, indem er sagt (l. c. p. 289): „Der von Kölliker entdeckte und als Terminalnetz beschriebene Terminalplexus ist nur scheinbar ein Netz. Hierin haben Remak and Boll Recht gegenüber andern Beobachtern, namentlich Ciaccio und Ranvier, die wenigstens zuweilen vorkommende Anastomosen ler freien Axencylinder aufrecht halten wollen. Die Silbernitratmethode lässt bei richtiger Ausführung darüber keinen Zweifel. Mit anderen Methoden (Ueberosmiumsäure und Hämatoxylin oder Säurefuchsin, Goldchlorid u. s. w.) findet man neben freien Endigungen häufig genug auch Anastomosen. Aber die in der Flächenansicht breit aussehenden letzten Terminalfasern sind zugleich abgeplattet und sehr dicht gedrängt, sie überkreuzen sich und das entstehende Netz ist eben so wenig reell, wie das scheinbare Endnetz der blassen, noch von Neurilemm bekleideten Nervenfasern, wie es schwächere Vergrösserungen zeigen. Nur sind stärkere Linsen erforderlich, um das scheinbare Endnetz in einen terminalen Plexus aufzulösen, aus welchem überall frei und abgerundet endigende Terminalfasern austreten."

Zunächst hebe ich hervor, dass die Methode, auf welche W. Krause sich stïtzt, die Silbermethode ist, deren Unzuverlässigkeit and Unzulänglichkeit an diesem Object gerade dies Resultat W. Krause's beweist, wenn man dasselhe vergleicht mit den nach derselben Methode erhaltenen Ergebnissen anderer 
Ueber den Bau des elektrischen Organes von Torpedo ete. 539

Autoren (vgl. z. B. Boll und Ewald!!). Die bezligliche Abbildlung, welche W. Krause seiner Abhandlung (49) auf Taf. IV in Fig. 4 beigefiigt hat und auf welche er sich beruft, beweist nun das genaue Gegentheil von dem, was dieser Autor behauptet. Man sieht in der Figur zahlreiche netzförmige Anastomosen, deren Substanz kontinuirlich in einander iibergehend gezeichnet ist; von einer Ueberkreuzung der terminalen Aeste ist in dieser Zeichnung auch nicht die geringste Andeutung gegeben. Dass es W. Krause bei Anwendung stärkerer Linsen und Benutzung der Mikrometerschraube hat gelingen können, eine Ueberkreuzung festzustellen, muss ich auf das Entschiedenste bestreiten. Man überzeugt sich vielmehr bei Untersuchung mit Immersion durch Drehung der Mikrometerschraube, dass die Nervenendausbreitungen alle in einer Ebene liegen und Ueberkreuzungen derselben niemals stattfinden; natürlich muss der Theil der elektrischen Lamelle horizontal ausgebreitet, nicht gezert und ohne Faltungen sein. Hierfiir spricht auch das Querschnittsbild, in welchem die Nervenstïckchen alle nebeneinander in einer Reihe liegen. Es ist daher falsch, hier von einem ,Plexus" zu sprechen.

Ueber die Boll'sehe elektrische Punktirung ${ }^{1}$ ) (Palissadenpunktirung W. Krause) bemerkt der Autor sehr richtig, dass dieselbe in der Flächenansicht der Lamellen ansschliesslich den nervösen Terminalfasern folgt. L. c. p. 291: „Die Punkte begleiten alternirend oder einander gegenüber gestellt die Terminalfasern des genannten Plexus. Ihr Vorbandensein beschränkt sich auf deren Rand, sie fehlen in den Maschen des Terminalplexus, sowie in der Axe der Terminalfasern."

W. Krause hat aber die Endkiigelchen der elektrischen Stäbchen noch nicht erkannt; in Folge dessen erklärt er irrthümlich alle Punkte für den optischen Ausdruck der Stäbchen. „Die Punkte sind der optische Ausdruck von oben gesehener, im trischen Zustande $0,0015 \mathrm{~mm}$ langer, in Mittel $0,00022 \mathrm{~mm}$ dicker, solider Stäbchen, und identisch mit den Remak'schen Palissaden ; man kann sie an Zerzupfungspräparaten in Wasser isoliren ...... (p. 292). Die Palissaden sind cylindrische Stäbchen; der Anschein einer knopfförmigen oder birnförmigen Anschwellung ent-

1) Wie oben von mir ausgeführt ist, wurde die Punktirung als solche nicht, wie Krause will (p. 289), von Remak, sondern erst von Boll entdeckt. 
steht durch die Goldmethoden, indem sich häufig, aber nicht immer, mehr Gold auf das freie Ende des Stäbchens niederschlägt." Gegen die letztere Deutung hätte schon die constante Grösse und regelmässige, kugelrunde Gestalt der Körperchen sprechen müssen.

Auch darin kann ich $W$. Krause nicht beistimmen, dass ,die Palissadenpunktirung einer Art von Neurilemm angehört, welches die blassen Terminalfasern noch in die elektrische Lamelle begleitet". Im Gegentheil spricht Alles dafürr, wie ich oben ausgefiihrt habe, dass die Balken des Nervennetzes ohne Neurilemmuberzug sind, mithin die Stäbchen auch nicht die Bildung einer Nerrensclıcide sein können, für deren Existenz jeder Auhaltspunkt fehlt. Durch den Nachweis meines Stabchennetzes wird diese Vermuthung W. Krause's ja auch hinfällig. Es folgt hieraus auch die Haltlosigkeit der Annahme W. Krause's, dass (1. c. p. 293) „die Palissaden der erwähnten Punktirung gleichsam für eine Art von Nägeln zu halten seien, mit denen die abgeplatteten Terminaltasern angeheftet sind“.

In der dorsalen Schicht der elektrischen Platte, welche W. Krause nicht gut als "Gallertsubstanz" bezeichnet (siehe oben M. Schultze), beschrcibt dieser Forscher nun eine Struktur, welche ich näher besprechen muss. 49, p. 296 heisst es: „Dic Gallertsubstanz enthält nämlich ein Fasersystem, ein System undeutlich gestreifter, senkrecht zur Ebene der elektrischen Lamellen angeordneter Fibrillen. Am deutlichsten sind sie in der dorsalen Hälfte der Lamellendicke, verlaufen in dorso-ventraler Richtung stets etwas schräg und gebogen gegen den Palissadensaum hin. Einer Hypothese folgend, wonach diese Fasern die elektromotorische Kraft des Zitterrochenorganes verstärken, könnte man sie „elektromotorische Fasern" nennen, besser wird es jedoch sein, sie nach ihrem bogenförmigen Verlauf einfach als Bogenfasern zu bezeichnen. Dichter gedrängt in der Nähe der Dorsalmembran, durch weitere Zwischenräume, also durch mehr Gallertsubstanz von einander getrennt in der Gegend der interstitiellen Körnchen, biegen sie an deren Palissadensaum in eine der Lamellenebene parallele Richtung um. Indem sie sich netzförmig durchflechten, bilden sie eine dem Palissadensaum dorsalwärts unmittelbar aufliegende Membrana perforata. Die Maschen dieser durchbrochenen Membran correspondiren, wie schräge 
Ueber den Bau des elektrischen Organes von Torpedo etc. 541

Flächenschnitte zeigen, mit den Maschen des terminalen Plexus, dessen Forn sie wiederholen. Die Membran ist ohne Zweifel schon von Remak gesehen worden, der sie indessen auf die ventrale Fläche der Dorsalmembran verlegte" ${ }^{\prime 1}$ ).

Diese „Membrana perforata" W. Krause's existirt nun als solche nicht, d. h. als isolirbare, von dem übrigen Gewebe der Dorsalschicht abgesetzte und abtrennbare Membran. Wahrscheinlich meint W. Krause dasselbe, was ich als den aus weiteren Maschen gebildeten Theil des Netzgerüstes beschrieben habe, welcher, wie ich oben auseinander gesetzt habe, die unterste Lage des Gesammtnetzgerüstes der dorsalen Schicht bildet und mit dem letzteren continuirlich zusammenhängt. Dieser Theil bildet daher einen integrirenden Bestandtheil dieses Netzgerüstes und kaum also auch nicht als "Membran" bezeichnet werden. Als solehe könnte er nur imponiren, wenn ein Flächenschnitt gerade durch das Niveau dieser Schicht fiele. W. Krause sagt daher auch, 1. c. p. 297: „Um die Membrana perforata isolirt zu sehen, fertigt man am besten Wïchenschnitte der elektrischen Lamellen an." W. Krause meint ja auch selbst, lass seine „Bogenfasern" in diese "Membrana perforata" umbiegen und in dieselbe iibergehen, mithin die Substanz seiner Membran liefern.

Diese „Bogenfasern“, welche in regelmässigen Abständen liegen sollen, sind nach W. Krause nur in genau senkrechten Schnitten zu sehen; ,schräg ausgefallene Schnitte zeigen ein unregelmässig sich durchkreuzendes Faserwerk, ein Netzwerk, ans welchem die bestimmte, oben beschriebene, ganz constante Verlaufsrichtung schwer zu entnehmen sein würde".

„Eine regelmässige Querstreifung an den Bogenfasern wahrzunehmen", fährt der Autor fort, ,ist mir mit meinen Hülfsmitteln nicht gelungen, sie sind aber unzweifelhaft aus zwei verschieden lichtbrechenden und gegen Tinktionsmittel sich verschieden verhaltenden Substanzen zusammengesetzt. Die Fasern sehen nämlich körnig aus: regelmässig alternirend treten dunklere und etwas kürzere, hellere Abschnitte auf."

1) Diese historische Notiz ist nicht ganz richtig. Remak kannte die Dorsalmembran noch nicht; die "glashelle Membran“, von der er spricht, ist die ganze Dorsalschicht der elektrischen Lamelle, die_ihm noch homogen erscheint, „bis auf diese „Zeichnung von kleinen, unregelmässigen Ringen" (siehe oben). 
Diesen letzteren Ausfïhrungen W. Krause's ither das kiornige Aussehen der Fälchen muss ich durchaus beiptlichten; eine eigentliche Querstreifung ist indessen nicht vorhanden. Ich flïgc noch hinzu, wie meine Abbildungen auch zeigen, lass die in die Fädchen eingelagerten Körnchen nicht von ganz gleicher Grösse sind, die Körnelung vielmehr unregelmässig ist.

Was aber die „Bogenfasern" anbetrifft, so kann ich dieselben als solche, wie sie W. Kranse beschreiht, nicht anerkennen, d. h. als sehr regelnässig angeordnete, nicht miteinander in Verbindung stehende Fasern. Unzweifelhaft ist das, was W. Krause für „Bogenfasern" erklärt, ein Theil des ron mir beschriebenen Netzgerüstes, an welchem sich hier und da die körnigen Fädchen eine Strecke weit verfolgen lassen, wie auch meine Abbildungen zeigen. Auch auf dem vertikalen Durchschnitte treten solche Fïrlchen in dorso-ventraler Richtung hier und da deutlicher hervor. Da W. Krause aber das Netzgrerüst des dorsalen $\Lambda$ bschnittes noch nicht erkannt hat, wirl er jedenfalls auch häufig für den Ausdruck der "Bogenfasern" die Knotenpunkte dieses Netzgerïstes genommen haben, welche Knotenpunkte bei der Regelmässigkeit des zarten, engmaschigen, filzartigen Gerüstes auf dem genau vertikal angefertigten, feinen Durchschnitt optisch oft reihenweise angcordnet erscheinen und Fasern vortäuschen können. Die optisch verfolgharen dorso-ventral ziehenden Fädchen sind aber nicht, wie W. Krause will, isolirte, von einander getrennte, nicht communicirende Fasern ${ }^{1}$ ), sondern stellen integrirende Bestandtheile des feinsten von mir beschriebenen Fädchengerüstes dar, die durch die feinen Net\%gerüstbälkchen überall mit einander verbunden sind. Ich kann mich daher nicht damit einverstanden erklären, diese „Bogenfasern" als solche anzuerkennen und darin noch ein besonderes histologisches Strukturelement zu sehen. Ich stimme daher W. Krause nicht bei, wenn er in seiner zweiten Abhandlung (50), in welcher er die vorsichtige und damit auch richtiger gehaltene, in seiner ersten Mittheilung (49) entworfene Schilderung von dem

1) Eine Theilung seiner Bogenfasern giebt W. Krause indessen zu, indem er sagt (50, S. 385): „Die Bogenfasern treten als von einander durch helle, mit Gallertmasse gefüillte Zwischenräume getrennte, häufig sich theilende und scheinbar anastomosirende Elemente hervor." 
Ueber den Bau des elektrischen Organes von Torpedo etc. 543

elektrischen Gewebe weiter ansspinnt, über seine „Bogenfasern“ sagrt: 50, p. 371 und folgende: ,Zunächst schien es darauf anzukommen, den Spuren von Querstreifung an den Bogenfasern nachzugehen." „Schon mit dem stärkeren Trockensystem (eines Zeiss'schen Apochromaten) war die Querstreifung in aller wünschenswerthen Dentlichkeit wahrzunehmen." „Es unterliegt also keinem Zweifel, dass die Bogenfasern aus zwei verschieden stark lichtbrechenden Substanzen, die regelmässig alterniren, zusammengesetzt sind: sie verhalten sich genau wic Fibrillen quergestreifter Muskelfasern, nur ist die Querstreifung gleichsam zarter.“ „Einen feineren, nur 0,005 mm dicken Querschnitt aus einem Ueberosminmsäure-Präparat stellt Fig. 6 dar. Man sieht den wahren, sich durchkreuzenden, gebogenen Verlauf der Bogenfasern, die chen diesem Verlaufe ihre einfachste Benennung verdanken. Sic anastomosiren nicht unter einander, was in der Abbildung nicht ganz dentlich darzustellen war, während die Verfolgung mit Hülfe der Mikrometerschraube darüber keinen Zweifel lässt. Die Faser bei F. geht direkt in die Membrana perforata über."

Dass die "Querstreifung" der Fädchen denn doch nicht "alle wünschenswerthe Deutlichkeit" besitzt, berveisen schon dic Abbildungen, welche der Autor seiner Abhandlung (50) auf Tafel XVI and XVII beigegeben hat. In den Figuren 5, 6, 8 und 11 sind die "Bogenfasern" auf verticalen Durchschnitten abgebildet. Man sieht in denselben dunkle Stellen, alternirend mit hellen, sn dass ein Aussehen entsteht, welches einigermaassen an Querstreifung erinnert, indessen bedingt wird durch die eingelagerten kleinen Körncheu. In diesen Figuren, besonders in Figg. 5, und 11, sind aber schon diese dunklen Stellen unregelmäissig und von verschiedener Grösse angegeben, so dass das Bild doch sehr verschieden ist von der, regelmässigen, so characteristischen Anordnung der isotropen und anisotropen Substanz in der quergestreiften Muskelfibrille. Kurz und gut, ich muss eine „Querstreifung $^{\prime \prime}$ der Fädchen, welche sich mit der Querstreifung der Muskelfibrille vergleichen, geschweige denn identifiziren liesse, ganz entschieden in Abrede stellen. Dass.W. Krause nun das feine von mir beschriebene Netzgerïst des elektrischen Gewebes der dorsalen Schicht nicht gesehen hat, erklärt sich wohl hauptsächlich dadurch, dass er die Schnitte, wie in seiner zweiten Abhandlung erwähnt wird, in Glycerin und Kanadabalsam unter- 
suchte; um dasselbe zu erkennen, ist aber rlic Untersucbung in Wasser erforderlich. In Glycerin und Balsam wird die Anfhellung dieser zartesten Structur eine zu starke, so rlass nur die gröberen Fädchen des Netzgeristes, die W. Krause als „Bogenfasern" imponirten, hervortreten und auch die zarten Netzverbindungen dieser Fälchen entschwinden, so dass W. Krause dieselben entgangen sind und er den „Bogenfasern" eine gegenseitige Verbindung abspricht.

Auf die weiteren Mitheilungen W. Kra us e's uber seine „Membrana perforata" brauche ich nach Obigem nicht näher eillzugehen. In Fig. 3 ist ein Sttlek dieser "Menbran" in der Flächenansicht dargestellt, aus einem Osmiumsäurepäparat nach Einschluss in Canadabalsam, ein Einschluss, der bei der schwachen Fuchsinfärbung, welche angewandt wurde, für diese zarten Structuren durchaus ungeeignet ist. Man sieht in dieser Figur einen Gewebsfetzen mit unregelmässigen Löchern und eingelagèrten „dunklen schwarzen Gruppen interstitieller Körnchen der rallertsubstan\% in der Ansicht der Dorsalseite." Wie mir scheint, handlelt es sich hier un ein durch die Behandlung etwas derangrirtes Stück der ganzen Dorsalschicht der Platte.

Was W. Kra use über die Dorsalmembran und die der letzteren dorsalwärts aufgelagerten Bindegewebsfibrillen sagt, kann ich nur bestaitigen; die letzteren sind auch in dem Durchschnitt auf der dorsalen Fläche der Membran stets zu erkennen. Die Dorsalmembran sehe auch ich so, wie sie in Figur 4 auf Tafel XVI von W. K ra use abgebildet ist.

In Betreff der "Palissadenpunktirung" giebt W. Kra us e zu, dass, obwobl dieselbe anf die Nervenfasern des, Terminalplexus" beschränkt ist, doch in der Flächenansicht bisweilen cinzelne Palissaden als Punkte in den Lucken der Nervenausbreitung wahrgenommen werden. „Es ist nur $z$ verwundern, wenn man z. B. an Flächenansichten der nicht eingebetteten, in Chromsäure oder Ueberosminmsäure gehärteten Retina denkt, dass nicht mehr als nur einige wenige Palissaden beim Abziehen der Membrana perforata und Auflegen des Deckglases abgefallen sind: die umgefallenen können sich mit ihren Enden, deren quere Durchschnitte natürlich anch als kleinste Kreise erscheinen, sehr leicht in die Waschen des Terminalplexus projiciren. Dies ist, 
Ueber den Bau des elektrischen Organes von Torpedo etc. 545

wie gesagt, so selbstverständlich, dass es nicht nöthig erschien, es besonders auseinander zu setzen, um so weniger, als unter anderen Boll ebenfalls die Maschen frei von der Palissadenpunktirung abbildet."

Dass diese Erklärung, welche an die Deutung derselben Erscheinung durch Ranvier (siehe oben) erinnert, nicht zntrifft, geht aus meiner Beschreibung. des Stäbchennetzes und der Endkügelchen der Stäbchen hervor.

Mit Bezug auf den ${ }_{n}$ Terminalplexus" muss ich auf meine Kritik desselben bei Besprechung der ersten Abhandlung W. Krause's verweisen, da hier nichts Neues vorgebracht wird.

In seiner dritten Mitheilung bespricht $W$. $\mathrm{Kr}$ a use die Arbeiten von Ciaccio, Ramón y Cajal und Fritsch, olne Anderes, als in seinen friberen Abhandlungen zu bringren. In Betreff der Querstreifung der Bogenfasern reservirt sich der Autor jet $\%$, indem er sagt (51, p. 256): „Keineswegs sollte eine Identität mit der Substanz der Muskelfibrillen behauptet werden, wie $\mathrm{R}$ amón y Cajal zu glauben scheint, da ja dic elektrischen Lamellen nicht etwa contraktil sind. Will man dic Fasern lieber varikös statt quergestreift nennen, so kann man sich dabei auf die Osmiumpräparate berufen."

Der Behauptung von W. Kra use, dass der Anschein, dass statt der "Bogenfasern" ein aus feinen Fibrillen gebildetes Net\%werk im dorsalen Abschnitt der elektrischen Lamelle vorbanden sei, nur an etwas dickeren Schichten entsteht, muss ich entgegentreten; denn ich sehe auch an den feinsten, genau vertikal angefertigten Mikrotomschnitten das feine Netzwerk, und nicht isolirte ${ }_{n}$ Bogenfasern", falls nur in Wasser untersucht wird. Wenn ich auch zugebe, dass in Folge der Behandlung durch Osmiumsäure und andere Reagentien eine Schrumpfung der dorsalen Schicht der elektrischen Lamelle eintritt, so kann hierdurch doch nur die Grösse und Form der Maschen, aber nicht das Netzgerïst als solches beeinflusst werden.

Unter allen Autoren der Wahrheit am nächsten in der Erkenntniss der Struktur der dorsalen Schicht ist Ramón y Cajal gekommen, indem er sagt ${ }^{1}$ ): „Diese Platten sind unter dem Namen elek-

1) Citirt nach der Tobersetzung von W. Kra ase, Internationale Monatsschrift für Anatomie und Physiologie, Bu. VIII, p. 252. 
trische Lamellen bekannt, sie sind wahre vielkernige Riesenzellen, welche eine hyaline glänzende, durch Hämatoxilin oder Anilinfarben tingirbare Dorsalmembran besitzen ; eine untere Grenzschicht, körnig, kaum wahrnehmbar, an deren Oberfläche rlie Nervenfasern endigen; und eine mittlere protoplasmatische Schicht, schr durchscheinend, welche hier und da eingestreute sparsame kuglige oder etwas abgeplattete Kerne enthält. Dieses Protoplasma erscheint mit starken Objektiven untersucht als ans einem sehr feinen Netzwerk gebildet, von gewundenen, perlschnnfürmigen Fïden, welche ron der Dorsalmembran ausgehen, um sich theils an der unteren Grenzschicht, theils in der Mitte der Dicke des Protoplasma zu verlieren. Gewöhnlich zeigt sich das Protoplasma an der Dorsalmembran angehäuft, während cin hellerer Raum in der unteren Hälfte der elektrisehen Lamelle existirt. Wir können die Versicherung von Krause nicht bestätigen, der sagt, er habe dentliche Querstreifen an den Fäden des Netzwerkes gesehen. Nach diesem Autor wïrden die Existenz solcher Streifungen und die Analogie der Eigcnschaften, welche dieselben, mit den Muskeln verglichen, darbieten, gestatten, das Netzwerk der elektrischen Lamellen als im wesentlichen identisch mit den Muskelfasern zu betrachten."

Diesen Worten Ramón y Cajal's kann ich nur beistimmen. Was die Auffassung dieses Forschers von der protoplasmatischen Natur der dorsalen Schicht anbetrifft, so verweise ich auf meine Ausführungen auf p. 481.

Weniger Glitck hat dieser Autor mit den Nervenendigungen gehabt, indem er das Vorhandensein der Anastomosen bestreitet. "Was den Axencylinder anlangt, so theilt er sich wiederholt unter einem stumpfen Winkel und seine zarteren Aeste liefern eine Unzahl kurzer gebogener, ebenfalls grob körniger Zweige, die cine sehr complicirte baumförmige Verzweigung darstellen. Da die blassen Fasern sehr zahlreich sind und die Veräistelungen, welche jede derselben liefert, sehr dicht an einander liegen, so kann man behaupten, dass die ganze ventrale Fläche der elektrischen Lanelle von der Terminalverästelung bekleidet wird. Gegenuiber der Ansicht gewisser Schriftsteller glanben wir, dass die terminalen $Z$ weige nicht anastomosiren; hiervon kann sich Jeder ziemlich leicht überzengen, wenn man eine mit Silbernitrat dargestellte Vorweigung untersucht. An len Stellen, wo die 
Ueber den Bau des elektrischen Organes von Torpedo ete. 547

Zweige zu verschmelzen scheinen, zeigt ein sutes Immersionssystem, dass es sich um einfachc Uebereinanderlagerung handelt."

Dieses Resultat Ramón y Cajal's kann keine Bedeutung. beanspruchen, da dasselbe auf Grund der Silbermethode gewonnen wurde (vgl. über dieselbe oben z. B. Boll, Ranvier, Ewald). Wie es aber möglich sein soll, an diesen negativen Silberbildern, in denen die Nerven farblos erscheinen, genan festzustellen, dass keine Verbindungen, sondern "einfache Ueberlagerungen" der Nerventasern bestehen, ist mir unerfindlich.

Die l'unktirung deutet $R$ amin y $\mathrm{Cajal}$ ebenso wie $\mathrm{W}$. Krause, woriiber bei letzterem Autor zu vergleichen ist: "Von der oberen Wand der blassen Fasern gehen Cilien oder kurze grlänzende Fasem aus, welche aufhören, indem sic sich innig. an das Protoplasma der elektrischen Lanelle anheften. Diese Cilien, welche in der Flächenansicht der Lamellen wie eine dunkle Punktirung erscheinen, zeigen sich sehr dentlich anf Querschnitten in Form einer Streifung des Randes. Aufmerksame Beobachtung dieser kurzen Fäden ergiebt klar, dass jene Cilien ausschliesslich ron den blassen Zweigen der baumförmigen Veräistelung und nicht von der durchsichtigen Substanz ausgehen, welche sie tremnt." Die letztere Bemerkung ist sehr richtig. Gegen eine imnige Anheftung an die dorsale Schicht spricht aber der Umstand, dass die Nervenplatte sich häufig von der Dorsalschicht trennt, wobei stets die Staibchen und bisweilen auch ein Theil der an der Grenze liegenden Körner im Zusammenhange mit der Nerrenplatte bleiben.

Einen eigenen und nach meinen Untersuchungen durchaus irrthümlichen Standpunkt nimmt Fritsch ein, welcher in seiner sonst so prächtigen Monographie der Torpedineen (53) auch Mittheilungen uber die feinere Zusammensetzung der elektrischen Platte gemacht hat. Die Anschanung, welche Fritsch vom Bane der elektrischen Platte hier entwickelt, ist von Anfang bis zn Ende eine irrige, ich bedauere, dies Urtheil füllen zn mïssen. Es ist unbegreiflich, wie man die Terminalausbreitung der elektrischen Nerven in Abrede stellen kann und dafür "Körnchen" sehen will. Ebenso unbegreiflich ist, dass F rits ch die $\mathrm{Boll}$ 'sche elektrische Punktirung nicht sieht, oder wenigstens nicht erkennt; dem dass er sie gesehen hat, ohne sie zl erkennen, werde ich zeigen. Beide Bildungen, Terminalrerweigung md Pinktchen, 
sind ja an jeder frischen Platte, in jedem gut fixirten Prïparat mit aller nur wünschenswerthen Deutlichkeit auf das schönste za sehen.

Ich will indessen auch auf diese Angaben von Fritsch etwas näher eingehen, um die Fehlerquellen aufzudecken, dic Frițch zu seinen Ansichten geführt laben.

Der Grund hierfür ist hauptsäichlich darin zu suchen, dass Fritsch seine Untersuchungen nach einer einzigen, für dieses Gewebe ungeeigneten Methode anstellte, die ührigen Methoden, besonders auch die Behaudlung mit Osmiumsäure, aher vollstiindig ausser Acht liess, obgleich er von dem letzteren Reagens selbst sagt, dass es "schon früher mit grossem Nutzen verwandt" wäre. Dies ist um so merkwurdiger, als $\mathrm{Fr}$ itsclı selbst die cinseitige Verwendung der von den friiheren Autoren benutrten Reagentien tadelt und nit Recht auf die Nebenwirkungen derselben hinweist, indem er sagt 1. c. p. 108: „Man suchte nach Reagentien, welche die Nervenver\%weigung auch in ihren feinsten Verzweigungen durch Firbung deutlich machen sollten, und dazu boten sich naturgemäss die Goldsalze an erster Stelle dar; nächstdem musste natiurlich das viel gemissbrauchte Argentum nitricum hiilfreiche Dienste thun.

Besonders die Gold- und Silberverbindungen tanden \%ur Untersuchung viel Anklang, und wenn das eine Reagens nicht ausreichte, wurde es mit dem anderen verbunden. So wurden Bilder hervorgerufen, beschrieben und abgebildet, welche unbestreitbar sämmtlich muter dem Einfluss der genannten Chemicalien enstanden sind, ohne dass den doch sicher vorhandenen Nebenwirkungen derselben irgendwie gebührend Rechnung getragen worden wäre.

Die genannten Metallsalze, bei deren Anwendung zum Theil kräftige organische Säuren, Essigsäure, Ameisensäure, Citronensäure benutzt werden, müssen zarte organische Membranen al ihren Oberflächenverhältnissen beeinflussen, indem sie einzelne Theile aufquellen, während andere bei der Gerinnung schrumpfen."

Diese Bemerkungen sind sehr zutreffend, ich habe darauf selbst bei Besprechung der Silber- und Goldmethode oben hingewiesen. Ich füge hinzu, dass nicht allein die, OberflächenVerhältnisse" bjerdnreh beeinflusst werden, sondern anch, was 
Ueber den Bau des elektrischen Organes von Torpedo etc. 549

wichtiger ist, die zarten Strukturen in der elektrischen Lamelle selbst.

Die von Fritsch in Anwendung gezogene Methode ist nun folgende 1. c. p. 103: Einlegen in Salpetersäure genau bestimmter Concentration $(10 \%)$ für 24 Stunden, Vermeidung jedes nachherigen Waschens, Uebertragen in Ueberosmiumsäure $(1 \%)$ ebenfalls für 24 Stunden, alsdann Alcohol in steigender Concentration. Hierdurch sollen hauptsächlich Quellungserscheinungen vermieden werden. Wenn ich auch das letztere zugebe, so muss ich diese Behandlungsart doch als ungeeignet für die Untersuchung des elektrischen Plattengewebes bezeichnen. Ich habe kleinste Stücke des ganz frischen elektrischen Gewebes genau nach der von Fits $\mathrm{ch}$ angegebenen Methode behandelt und gefunden, dass dieselbe, besonders in der ventralen Nervenplatte, nur sehr ungenügend die Strukturen conservirt. Es wäre das auch zuviel verlangt von einer $10 \%$ igen Salpetersäure, wenn man erwarten wollte, dass dadurch so äusserst feine, protoplasmatische Bildungen und zarteste Nervenverzweigungen fixirt und sichtbar gemacht wïrden. Es wäre gerade so, als wollte man den feinsten Bau und die Verzweigungen der nervösen Elemente in der Retina durch Behandlung mit 10\% iger Salpetersäure feststellen; denn die Retina ist gewiss nicht zarter und delikater, als die elektrische Platte. W. Kra us e hat die Unzulänglichkeit dieser Fritsch'schen Methode schon genügend hervorgehoben (õ1). Mit Recht betont dieser Autor, dass die nachträgliche Behandlung mit $1 \%$ iger Osmiumsäure, wie sie von Fritsch geübt wurde, vollständig gleichgültig und überflüssig ist; denn es kann dadurch, nach der Behandlung mit der 10\% igen Salpetersäure, im Gewebe nichts mehr wieder gut gemacht werden; höchstens erhalten die Nerven dadurch noch eine dunklere Färbung.

Der Hauptdifferenzpunkt der Fritsch'schen Resultate mit den meinigen liegt nun in der Auffassung der ventralen Nerrenplatte. Wie oben schon angedentet, leugnet Fritsch die Nervenendrerzweigung und die $\mathrm{B}$ oll'sche Punktirung, steht damit im Widerspruch mit allen früheren Beobachtern. Die Differenz ist um so grösser, als Frits ch statt des Nervenendnetzes Körner, ein "stratum granulosum" sieht, die Boll'sche Punktirung aber überhaupt nicht wahrnehmen kann.

Sehen wir zuerst, was F rits ch statt des Nervenendnetzes Archiv f. mikrosk. Anat Bd. 42 
findet. Auf p. 109 heisst es: „Der angedeutete Zwiespalt der Meinungen beginnt also erst in dem Bestreben, die Nervenfäserchen uiber diese Stelle der deutlichen Endigung (die von R. Wag. ner gesehenen Nervenzweige) zu verfolgen. Wir befinden uns hier unmittelbar auf der untersten Schicht der elektrischen Platte, welche durchaus regelmässig punktirt erscheint, wenn man nicht das normale Bild durch Anwendung eingreifender Behandlung getrübt hat.

Abgesehen von dieser, dem frischen, sorgfältig ausgebreiteten Material zukommenden Erscheinung kann man das gleiche Bild an conservirten Platten erhalten, wenn man dieselben nacl der Salpetersäure-Osmium-Methode behandelt."

Um diese Darstellung zu begründen, sucht Fritsch den Beweis in einer Photographie zu liefern, die mit $\mathrm{Z}$ eiss' apochromatischem System ron 1,3 Apert. anfgenommen und sodann photographisch auf 3000 lin. Vergrösserung gebracht wurde. In Fig. 58 auf Tafel XIX ist diese Photographie abgezeichnet; sie zeigt eine grosse Zahl dicht nebeneinander gelegener, etwas ungleich grosser, meist riemlich kreisrunder heller Stellen, welche durch verschwommene, in ilren Begrenzungen ganz unscharfe, netzartige Schattenlinien von einander getrennt werden. Wenn man diese Abbildung 11 m genauer betrachtet, so stellt man fest, dass in der ganzen grossen Zeichnung nur zwei Kerne scharf sichtbar sind, mithin genau eingestellt waren. Alles andere ist undeutlich und verschwommen. Diese Kerne stellen einen Nervenkern (nk) und den Kern einer Bindegewebszelle (Spz) dar, also Gebilde, welche sich der Lage nach in einiger Entfernung von der Nervenendplatte befinden. Da nun aber die Mikrophotographie bekanntlich nur eine einzige optische Ebene scharf und getreu wieder giebt, ist hier nur das Niveau dieser beiden Kerne und der Ebene, in welcher sie sich befinden, scharf und getreu wiedergegeben, was darunter und daruber liegt, ist mithin unscharf und daher nicht beweisend. Ich babe nun oben p. 486 u. 494 angeführt, dass das Nervenendnetz bei unscharfer Einstellung von der ventralen Seite aus das Trugbild darbietet, als bestände es aus nebeneinander gelegenen hellen Kügelchen. Es bernht dies wahrscheinlich auf dem starken Lichtbrechungsvermögen der an den Rändern abgerundeten Netzbalken des Nerrennetzes. Dieses Trugbild verschwindet aber, sobald das Nervenendnetz genau eingestellt wird; 
Ueber den Bau des elektrischen Organes ron Torpedo etc. 551

gerade die genaue Einstellung spielt hier eine grosse Rolle, da, wie wir bei der Durehwandermg der elektrischen Lamelle mit dem Focus gesehen haben (vgl. oben p. 485-489), die geringsten Niveaudifferenzen schon ganz verschiedene Bilder bedingen (vgl. z. B. Nervenendnetz und Boll'sche Punktirung p. 486). Fritsch ist daher an derselben Klippe gescheitert, welche Remak sehr wohl zu vermeiden wusste, indem er sagt (13): "Znü̈chst ist zu beachten, dass in dem Masse, als die kleinen eckigen Ringe dentlicher hervortreten, auch der Auschein der Körnchen, welche man zu sehen glaubt, verschwindet"; cin Passus, den Fritsch sogar citirt. Aus dem Gesignten folgt, dass Fritsch das erwähnte Trugbild auf der Platte aufgefangen hat; seine Photographic beweist daher für seine Anffassung nicht nur Nichts, sondern zeigt uns, wie ich sogleich beweisen werde, gerade das Gegentheil.

Das Gleiche gilt anch von der Erlänterung; welche Fritsch in Text zu seiner Photographic gibt, sodass seine eigenen Worte ihn widerlegen. Auf p. 110 heisst es: nduf der punktirten Fläche sieht man Nichts ron eckigen Maschen des M. S chultze'schen Nervennetzes, Nichts von Remak's eckigen Ringen als Zwvischenräume seiner Nervenverzweigung, Nichts von Herrn Ranvier's "Arborisation en pilons" der Nerven, Nichts von Herrn Krause"s Terminalplexus." Das ist ja selbstverständlich, da Fritsch die Nervenendplatte nicht eingestellt hatte!

"Gleichwohl wird man nicht umhin können", fährt der Antor fort, „mit diesem Bilde zu rechnen, und es ist daher näher zu erläutern.

Wenn man eine nicht gerunzelte Platte selbst nach Anwendung der Salpetersäure-Osmium-Methode mit den stärksten mikroskopischen Systemen untersucht, so bietet sich ein unerwarteter Anblick dar. Im gewöhnlichen mikroskopischen Bilde bei Anwendung der stärksten Trocken- oder schwächeren ImmersionsSysteme erscheinen die sogenannten "Pünktchen" schwarz, und wird dies nach Osmiumeinwirkung meist ganz auf Rechnung dieses Chemikals gesetzt. Bei stärkerer Vergrösserung. erkennt man jedoch, dass die Osmiumwirkung sie gar nicht, oder wenigstens nicht allein so schwarz gemacht hat, sondern dass Totalreflexion in kleinen, stärker lichtbrechenden Körperchen, deren Focus man durch die Einstellung nicht nahe kom- 
men kann, die Osminmwirkung verstärkt; denn es lassen sich mit starken Apochromaten selbst mit Osmium behandelte Punktirungen der Platte als hell aufleuchtende Körper einstellen, d. h. man bekommt das oben erwähnte positive Bild der Pleurosigna-Schuppe unter Einstellen auf den Focus der als Sammellinsen wirkenden Körperchen.

Der Beweis für dies optische Verhältniss ist photographisch ungemein leicht zu erbringen; denn bei der Aufnahme des Objectes mit starken Apochromaten erscheinen die im gewöhnlichen mikroskopischen Bilde schwarz aussehenden Körperchen auf der photographischen Negativplatte ebenfalls schwarz, also in entgegengesetzter Lichtwirkung.

So stellte sich die photographische Platte fest und sicher auf meine Seite, um ein Verhältniss des elektrischen Gewebes zu begründen, von welchem man auf andere Weise eine so über«engende Erklärung nicht geben kounte, wenn auch die Beobachtungen mancher Forscher hart genug an die Wahrheit streiften".

Das ist es ja gerade, dass Fritsch ,dem Focus (seiner Körperchen) nicht nahe kommen konnte", dass er nicht scharf einstellte, weil die von ihm untersuchten Schichten und Schnitte wohl zu dick waren.

Wenn Fritscb nun meint, dass die photographische Platte sich „fest und sicher" auf seine Seite stelle, so ist das ein grosser Irrthum. Denn der Umstand, dass seine „Körperchen", die „,im gewöhnlichen mikroskopischen Bilde schwarz aussehen" ${ }^{1}$ ), mit starken Apochromaten betrachtet aber als „hell aufleuchtende Körperchen" erscheinen, auf der photographischen Negativ-Platte ebenfalls schwarz werden, beweist doch nur, dass hier an diesen Stellen mehr Licht durch das Präparat dringen und die Platte erreichen kann, während es dazwischen absorbirt und zerstreut wird. Dies wird dadurch ermöglicht, dass die hellen Stellen (helle Körperchen nach Fritsch) die unscharf eingestellten Lücken des Netzes sind, während die Netzbalken das Licht am Durchtritt verhindern.

Fritsch hat sich eben bei der Deutung seines unklar eingestellten Bildes ganz und gar von dem Bilde der Pleurosigma-

1) Vgl. die Abbildungen von von Kölliker und M. Schultze, wo bei schwächerer Vergrösserung die Lücken des Netzes dunkel erscheinen. 
Ueber den Bau des elektrischen Organes von Torpedo etc. $\mathbf{5 5 3}$

Schuppe bestimmen lassen, von welchem er bei seiner Schilderunı* des Baues der elektrischen Platte sogar ausgeht; das Relief eines trockenen Kieselpanzers ist aber doch etwas ganz anderes als dieses zarte Gewebe. Während daher Fritsch Max Schultze vorwirtt, wie ich hinzufüge, ungerechtfertigter Weise, dass dieser scharfe and genaue Beobachter ,sein Pleurosigma-Gitter in Gedanken hatte, als er die elektrische Platte beschrieb, und dadurch auf Abwege kam", verschreibt sich gerade Fritsch diesem Fehler mit Leib und Seele.

Um nun doch einigermassen eine Erklärung dafür zu liefern, dlass frühere Beobachter eine regelmässige Nervenzeichnung" gesehen haben, verfällt Fritsch auf einen ganz absonderlichen Erklärungsversuch, indem er diese regelmässigen Netzzeichnungen für „Oberflächenrunzelungen“ erklärt. L. c. p. 109: „Wird die glatte Oberfläche der Platte verändert, sei es, dass sich feine Nervenfäserchen fest auflagern, sei es, dass eine Runzelung eintritt, so wird es nicht mehr möglich sein, eine regelmässige Punktirung im mikroskopischen Bilde zu zeigen. Gewöhnlich werden alle Systeme sich bildender Runzeln wegen des grösseren Widerstandes der Nervenfäserchen an diese selbst angeschlossen werden, und die verzweigten Runzeln erscheinen selbstverständlich als Fortsetzungen der Terminalverzweigungen der Nerven. Die in's gleiche Niveau erhobenen Pünktchen der Platte werden gleichzeitig gesehen, die dazwischen in anderen Ebenen lagernden, auf welche nicht eingestellt wurde, verschwinden."

Es ist überflüssig, auf die Absurdität dieses Erklärungsversuches hinzuweisen, für Jemand, der nur einmal die in einer horizontalen Ebene ausgebreiteten Terminalverzweigungen im frischen oder gut fixirten und gefärbten Präparat gesehen hat; Fritsch allerdings hat sie nicht gesehen.

Schliesslich hat Fritsch auch das Querschnittsbild der elektrischen Platte herangezogen, um sein ,Stratum granulosum“ darzuthun, aber auch wieder an ungenügenden Präparaten. Fritsch tadelt zunächst an den Abbildungen der Plattenquerschnitte von W. Krause mit Recht, dass hier die dunkle Schicht, welche den Durchschnitt durch das Nervennetz darstellen soll, aus einer Reihe dunkel gerandeter, seitlich mit den Nachbarelementen zusammenfliessender Körper besteht, während 
die naturgemäss vorhandenen Lïcken hier nicht $z u$ sehen sind ${ }^{1}$ ). Die beiden Abbildungen, welche Fritsch in den Figg. 55 und 56 seiner Tafel XIX giebt, lassen dafür an derselben Stelle eine Reihe gleich grrosser, hellglänzender Kügclchen erkennen. Hiergegen wende ich ein, wic ich oben (p. 490) geschildert habe, dass man an dieser Stelle als Durchschnittsbill des Nervenendnetzes an gut fixirten und hinreichend dïnnen Schnitten stets eine Reilse platter, etwas verschieden grosser, nebeneinander liegrender Stücke, die Durchschnitte durch die Balken des Nervenendnetzes, erhält, welche dureh sehr dentliche, gleichfalls etwas verschieden grosse helle Lücken von einander getrennt werden; die letzteren sind ler Auslluck der Netaliicken. Das Durchschnittsbild giebt also auch den Bewreis von dem Vorhaudensein einer netzförmigen Terminalausbreitung der Nerven. Fritsch hat in seinen Durchschnitten ungenügend fixirtes (Salpetersäure-Osinimm-Yethode) Material und auch wohl \%u dicke Schnitte vor sich gehabt. Wie miisste diese ventrale Lage nach der "Runzelungstheorie" ron Fritsch wohl anf dem Durchschnitte aussehen?!

Der zweite auffallige Differenzpunkt hestcht in ller Bollschen Punktirung. Frits ch sagt licrüber l. c. pg. 107: „Ueberall in den genaunten Autoren, von Wagner mol $r$. Kölliker, Max Schultze und Remak, begegnen wir Beschreibungen und $A b$ bildungen punktirter elektrischer Platten, und es ist mir daher eins der ungelösten literarischen Räthsel geblieben, wie $B$ oll viele Jahre später die Punktirung der Platte als ein nenes, von ihm entdecktes Strukturverhälniss beschreiben konnte und viele Autoren bis anf den heutigen Tag seinen Namen mit demselben verbinden. Die Möglichkeit dazı wurde wohl nur dadurch gegeben, dass Boll ein nicht existirendes grobes 'Terminalnetz der Nervenfasern, welches er selbst später widerlegte, nrsprïnglich annahm und dahinein eine Punktirung zeichnete, die angeblich nur erst bei Anwendung eines Immersionssystems $\mathrm{Nr}$. IX $\mathrm{Har}$ nack zu erkennen sein sollte; demnach hätten die früheren

1) Vergl. z. B. auch (51) W. Krause, Die Nervenendigung in eiektrischen Organ. Internationale Monatsschrift fïr Anatomie und Physiologie, Bd. VIII, Taf. XII, Fig. 1. Fritseh (l. c. p. 111) wirft Krause vor, dass die Abbildungen seincr Abhandlung, "etwas roh in der Zeichnung" seien. Ieh möchte diesen Vorwurf eher den Zeichnungen Fig. 55-5s auf Taf. XLX des Fritsch'schen Werkes machen. 
Ueber den Bau des elektrischen Organes von Torpedo etc. 555

Autoren mit ihren schwächeren Vergrösserungen das Verhältniss überhaupt nicht sehen können. Dies ist ein leicht nachweisbarer Irrthum; denn die einzige auf der Platte vorhandene Punktirung ist mit einem guten Trockensystem Nr. VII Hartnack sehr wohl zu sehen und ist thatsächlich ron den genannten früheren Autoren, zumal von Remak, unzweifelhaft gesehen worden" 1 ).

Aus diesen Worten folgt klal und deutlich, dass Fritsch die Boll'sche Punktirung überhaupt nicht erkannt hat und sie leugnet; denn die ,einzige in der Platte vorhandene Punktirung", von der er spricht, ist, wie soeben dargelegt, das ungenügend eingestellte Terminalnetz. Hätte Fritsch doch nur einmal eine beliebige frische elektrische Platte mit einer guten Immersion eingestellt und sich genan angesehen, so hätte er sich dies für ihn „ungelöste literarische Räthscl“ sehr leicht selbst löscn können. Und doch hat Fritsch diese Boll'sche Punktirung gesehen, ja sogar abgebildet und photographirt, aloer nicht erkaunt!! In Fig. 58 der Tafel XIX der vergrösserten Photographie sind in der dunklen verschwommenen Netzzeichnung; welche die hellen Stellen umgiebt, hier und da dunkle, gleichgrosse, kleine Pünktchen eingezeichnet. Diese gleichgrossen, kleinen, dunklen Pünktchen sind noch zahlreicher und regelmässiger vertheilt in Fig. 57, welche einen Flachschnitt durch die elektrische Platte darstellt. Dass auch dies ein ziemlich dicker Schnitt gewesen sein muss, beweist schon der Umstand, dass in demselben rechts ein längeres Schrïgstück eines dickeren Nerven in ganzer Dicke mitgekommen ist. Es ist daher hier ebenso, wie in Fig. 58 die Schicht des Nervennetzes unscharf eingestellt; wie es im Texte heisst, umbüllt in diesem Schnitt noch das gallertige Bindegewebe auf dem nervösen Gliede die Schicht wie ein durchsichtiger Schleier. Es bietet daher die anch hier unscharf eingestellte Nervenschicht dasselbe Bild, wie in Fig. 58; aber auch hier sind die dunklen Pünktchen alle in den dunklen Netzlinien gelegen. Fritsch hat nun nicht gewusst, was er mit diesen Pünktchen anfangen sollte; er hat sie daher in seinen Abbildungen 57 und 58 einfach mit einem Fragezeichen (?) bezeichnet. Auch im Text (l. c. pg. 112) werden diese Pünktchen erwähnt: „Auch wurde daran (an Fig. 57) ein äusserst schwierig sichtbar zu machendes Verhältniss 
optisch erkannt, welches mir schon vorher die photographische Platte besser enthüllt hatte, nämlich, dass zwischen den Körnchen kleine unregelmässig begrenzte dunkle Fleckchen erscheinen, welche besonders bei etwas tieferer Einstellung deutlich werden." Fritsch ist mit einer Erklärung, die eben so unklar wie falsch ist, hier schnell bereit, indem er äussert: „Da an den betreffenden Stellen feinste Nervenverzweigtungen nicht in der Nïhe waren, so bin ich geneigt, diese dunklen Pünktchen als den Ausdruck ron Porenkanälen aufzufassen, welche die Körnchenschicht durchsetzen; wo sie lagern, werden aber anch hier und da die feinsten Nervenfädchen in verstreuten Gruppen durchzutreten liaben."

Diese Fritsch so rählselhaften dunklen Pünktchen sind nun ganz unzweifelhaft die Boll'schen Pünktchen, welche bei der ungenanen Einstellung und jedenfalls auch wohl in Folge ihrer mangelhaften Konservirung in ren Fritsch'schen Präiparaten nur hier und da aus der Tiefe ,unregelmässig begrentt" hervorschimmern. Dieses wirl bestimmt bewiesen durch die gleiche Grösse und die Vertheilung der Pünktchen, dann auch dureh die Bemerkung von Fritsch, dass dieselhen besonters bei etwas tieferer Einstellung dentlich werden. Diese Pünktchen liegen nun in den Fritsch'schen Abbildungen, auch in seiner Photographie Fig. 58, alle in dem dunklen Net $\%$ nicht in den hellen Räumen. Mithin entsprechen diese verschwommenen Netzzeichnungen den unscharf eingestellten Netzbalken des Nervennetzes, ra die Boll'schen Pünktchen nur diesen korrespondiren. Fritsch wird mithin durch seine eigenen Photograplien und Abbildungen widerlegt, wenn er behauptet, obwohl er die Boll sche Punktirung. gar nicht einmal kennt, 1. c. pg. 108: ,die Behauptmug, dass in den Zwischenräumen die Punktirung nicht vorhanden sei, obgleich von Boll sowie späteren Autoren ausdriicklich aufgestellt, ist gänzlich unbegründet."

Da Fritsch die Boll'sche Punktirung nicht erkennen konnte, muss er natürlich auch die Stäbchen in Abrede stellen, obwohl er den sogenannten Palissadensaum mit seiner vertikalen Strichelung sieht und abbildet. In Betreff der letzteren sagt der Autor sehr richtig, dass dieselbe nicht als eine geschlossene Schicht dicht aneinander gereihter Stäbchen besteht, als solche vielmehr nur in einigermassen dickeren Schnitten erscheint. In Fig. 55 und 56 ist dieser Palissadensaum in zwei Durehschnitten 
Ueber den Bau des elektrischen Organes von Torpedo etc. 557

mit seiner undeatlichen vertikalen Strichelung gezeichnet, erscheint aber im Verhältniss zu der dorsalen Schicht der Platte viel zu breit. Einen Theil dieser vertikalen Striche (ob alle? wird nicht gesagt) fuihrt Fritsch nun zurück auf vertikal durchtretende kleine Nervenfüdchen and beschreibt eine ganz neue Art der Nervenendigung. Obwohl sich der Autor ${ }_{n}$ mit allem Vorbehalt der Hoffnung hingiebt, dass weitere technische Fortschritte uns wahrheitsgetrenere Bilder der Endigungen enthüllen werden, " formulirt er doch mit gesperrtem Druck am Schluss des Abschnittes die These 1. c. pg. 113: „Die letzten Enden der feinsten Nervenfasern auf dem nervösen Glied der Platte dringen in Gestalt feinster Stiftchen senkrecht zur Plattenrichtung durch die Körnerschicht in das Innere vor und endigen gruppenweise vertheilt an der Grenze zwischen ventraler und dorsaler Schicht zu zarten Protoplasmakörpern erweitert, deren exakte Form sich unserer Beobachtung entzieht."

Eine nähere Kritik erweist uns die vollständige Haltlosigkeit dieser Annahme, denn als solche kann ich diese Formulirung: nur bereichnen. Die Annahme stiitzt sich auf folgende Begründung. L. c. pg. 112 wird behauptet: „In der That gelingt es an besonders günstigen Stellen der Durchschnitte, feinste Nervenfädchen senkrecht zurPlattenrichtung an die Körnchenschicht herantreten und zwischen den Körnchen verschwinden zu sehen. Das starke Lichtbrechungsvermögen der dicht gelagerten Körnchen löscht mit Nothwendigkeit beim Durchtreten den Umriss der zarten Fäserchen aus, aber jenseits im Palissadensaum wird das Bild wieder deutlich, und man ist bei der übereinstimmenden Lagerung gewiss berechtigt, den Zusammenhang der ausserhalb und innerhalb des nervösen Plattengliedes lagernden Theile anzanebmen." Diese Berechtigung muss ich bestreiten, denn, ganz abgesehen davon, dass die von Fritsch angewandte Methode gan\% ausser Stande ist, irgendwie sichere Aufschlïsse über die so äusserst feinen Nervenendigungen zu geben, so sind das, was Fritsch in Gestalt vertikaler Striche gesehen hat, keine Nerven, sondern vertikal gestellte Stäbchen gewesen. Die Nerven, welche an das ventrale Glied herantreten, gehen sämmtlich in das Nervenendnetz über, wie gut fixirte Flächenbilder zeigen. Ich muss es daher auch für einen Irrthum erklären, wenn Fritsch n Fig. 56 von einem stärkeren Nerven (n) feinste Fädchen ver- 
tikal abgehen lässt; solehe Fädchen habe ich an feinsten Durchschnitten niemals gesehen.

Wie Fritsch nun aber bei der vertikalen Richtung seiner vermeintlichen Nervenfäden über den Verlauf derselben noch genaueren Aufschluss an Flachschnitten erhalten will, ist mir unerfindlich. Und doch wird zu diesem Zwecke in Fig. 57 ein solcher Flachschnitt mit Nerven abgebildet (Salpetersäure-OsmiumMethode) und folgendermassen beschrieben 1. c. pg. 112: "Der Schnitt zeigt einen sich an der Platte nochmals theilenden Nervenzweig, dessen Endästchen in den auf die Körnerschicht folgenden, sehr fein granulirten Palissadensaum eintreten, die im reinen Querschnitt als eine Gruppe von "Palissaden" erschienen wären. An sie lagern sich rundliche, durch Osminm lebhaft geschwälzte Körperchen an, deren Vertheilung in grösseren Hohlräumen der Schicht auf eine bei der Präparation erfolgte Schrumpfung. äusserst zarter Gebilde, die den Reagentien nicht zu widerstehen vermögen, hinweist. Also diese beerenartig den Nervenstiftchen sich anfügenden Körperchen sind nach meiner Ueberzeugungrg gewiss nicht der Natur entsprechend zur Darstellung gelangt." In den Figuren 55 und 56 sind in dem oberen Theil des „Palissadensaumes" und an der Grenze rundliche dunkle Körper von verschiedener Grösse gezeichnet, die, wie Krause schon hervorgehoben hat, keine Entdeckung von Fritsch, sondern schon lange bekannt sind und die sogenannten interstitiellen Körner darstellen (siehe oben). Nur ist ihre Lage in den Durchschnitten in einer zu schmalen Zone angegeben. Diese Körner, welche gerade recht resistent sind, hängen nun keineswegs mit Nerven zusammen, wie Fritsch sich gedacht hat und auch abbildet. Jedenfalls ist Fritsch hier irregeleitet worden durch vertikale Stäbchen, welche als dunkle Striche bisweilen an ein Korn oder eine Körnergruppe heranreichen. Hätte Fritsch aber hinreichend dünne und gut fixirte Durchschnitte untersucht und zwar genau, so hätte er finden können, dass hier durchaus keine Verbindung besteht, dass die Stäbchen vielmehr mit dem charakteristischen Endkitgelchen aufhören. Von den Endkügelchen hat Frits c h in seinen Durchschnitten aber überhaupt nichts gesehen, Beweis genug, dass die Schnitte entweder ungentigend fixirt und konservirt waren oder nicht genau genug untersucht wurden. Aus dem Angeführten folgt, 
Ueber den Bau des elektrischen Organes von Torpedo etc. 559

dass ich diese von Fritsch beschriebene Art der Nervenendigung durchaus in Abrede stellen muss.

Endlich hat Fritsch anch noch eine Struktur der dorsalen Schicht der elektrischen Lamelle beschrieben. Auch hier nimmt der Autor eine regelmässige Zusammensetzung aus Körnchen an; auch hier sehe ich mich gezwungen, zu widersprechen. L. c. pg. 114 heisst es: "Man erkennt, dass die Substanz der Schicht thatsächlich nicht homogen ist, sondern grösstentheils aus kleinsten Theilchen zusammengesetzt erscheint. Das Wichtigste an der ganzen Erscheinung dürfte der unzweifelhaft regelmässige Aufbau derselben in Reihen genau parallel der Säulenaxe sein." In den Durchschnittsfiguren 55-56 ist nun die dorsale Sehicht dargestellt, als bestände sie aus parallelen Reihen kleinster Kügelchen, welche durch eine undeutliche Netzzeichnung von einander getrennt werden. Das Bild ist ein ähnliches, wie das von Fritsch gezeichnete Bild der Nervenendplatte, nur feiner. Unzweifelhaft hat Fritsch hier das von mir näher beschriebene feinste Netzgeriist vor sich gehabt, aber falsch gedeutet. Der Autor sagt schon, dass das Lichtbrechungsvermögen seiner Kügrelchen dasjenige der Zwischensubstanz nur äusserst wenig übertrifft, die Anordnung dieser Körperchen nur ganz blass gesehen wird und die Darstellung derselben in den genannten Abbildunren vielleicht schon etwas zu derb ausgefallen ist. Dies stimmt durchaus mit meinen Beobachtungen überein; es ist die ,Zwischensubstanz" von Fritsch dasselbe wie mein feinstes Netzgerüst. Nur muss ich die Möglichkeit zurückweisen, dass die Lücken derselben, wie Fritsch will, von Körnchen ausgefüllt werden; ich verweise in Betreff dieses Punktes auf meine Begründung auf p. 481 und 489 .

Schliesslich sei noch eine kurze Mittheilung von W. W olff $(54)$, cines Schülers von G. Frits ch, erwähnt, welche in den Sitzungsherichten der Berliner physiologischen Gesellschaft, Sitzung vom 1. Februar 1884, erschienen ist, obwohl dieselbe eigentlich keine Erwähnung verdient. Indessen weist Fritsch ausdriicklich auf diese Mittheilung hin und möge dieselbe daher Berüeksichtigung finden.

Im Betreff der Zusammensetzung der ventralen Nervenplatte steht W. Wolff auf demselben Standpunkt wie Fritsch, indem er sagt I. c. pg. 181: „Die untere der Banchseite des Fisches 
zugewandte Fläche der Platte erscheint bei mittleren Vergrösserungen fein punktirt. Bei starken Vergrösserungen ergiebt sich, dass diese Punktirung der optische Ausdruck von lauter, das Licht stark brechenden, dicht nebeneinander gelagerten kleinen Körnchen ist, die in einer das Licht fast gar nicht brechenden balbflussigen Substanz liegen, welche die untere Fläche der Platte überzieht." Was W. Wolff aber unter seiner „feinkörnigen Substanz" versteht, wird nicht klar, da er sagt, dass die Körnchen in Allgemeinen mit den Kernen des Gewebes dieselben Reaktionen gegen Farbstoffe zeigen; die Boll'schen Pünktchen (die Wolff jedoch nicht erwähnt), färben sich nun aber mit Carmin und Hämatoxylin.

In Betreff der Nervenendigung ist W. Wolff nicht tiber den Standpunkt von R. Wagner hinausgekommen. Wenn aber W. Wolff sagt, dass am Ende der Nerven, ,die Schwann'sche Scheide mit der Membran der Platte verschmilzt", so ist das cine unbewiesene Behauptung, abgesehen davon, dass nicht gesagt wird, was unter „Membran der Platte" verstanden wird. Ferner ist falsch, dass die Bindegewebszellen "ausserordentlich spärlich" vorhanden sind. Grundfalsch ist auch, dass die Platten hauptsächlich durch die an ihrer unteren Fläche befindliche, erwähnte, feinkörnige Substanz(?), die sehr ,kklebrig"“(!) sein soll, mit einander verbunden werden. Geradezu naiv ist es, dass W. Wolff die von den Autoren beschriebenen regelmässigen Nerven-Zeichnungen der unteren Fläche der Platte für Gerinnungserscheinungen seiner halbflüssigen feinkörnigen Substanz erklärt.

Schliesslich sieht das Ganze nach einem histologischen Anfängerversuch ans, wenn W. Wolff am Ende seines Aufsatzes von seiner Methodik berichtet, dass er die Platten frisch mit Carmin und mehreren Anilinfarben, mit verdtin ntem Holzessig u. s. w. behandelt hat. 
Ueber den Bau des elektrischen Organes von Torpedo etc. 561

\section{Literatur-Verzeichniss.}

1. John Hunter, Anatomical Observations on the Torpedo. Philosoph. transactions, 1773.

2. Delle Chiaje, Anatomiche disamine sulle Torpedini. Atti del Real Instituto d'Incoragiamento alle Scienze naturali di Napoli VI. 1840.

3. Valentin, Elektricität der Thiere. In Wagner's Handbuch der Physiologie, Bd. I.

4. Paul Savi, Études anatomiques sur le système nerveux et sur l'organe électrique de la Torpille. Als Anhang in dem Werke von Matteucci, Traité des phénomènes électro-physiologiques des animaux. Paris 1844.

5. Calamai, Osservazioni sull anatomia delle torpedini. Atti del VII. Congresso degli scienziati italiani. Parte I, Napoli 1846. Nach Ciaccio citirt; war mir nicht zugänglich.

6. Rudolf Wagner, Neue Untersuchungen über die Elemente der Nervensubstanz. Vorgelegt der K. Societät am 11. Februar 1847. Abgedruckt in den Nachrichten von der G. A. Universität und der K. Gesellschaft d. Wissenschaften 1847. No. 2, Februar 15. und No. 5, April 26.

7. Derselbe, Neue Untersuchungen über den Ban und die Endigung der Nerven und die Struktur der Ganglien. Leipzig 1847.

8. Derselbe, Artikel: Sympathischer Nerv, Ganglienstruktur und Nervenendigung, im 3. Bande von Wagner's Handwörterbuch der Physiologie.

9. Derselbe, Ueber den feineren Bau des elektrischen Organs im Zitterrochen. Abhandlungen der Königlichen Gesellschaft der Wissenschaften zu Göttingen. Bd. III, 1847.

10. A. Ecker, Einige Beobachtungen über die Entwicklung der Nerven des elektrischen Organs von Torpedo Galvanii. Zeitschrift f. wissensch. Zoologie. Bd. I, 1849.

11. H. Müller, Zur Demonstration der Nerven im elektrischen Organ. Verhandlungen der physik.-medicinischen Gesellschaft in Würzburg. Sitzung vom 4. Januar 1851. Würzburg 1852, Bd. II.

12. Pacini, Sulla struttura intima dell' organo elettrico del Gimnoto e di altri pesci elettrici. Gazzetta medica italiana - Federativa - Toscana. - Firenze 1852.

13. R. Remak, Ueber die Enden der Nerven im elektrischen Organ der Zitterrochen. Archiv für Anatomie, Physiologie u. wissensch. Medicin. Jahrgang. 1856. 
14. A. Kölliker, Untersuchungen zur vergleichenden Gewebelehre, angestellt in Nizza im Herbste 1856. I. Ueber die Endigungen der Nerven im elektrischen Organ der Zitterrochen. Verhandlungen der physik.-medicin. Gesellschaft in Würzburg. Bd. 8, 1858, p. 2.

15. M. Schultze, Ueber die elektrischen Organe der Fische. Bericht über die Sitzungen der naturforschenden Gesellschaft zu Halle in Jahre 1857, Sitzung vom 28. November, p. 16. In den Abhandlungen der naturforschenden Gesellschaft zu Halle. Bd. IV. 1858.

16. Derselbe, Zur Kenntniss der elektrischen Organe der Fische. II. Abtheilung: Torpedo. Abhandlungen der naturforschenden Gesellschaft zu Halle. Bd. V, 1856, p. 15.

17. Fr. Boll, Beiträge zur Physiologie von Torpedo. Archiv für Anatomie, Physiologie und wissenschaftliche Medicin. Jahrgang 1873.

18. Derselbe, Die Struktur der elektrischen Platten von Torpedo. Archiv für mikroskopische Anatomie, Bd. X, p. 101, 1874.

19. Derselbe, Die Strulitur der elektrischen Platten von Malapterurus. Archiv für mikroskopische Anatomie, Bd. X, p. 242, 1874.

20. Derselbe, Neue Untersuchungen zur Anatomie und Physiologie von Torpedo. IV. Die Strulitur der elektrischen Platten von Torpedo. Monatsberichte der Königlich Preussischen Akademie der Wissenschaften zu Berlin. Berlin 1875, p. 716.

21. Derselbe, Neue Untersuchungen über die Struktur der elektrischen Platten von Torpedo. Archiv für Anatomie, Physiologie u. wissenschaftliche Medicin. Jahrgang 1876.

22. Derselbe; Nuove ricerche sulla struttura delle piastre elettriche della torpedine. Atti della Reale Accademia dei Lincei Ser. II. Tom. III, 1876.

23. Derselbe, Sur la structure des plaques électriques. Journal de micrographie I, 1877.

24. De Sanctis, Embriogenia degli organi elettrici delle torpedini e degli organi pseudoelettrici delle Raje. Atti della R. Accademia delle science Fisiche e Matematiche di Napoli. Vol. V, 1872. War mir nicht zugänglich; ist mir nur durch die Referate Boll's im Centralblatt für die medicinischen Wissenschaften 1873 und in seiner 1874 erschienenen Arbeit (18) bekannt. Die zahlreichen, theilweise recht groben Irrthümer De Sanctis sind hierin schon von Boll zum Theil berichtigt worden.

25. Derselbe, Embryogénie des organes électriques de la torpille et des organes pseudoélectriques de la raie. Journal de Zoologie p. Gervais II. Auszug aus der vorigen Arbeit.

26. Girardi, Saggio di osservazioni anatomiche intorno agli organi elettrici delle torpedini. Memorie di Matematica e Fisica della 
Ueber den Bau des elektrischen Organes von Torpedo etc. 563

Societí italiana. Tomo III, Verona 1876. Nach Ciaccio citirt; war mir nicht zugänglich.

27. Ciaccio, Intorno al finale distribuimento dei nervi nell' organo elettrico della Torpedine (Torpedo Narke Risso). Archivio per la Zoologia, l'Anatomia e la Fisiologia, publicato per cura dei professori S. Richiardi e G. Canestrini (Edizione di soli 100 esemplari). Serie II, Vol. II, Fascicolo I, Marzo 1870. War mir nicht zugäinglich; der Inhalt ist mir durch das Referat von Boll im Centralblatt für die medicinischen Wissenschaften 1873, p. 677 bekannt.

28. Derselbe, Intorno all intima tessitura dell' organo elettrico della Torpedine (Torpedo narke). Rendiconti dell' Accademia delle scienze dell' Istituto di Bologna. Sessione del 21. Maggio 1874. Deutsch in Moleschott's Untersuchungen zur Naturlehre. XI. Bd. 1876, p. XXIII.

29. Derselbe, Nuove osservazioni intorno all' intima tessitura dell' organo elettrico della Torpedine (Torpedo narke Risso e Torpedo Galvanii Bonap.) Lo Spallanzani, Rivista di Scienze mediche e naturali. Anno XIII, Fasc. X, Modena 1875. War mir nicht zugänglich; der Inhalt ist mir nur aus der kurzen Besprechung desselben durch Boll in seiner im Archiv für Anatomie, Physiologie und wissenschaftliche Medicin 1876 (21), p. 465 erschienenen Arbeit bekannt.

30. Derselbe, Della somiglianza tra la piastra elettrica e l'escitomotoria della torpedine e di alcune differenze che mostrano nella struttura loro i segmenti interanulari delle fibre nervee che vanno all organo elettrico della stessa. Rendiconto dell' accademia delle scienze dell' Istituto di Bologna 11. Novembre 1875.

31. Derselbe, Osservazioni intorno al modo come terminano i nervi motori ne' muscoli striati delle torpedini e delle Razze e intorno alla somiglianza tra la piastra elettrica delle Torpedini e la motrice. Memorie della Accademia delle scienze dell' istituto di Bologna. Tomo VIII, Serie III. Bologna 1877.

32. Derselbe, Observations sur la terminaison des nerfs moteurs dans les muscles striés des torpilles et des raies et sur la rassemblance de la plaque électrique et de la plaque motrice de la torpille. Journal de micrographie 1878. Dasselbe, wie 31.

33. Derselbe, La terminaison des Nerfs dans les plaques électriques de la torpille. Journal de Micrographie 1888. Douzième année. p. 433.

34. Derselbe, Se la terminazione dei nervi nelle piastre elettriche delle torpedini sia un plesso o una rete o veramente né l'uno nè l'altro, ma una cosa tutta speciale. Lo Spallanzani, Ser. II, Tomo 18. Roma 1888. War mir nicht zugänglich; ist, nach den Referaten zu urtheilen, dasselbe wie 33 . 
35. Ranvier, Sur les terminaisons nerveuses dans les lames électriques de la Torpille. Comptes rendus hebdomadaires des séances de l'Akadémie des sciences. Paris. Tome 81. Séance du lundi, 20. Décembre 1875.

36. Derselbe, Dasselbe; Bulletin hebdomadaire de l'Association scientifique de France. T. XVII, 1876.

37. Derselbe, Sur l'organe électrique de la Torpille. Journal de Micrographie. I, 1877.

38. Derselbe, Leçons sur l'Histologie du Système nerveux. Tome second. Paris 1878.

39. Derselbe, Technisches Lehrbuch der Histologie, ubersetat von Dr. W. Nicati und Dr. von Wyss. Leipzig 1888.

40. Sihleanu, De' pesci elettrici e pseudo-elettrici. Dissert. libera. Napoli 1876. Ist nur eine Compilation; citirt nach den Jahresberichten über die Fortschritte der Anatomie und Physiologie von Hoffmann u. Schwalbe, Literatur 1876.

41. M. Ch. Rouget, Bulletins de l'Académie de Médecine. 1876.

42. Derselbe, Sur les terminaisons nerveuses dans l'appareil électrique de la Torpille. Cornptes rendus hebdomadaires des séances de l'Académie des Sciences. Paris 1876, Tome 81.

43. Derselbe, Sur l'appareil électrique de la Torpille. Deuxième note. Ebenda, Tome 83, Paris 1876.

44. Derselbe, Note sur la terminaison des nerfs dans l'appareil électrique de la Torpille. Ebenda, Tome 85, Paris 1877.

45. Derselbe, Note sur la terminaison des nerfs dans l'appareil électrique de la Torpille. Journal de micrographie, 1878.

46. Babuchin, Entwicklung der elektrischen Organe und Bedeutung der motorischen Endplatten. Centralblatt fuir die medicinischen Wissenschatten 1870.

47. Derselbe, Uebersicht der neuen Untersuchungen über Entwicklung, Bau und physiologische Verhältnisse der elektrischen und pseudoelektrischen Organe. Archir für Anatomie, Physiologie und wissenschaftliche Medicin. Jahrgang 1876.

48. Aug. Ewald, Ueber den Modus der Nervenverbreitung im elektrischen Organ von Torpedo und die Bedeutung desselben für die Physiologie der Entladung des Organs. Habilitationsschrift. Heidelberg 1881. Abgedruckt auch in Bd. IV, Heft 1 der Untersuchungen des physiologischen Instituts der Universität Heidelberg.

49. W. Krause, Die Nervenendigung im elektrischen Organ. Internationale Monatsschrift für Anatomie und Histologie. Bd. III, 1886.

50. Derselbe, Die Nervenendigung im elektrischen Organ. Zweiter Artikel. Internationale Monatsschrift für Anatomie und Physiologie. Bd. IV, 1887. 
Ueber den Ban des elektrischen Organes von Torpedo etc. 565

51. Derselbe, Die Nervenendigung in elektrischen Organ. Dritter Artikel. Internationale Monatsschrift für Anatomie und Physiologie. Bd. VIII, 1891.

52. Ramón y Cajal, Manual de histologia normal y de tecnica micrográfica. Valencia 1888. Citirt nach der Uebersetzung der betreffenden Stelle von W. Krause, Internationale Monatsschrift für Anatomie und Physiologie. Bd. VIIT, p. 252-254.

53. G. Fritsch, Die elektrischen Fische. II. Abtheilung. Die Torpedineen. Leipzig 1890.

54. W. Wolff, Ueber die elektrische Platte von Torpedo. Verhandlungen der Berliner physiologischen Gesellschaft, VII. Sitzung vom 1. Februar 1884. Archiv für Anatomie und Physiologie. Physiologische Abtheilung. Jahrg:ing 1884, p. 180.

\section{Erklärung der Abbildungen auf Tafel XXIX, XXX u. XXXI.}

Sämmtliche Abbildungen wurden nach Präparaten aus Querschnitten durch die Sïulchen des elektrischen Organs von Torpedo Narce Risso gezeichnet, die nach der schnellen Golgi'schen Methode gewonnen wurden.

\section{Tafel XXIX.}

Fig. 1. Elektrisches Stäbchennetz mit den Stäbchen und Stäbchenkombinationen, Endkügelchen der Stäbchen deutlich. Der rechte Theil des Netzes hat sich umgebogen, so dass der rechte Rand gebogen und umgefaltet ist; dadurch werden die vertikal hervorragenden Stäbchen und die Stäbchenkrümmungen sichtbar. Winkels homogene Immersion $1 / 24$, Oc. 3.

Fig. 2. Auf einem Theil des Stäbchennetzes hat sich das dunkel gefärbte Nervenendnetz imprägnirt. Die Maschen des Nervenendnetzes folgen genau den Masch en des Stäbchennetzes, so dass ein geschlossenes Netz entsteht, dort, wo die Imprägnation eine vollständige geworden ist (grösster Theil der oberen Hiilfte der Zeichnung). An den anderen Stellen ist die Imprägnation nur unvollkommen ausgefallen, so dass eine unregelmässige Arabesken-Zeichnung entstanden ist, stets entsprechend den Netzbalken des Stäbchennetzes. Nicht imprägnirte Maschen des Stäbchennetzes verbinden die stumpfen, 
abgerundeten Seitensprossen der Arabesken-Zeichnung. Links oben hat sich das dunkle Nervenendnetz eine Strecke weit isolirt gefärbt, olnne dass es dort zur Ausprägung des Stiibchennetzes gekommen wire. Zwei zu dem Nervenendnetz an gesonderten Stellen hinzutretende kurze Nervenstümpfe sind in der Zeichnung fortgelassen, um die Uebersichtlichkeit derselben nicht zu stören. Vergrösserung wie in Fig. 1.

Fig. 3. Theil eines grossen Stäbchennetzes, auf welchem sich fleckenweise Theile des Nervenendnetzes imprägnirt haben. Vollkommen gesehlossene Maschen des Nervenendnetzes auf den Stäbchennetze setzen sich mit je einem Nervenendfaden in direkte Verbindung und hingen durch eine nicht vollstiandig ausgefürbte Brücke des Nervenendnetzes auf dem Stäbchennetz unter sich zusammen. Drei andere Endüste desselben Nervenstammes treten mit vollstiindig impriignirten Abschnitten des Nervenendnetzes in Zusammenhang, welche isolirt liegen, ohne dass es hier zur Fïrbung des Stibchennetzes gekommen wäre (vgl. die folgende Tafel). Endkügelehen der Stäbchen und Stiibchenkombinationen auf dem Stïbchennetz deutlich. Vergrösserung wie in Fig. 1.

\section{Tafel XXX.}

Fig. 4. Drei Nervenbiumchen mit den Wagn er'schen Geweihfasern. Dazwischen ein sich verzweigender, feiner, varicöser Faden, wohl die letzte Ausstrahlung eines Astes einer Gallertzelle. Zeiss Obj. A, Oc. 5.

Fig. 5. Ein Nervenbäumchen, an welchem sich, in Verbindung mit den Endasten, an mehreren Stellen blasse Netze (ohne Stäbchen) gefärbt haben. Braune Imprägnationen gehen auf den Maschen des Netzes in der Richtung der Endfasern von der Verbindungsstelle der letzteren mit dem Netz aus. Vergrösserung wie in Fig. 4.

Fig. 6. Ein Nervenendfaden in Verbindung mit einem Stück des blassen Netzes ohne Stäbchen aus einem der vorigen Präparate (Fig. 8) bei starker Vergrösserung (Winkels homogene Immersion $1 / 24$ ). Zwei braun imprägnirte Stränge verlaufen auf dem Netz in der Richtung des zutretenden Nerven. Ausserdem sind hier und da Stellen des Netzes dunkel imprägnirt. In dem linken unteren Viertel tritt auf den Maschen eine Punktirung (B oll's elektrische Punktirung) deutlich hervor, bedingt durch die Färbung der Endkügelchen der Stäbchen und Stäbchenkombinationen, deren mittlerer Theil ungefärbt geblieben ist.

Fig. 7. Uebersichtsbild über die Nervenverzweigungen und die dunklen isolirt gefärbten Nervenendnetze in Verbindung mit den nervösen Endzweigen. Das Stäbchennetz ist hier nicht zur 
Ueber den Bau des elektrischen Organes von Torpedo etc. 567

Imprägnation gekommen. Unvollständige Fiirbung: viele Endiste der Nerven scheinbar frei endigend; von der Membran des Nervenendnetzes nur Stïcke gefärbt; nur links unten ist ein grösserer Abschnitt dieser terminalen Netzmembran zusammenhängend imprägnirt. Die Stücke der Nervenendnetze benachbarter Nervenstämmchen hängen hier und da zusammen, so dass die Endnetze kontinuirlich in einander uibergehen. Zeiss Obj. A, Oc. 2.

Fig. 8. Nervenfaden im Zusammenhange mit einem Stück des dunklen Nervenendnetzes aus dem vorigen Präparat bei starker Vergrösserung. Winkels homogene Immersion 1/21. Unvollstäindige Impriagnation: Arabesken-Zeichnung. An vielen Stellen werden die stumpf endigenden, sprossenartigen Fortsïtze und Höcker durch blass gefärbte Netzzüge des dünnen Stiibcheunetzes, an dem die Stäbchen aber nicht gefärbt sind, verbunden, so dass dadurch an vielen Stellen die Arabesken-Zeichnung zu einem vollständigen Netz erg:inzt wird. In den hellen Lücken an den dunklen Netzzügen hier und da dunkle Pünktchen, bisweilen mit den Netzzügen durch schmale Stiele verbunden: die gefärbten Endkügelchen der Stäbchen auf dem an diesen Stellen nicht sichtbar gewordenen Stäbchennetz; von den Stäbehen sind hier nur geschrumpfte Theile in Gestalt der Stiele sichtbar.

Fig. 9. Eine ähnliche Stelle wie Fig. 8 (bei etwas schwächerer Vergrösserung). Unvollkommene Imprägnation: schöne Arabesken-Zeichnung; die Vorsprünge hier nicht durch Züge des Stäbchennetzes verbunden, da das Stäbchennetz vollständig: ungefärbt geblieben ist. In dem oberen Theil der dunklen Netzzüge mehrere helle Punkte (siehe Text). In den Lücken an den dunklen Netzbalken zahlreiche oft mit Stiel versehene Pünktchen von gleicher Grösse: die Endkügelchen der Stäbchen, deren mittlerer, anscheinend geschrumpfter Theil hier und da die feinen Stiele bildet, meist aber ungefärbt geblieben ist.

Fig. 10 und 11. Gallertzellen mit Kern und Fortsätzen. Zeiss Obj. D, Oc. 2.

Fig. 12. Ein Protoplasmafortsatz einer Gallertzelle mit den feinen Reiserchen bei starker Vergrösserung (Winkels homgene Immersion $1 / 24$ ).

\section{Tafel XXXI.}

Fig. 13. Uebersichtsbild (bei ganz schwacher Vergrösserung) über die flitterartigen imprägnirten Stïcke der Gerüstsubstanz.

Fig. 14. Uebersichtsbild über einen grösseren Abschnitt der elektrischen Lamelle mit zusammenhängend imprägnirter Gerüstsubstanz des dorsalen Theiles. Blattrippenartige Faltungen. Zellhöhlen 
568 Emil Ballowitz: Ueber den Bau d. elektr. Organes v. Torpedo etc.

mit Kern, z. Th. auf der einen Seite kapselartig geschlossen. Links totale Imprägnation der Lamelle (siehe Text). Zeiss Obj. A, Oc. 2.

Fig. 15. Imprägnirte Gerüstsubstanz bei stärkerer Vergrösserung" (Winkels homogene Immersion $1 / 24$ ). Netzgerüst der mit eingelagerten Körnchen versehenen Fädchen. An der einen (ventralen) Fläche hebt sich das grobmaschige Netz von der übrigen Gerüstsubstanz deutlich ab. In die Hohlräume des Netzgerüstes und an dessen unterer Grenze sind gröbere, meist mit Delle versehene Körner eingelagert (seltenerer Befund; meist sind die Körner nicht zur Darstellung gekommen). Winkels homogene Immersion $1 / 21$.

Fig. 16. Winkels homogene Immersion $1 / 2$. Aus einem schon etwas abgeblassten Präparat mit sehr unvollkommener Färbung der Gerüstsubstanz. Die Füdchen des Gerüstnetzes sind schon farblos geworden und unsichtbar. Nur die in die Fädchen eingelagerten Körnchen sind zum Theil deutlich und deuten den Verlauf der Gerüstfädchen an. Die meist mit Delle versehenen Körner intensiv gefärbt.

Fig. 17. Winkels homogene Immersion 1/21. Unvollkommene Fïrbung. Stück vom Rande eines in grösserer Ausdehnung gefüirbten Netzgerüstes. Das grobmaschige Netz der ventralen Flïche der Gerüstlamelle zum Theil isolirt gefärbt. Eingelagerte Körnchen und Körner.

Fig. 18, 19, 20. Winkels homogene Immersion $1 / 21$. Zellkapseln der Gerüstsubstanz, welche die Zelle mit dem grossen Kern und Kernkörperchen einschliessen.

Fig. 18. Kapsel auf der einen Seite von einer dünnen Fortsetzung der Gerüstsubstanz vollkommen geschlossen, feinstes Netzgerüst mit deutlichen Maschenziigen des grobmaschigen Netzes.

Fig. 19. Kapsel, auf der einen Seite nur unvollkommen geschlossen; Körnchenführende Fäden isolirt zu verfolgen.

Fig. 20. Zellkapsel, auf beiden Seiten offen. Anscheinend homogener Zellleib, Kern und Kernkörperchen sichtbar. 